This material is presented to ensure timely dissemination of scholarly and technical work. Copyright and all rights therein are retained by authors or by other copyright holders. All persons copying this information are expected to adhere to the terms and constraints invoked by each author's copyright. In most cases, these works may not be reposted without the explicit permission of the copyright holder.

This version of the referenced work is the post-print version of the article-it is NOT the final published version nor the corrected proofs. If you would like to receive the final published version please send a request to any of the authors and we will be happy to send you the latest version. Moreover, you can contact the publisher's website and order the final version there, as well.

The current reference for this work is as follows:

Gregory D. Moody, Paul Benjamin Lowry, and Dennis Galletta (2015). “It’s complicated: Explaining the relationship between trust, distrust, and ambivalence in online transaction relationships using polynomial regression analysis and response surface analysis," European Journal of Information Systems (EJIS) (accepted 20-Aug-2015)..

If you have any questions, would like a copy of the final version of the article, or would like copies of other articles we've published, please email any of us directly.

Paul also has an online system that you can use to request any of his published or forthcoming articles. To go to this system, click on the following link: https://seanacademic.qualtrics.com/SE/?SID=SV_7WCaP0V7FA0GWWx 


\title{
It's Complicated: Explaining the Relationship between Trust, Distrust, and Ambivalence in Online Transaction Relationships Using Polynomial Regression Analysis and Response Surface Analysis
}

\begin{abstract}
Trust and distrust are considered crucial elements affecting online relationships - particularly those involving electronic transactions. Although some studies propose that they are distinct, others claim that they are merely opposite ends of one continuum. Further adding to the debate is the possibility of ambivalence, a topic that has not been examined in electronic transaction relationships. Unfortunately, current models of trust and distrust have limitations that impede explanations of how - or even if ambivalence is generated by feelings of trust and distrust and how these two constructs can best coexist. We thus propose a hybrid model which considers the limitations and strengths of previous models. Namely, we posit that trust and distrust can coexist as separate components with related continua. We use polynomial regression analysis (PRA) and response surface analysis (RSA) to test these complex relationships.

Using an empirical study of online consumer behaviour with 521 experienced online consumers, strong empirical validation is found for the model. We examine the effects of ambivalence on the truster's intentions towards a website and find a small positive effect which increases such intentions. PRA and RSA confirm that trust and distrust are most likely separate components - not opposite ends of a continuum - with related continua. The continua within the subconstructs of trust and distrust likely have more complex and interesting relationships than have been considered previously. These findings lead to interesting future research opportunities on trust, distrust and ambivalence using advanced techniques such as PRA and RSA.
\end{abstract}

\section{Keywords}

Trust, distrust, ambivalence, electronic transactions, HCI, online behaviour, online relationships, polynomial regression analysis, response surface analysis, Internet, online consumer 
Substantial research has focused on the critical role of trust in the success of Internet-based online transactions and relationships (Jarvenpaa \& Tractinsky, 1999; Ba \& Pavlou, 2002; McKnight et al., 2002; Gefen et al., 2003; Naquin \& Paulson, 2003; Gefen \& Straub, 2004; Pavlou \& Fygenson, 2006; Komiak \& Benbasat, 2008; Lowry et al., 2008; Dimoka, 2010); referred to as online transactions here for brevity). Trust is typically more important online than with face-to-face relationships or transactions (Naquin \& Paulson, 2003; Yakovleva et al., 2010). It is evident when a truster displays a willingness to be vulnerable to the trustee based on expectations that the trustee will perform as desired (Mayer et al., 1995).

Conversely, distrust occurs when a person expects that the other party either will not or cannot perform the desired behaviours and is unwilling to cope with such outcomes, possibly acting in a negative manner towards the person (McKnight \& Chervany, 2001). Initially, researchers posited that distrust was simply low trust, and that distrust could be overcome simply through the development of trust (e.g., Mayer et al., 1995; McKnight et al., 1998). More recent research has proposed that distrust is a distinct construct that differs from low trust (Benamati et al., 2006; McKnight \& Choudhury, 2006; Wu et al., 2006; Komiak \& Benbasat, 2008; Dimoka, 2010; Lowry et al., 2014; Lowry et al., 2015). Given the obvious role of trust and distrust in the development of online transactions, it is crucial for researchers to understand both constructs and their relationships.

Adding to the potential complexity of the trust-distrust relationship is the possible creation of ambivalence, which has only recently been examined in the context of online transactions (Moody et al., 2014) and remains a compelling area for future e-commerce research (Jarvenpaa \& Majchrzak, 2010). Ambivalence is when an individual holds at least two contradictory attitudes of similar magnitudes (Thompson \& Zanna, 1995) towards the same object (Kaplan, 1972). Attitudinal ambivalence is an important psychological phenomenon that has been studied in many different personal and organisational behavioural contexts (e.g., Brooks et al., 2003; MacDonald \& Hynie, 2008; Oreg \& Sverdlik, 2011; Ziegler et al., 2012). Importantly, trust and distrust must exist as separate components if they are to work together to create ambivalence; distrust is a functional equivalent of trust, and it aids in the ability to understand one’s environment (Lewicki et al., 1998). Distrust can be conceptualised as a negative attitude, and trust as a positive one. In situations in which an individual feels both a positive and negative attitude towards the same object, both attitudes coexist, thereby engendering ambivalence. Earlier research on trust and distrust did not investigate the creation of ambivalence, because the two concepts were considered opposite ends of the same spectrum (Rotter, 1980; McKnight et al., 2002).

By extending the ambivalence literature to include both trust and distrust, the joint effects of trust and distrust in online transactions can be theoretically explored in light of conflicting attitudes towards online sellers, which can create ambivalence (Kaplan, 1972; Conner et al., 2002; Priester et al., 2007). Ambivalence could also alter how buyers process information. Moreover, observing and understanding 
this alteration could provide additional insights for future online transactions research (Priester et al., 2007; Jarvenpaa \& Majchrzak, 2010). Some researchers have proposed that distrust signals might increase the motivation to seek certainty, thereby causing information to be processed systematically; this might paradoxically lead buyers to engage in more trusting behaviours (Schul et al., 2008; Lowry et al., 2015). At a minimum, the intentions to engage are strengthened in either a positive or negative direction. This opportunity leads to the research question that guides this study:

$R Q$ : Can ambivalence be created in online transactions and relationships, and if so, which subconstructs of trust and distrust are the main drivers of such ambivalence?

To address the research question, we briefly review the different conceptualisations of trust and distrust and then dig deeply into the construct of ambivalence introduced by Moody et al. (2014), and investigate how it might be generated in online transactions and relationships. Current models of trust and distrust are limited because they fail to address how ambivalence is generated by trust and distrust, as well as how trust, distrust and ambivalence can best coexist. We thus propose a hybrid model of trust-distrust to account for the limitations and strengths of previous models of analysis. We then introduce a study that explores the research questions and tests the hybrid model of trust-distrust. Not surprisingly, these complex relationships cannot be tested through standard procedures. Klein et al. (2009) called for behavioural researchers to better test and understand complex constructs using more appropriate analytical techniques such as polynomial regression analysis (PRA) and response surface analysis (RSA). We have found strong support for the use of these techniques. The paper concludes with a discussion of the contributions and limitations of this research.

\section{Background on Trust, Distrust and Ambivalence}

\section{The Difference between Trust and Distrust Online}

Trust is crucial in face-to-face relationships. Because it enables consumers to enter into transactions with sellers, trust is even more crucial in online relationships in which the relationship between the individual and the organisation often lacks history, reliable information, a shared context (Dellarocas, 2006; Graebner, 2009; Dimoka, 2010) or expectations of future interactions (Dellarocas, 2003; Hann et al., 2007) and decision making (Lowry et al., 2010). Online relationships also exhibit significant asymmetries of information (Ba \& Pavlou, 2002; Dellarocas, 2006). Therefore, most online trust research has focussed on the critical role that trust plays in the success of the Internet (McKnight et al., 2002; Gefen et al., 2003; Pavlou \& Fygenson, 2006; Komiak \& Benbasat, 2008; Lowry et al., 2008).

This study adopts generally accepted conceptualisations of trust and distrust in the context of online transactions and relationships (i.e., McKnight et al., 2002; McKnight \& Choudhury, 2006; Komiak \& Benbasat, 2008; Dimoka, 2010; Lowry et al., 2014). The conceptual foundation of trust is trusting beliefs - the willingness of the truster to become vulnerable to the trustee based on the belief that the 
trustee will perform a desired behaviour (Mayer et al., 1995; McKnight et al., 1998). Trusting beliefs are grouped into three subconstructs, namely competence, benevolence and integrity (McKnight et al., 2002) ${ }^{\mathrm{i}}$. In contrast, distrusting beliefs involve unwillingness to become vulnerable to the trustee based on the belief that the trustee will not perform the desired behaviour (McKnight \& Chervany, 2001; McKnight et al., 2003). Distrusting beliefs are operationalised in terms of three subconstructs that hold the opposite valence of the trust subconstructs, namely incompetence, malevolence and deceit (McKnight et al., 2004; McKnight \& Choudhury, 2006; Lowry et al., 2014). Incompetence refers to the individual's belief that the organisation lacks the ability to perform a desired behaviour. Malevolence denotes the individual's belief that the organisation has the intention to harm him/her. Finally, deceit refers to the individual's belief that the organisation is dishonest and predisposed to provide false information. An organisation's website is a virtual agent that works towards building trust perceptions and diminishing distrust perceptions.

\section{Ambivalence Resulting from Conflicting Trust and Distrust Beliefs Online}

Responding to the call for ambivalence research in online transactions (Jarvenpaa \& Majchrzak, 2010), and extending the work of Moody et al. (2014), we propose ambivalence as a key addition to the online transaction literature on trust and distrust. In ambivalence, an individual is inclined to hold both positive and negative evaluations of an attitude object (Thompson \& Zanna, 1995), as two separate constructs; their combination has the potential to produce attitudinal ambivalence if they are both held at roughly equivalent intensities towards the same attitude object (Kaplan, 1972; Jonas et al., 1997).

A better understanding of attitudes is essential for understanding ambivalence. Research has posited that attitudes consist of multiple components, namely feelings, beliefs, and behaviours ${ }^{\mathrm{ii}}$ (e.g., Rosenberg \& Hovland, 1960; Trafimow \& Sheeran, 1998; Kachadourian et al., 2005). Ambivalence can occur within (i.e., intracomponent ambivalence) or between (i.e., intercomponent ambivalence) these three components (Thompson \& Zanna, 1995; Maio et al., 1996; MacDonald \& Zanna, 1998). Ambivalence can thus be created by conflicting attitudes within the same component (e.g., positive and negative feelings) or different components with opposing valences (e.g., positive feelings and negative beliefs). For example, ambivalence can occur in everyday decisions, such as in evaluating a car that has poor style (triggering negative affect) but good gas mileage (triggering positive beliefs), or in considering a candidate who has excellent media appeal (triggering positive affect) but has stated goals that are not personally beneficial (triggering negative beliefs).

During an online transaction, suppose that an online buyer holds trusting (positive) affect towards a seller because of numerous customer ratings, which serve as an indicator of the seller's benevolent reputation. Yet, the buyer might also feel distrust towards the seller because of the perception that the seller lacks competence, as demonstrated by errors or incomplete information about the product (Everard \& Galletta, 2005). Such a scenario would cause the buyer to feel both trust and distrust simultaneously 
related to different seller characteristics, which will eventually be used to formulate a decision (i.e., intention) regarding the purchase of an item from the seller. If each of these feelings is relatively strong, then it is likely that the buyer will experience a form of intercomponent ambivalence.

Authors of the extant literature on trust and distrust have concluded that these constructs can coexist and are of opposite valences (e.g., Lewicki \& Bunker, 1996). Specifically, trust involves positive expectations of the seller's behaviours, whereas distrust focusses on the buyer's negative expectations of these behaviours (Luhmann, 1979; Lewicki \& Bunker, 1996; McKnight et al., 2004). Each of these beliefs can result in a positive or negative expectation of the trustee's behaviour by the truster.

Accordingly, trusting and distrusting beliefs can be juxtaposed in a truster, resulting in conflicting beliefs regarding the seller's trustworthiness.

Mixed, concurrent beliefs have been shown to result in attitudinal ambivalence (Kaplan, 1972; Maio et al., 1996; Brooks et al., 2003; Kachadourian et al., 2005; Priester et al., 2007; MacDonald \& Hynie, 2008; Oreg \& Sverdlik, 2011; Ziegler et al., 2012). A similar effect has also been proposed regarding trust and distrust (Lewicki \& Bunker, 1996), but to our knowledge, this has never been tested until the present study. To help overcome some of the contradictions in the literature, we next propose a model, followed by testing in an empirical study.

\section{Proposing a Hybrid Model of Trust and Distrust}

Although bidimensional models of trust are gaining more acceptance than unidimensional ones, they both have advantages and disadvantages. This section thus first explains the models, reviews their strengths and weakness and combines their strengths to propose a unique hybrid model of trust and distrust; this is further tested using advanced methodology and analysis.

\section{Single versus Bidimensionality of Trusting and Distrusting Beliefs}

Despite widespread agreement on the definitions of trusting beliefs and distrusting beliefs, two major, contradictory approaches to conceptualising trust and distrust have emerged. The first approach assumes that trust and distrust are at opposite ends of one continuum; thus, increasing trust is all that is needed to avoid the possibility of distrust (Rotter, 1980; McKnight et al., 2002). The second approach posits that trust and distrust not only have opposite valences, but are also distinct, separate constructs (Lewicki et al., 1998; McKnight et al., 2003; Komiak \& Benbasat, 2008; Dimoka, 2010).

Unidimensional models treat trust and distrust as opposite ends of one continuum (Rotter, 1980; Barber, 1983), so that they are mutually exclusive (Lewicki \& Bunker, 1996), working as substitutes for each other (Lewis \& Weigert, 1984). The assumption is that if the global trust score is high, there is trust; if it is low, there is distrust. These models propose that trust has several components that can be captured within a global construct that measures a consumer's overall trust (McAllister, 1995; Williams, 2001). Based on the perception of the seller's trustworthiness, an individual expects that the organisation will 
behave in a desired manner, making him/her willing to become vulnerable to the organisation (Williams, 2001).

These unidimensional models of trust and distrust are built on earlier trust research based on economic game theory, wherein trust was conceptualised as cooperative behaviour, and distrust as opportunistic behaviour (Arrow, 1974). Additionally, this approach depicted trust and distrust as substitutes for one another (Lewis \& Weigert, 1984), as mutually exclusive rather than separate constructs (Lewicki \& Bunker, 1996).

The unidimensional assumption was challenged by the bidimensional approach to trust and distrust. Bidimensional models of trust (Lewicki et al., 1998; McKnight \& Choudhury, 2006; Dimoka, 2010) are based on the conceptual foundation that the trust construct, with its positive valence, is separate from the distrust construct, with its negative valence (Kaplan, 1972; Kahneman \& Tversky, 1979), with both generally consisting of corresponding but opposite underlying components. Under this conceptualisation, trust includes positive expectations regarding a trust target's conduct, whereas distrust includes negative expectations (Luhmann, 1979). The trust target is most often an organisation that could behave in an unpredictable manner.

Although both trust and distrust are used to describe expectations about the organisation's behaviour, nuanced theoretical differences exist between the two constructs. First, trust reduces an individual's expectations of possible undesirable actions by the organisation, whereas distrust increases such expectations (Luhmann, 1979). Both mechanisms help to reduce social complexity (Gefen, 2002), albeit in opposite directions. Trust enables individuals to consider future events by minimising the outcomes to include mainly positive events; distrust enables individuals to focus primarily on negative outcomes that may occur.

Although the two constructs are framed as having opposite valences and expectancies under the bidimensional conceptualization, they are treated as independent of each other (Lewicki et al., 1998), even though they are moderately correlated (McKnight \& Choudhury, 2006). Thus, low trust from this perspective is not conceptually equivalent to high distrust. Low trust refers to uncertainty or a lack of hope regarding the trustee's behaviour, whereas high distrust is associated with increased fear, scepticism and vigilance (Lewicki et al., 1998). Likewise, high trust is not the same as low distrust. High trust relates to feelings of hope, faith and confidence in the trustee, whereas low distrust suggests minimal fear, scepticism, cynicism or the need to monitor the trustee (Lewicki et al., 1998; 2006).

Bidimensional models of trust and distrust propose that the relationship between an individual and an organisation and its website is more complex than the unidimensional model considers it to be. Lewicki et al. (1998) explained that most relationships are complex and have various facets in which distrust or trust can be held simultaneously; thus, it impossible to assign a generic label of trust or distrust 
to a relationship. Instead, a relationship can contain a collection of rather specific aspects of an organisation that are trusted or distrusted separately ${ }^{\mathrm{iii}}$.

\section{Strengths and Shortcomings of Unidimensional Models of Trust}

Unidimensional approaches to trust and distrust have several strengths that we adopt in the model. First, the major advantage of such models is the ability to provide a single negative or positive trust score for a relationship between an individual and an organisation (McKnight et al., 2002; Krishnan et al., 2006; Puranam \& Vanneste, 2009; Tomlinson \& Mayer, 2009). Unidimensional models have been used in a variety of studies, largely because they are easier to measure than bidirectional models of trust, because they involve fewer items and subconstructs, if any.

Second, attitudinal research (Kaplan, 1972; Cacioppo \& Bernston, 1994; Williams \& Aaker, 2002) has shown that diametrically-opposed positive and negative beliefs about a specific item cannot exist in equal strength ${ }^{\text {iv }}$. Thus, unidimensional models assume and measure each attribute or fact as a single attitude, which is built on the related beliefs for that attribute or fact, which is consistent with how information is stored in long-term memory (Williams \& Aaker, 2002). Ultimately, an individual holds a single, more intense belief about each piece of information in memory and invalidates outdated information, a process consistent with cognitive dissonance theory (Festinger, 1957).

Third, unidimensional models have found strong empirical support for the nomological network of trust, which has advanced trust research greatly over the past several decades (Schoorman et al., 2007). Such research has highlighted numerous antecedents of trust that have not been applied to distrust. Amidst a paucity of research showing antecedents of distrust, greater explanatory power is provided by the unidimensional model of trust and distrust when exploring online individual-organisational trust relationships than the bidimensional conceptualisation.

Unidimensional approaches have several shortcomings. First, the basic premise of these models is that trust and distrust cannot coexist, and that an online user will utilise only one of the two states as a mechanism to simplify social situations by reducing the number of potential future outcomes with the organisation and its website (Deutsch, 1958; Rotter, 1980). However, recent work on trust and distrust has found that the two constructs do appear to coexist (Dimoka, 2010). Komiak and Benbasat (2008) specifically reported that trust and distrust existed in the users' attitudes towards online recommendation agents during an online transaction.

Second, these models' overemphasis on trust ignores the strong possibility that distrust, as a construct of negative valence, might have a stronger influence on intentions and subsequent behaviours (Kaplan, 1972; Kahneman \& Tversky, 1979). Several studies have demonstrated that distrust indeed has a stronger influence on individual attitudes and beliefs (Kahneman \& Tversky, 1979; Kramer, 1999). Likewise, Dimoka's (2010) fMRI study of trust and distrust in an online auction found that the 
subdimensions of distrust were the only significant predictors of price premiums.

Third, unidimensional models assume that trust between individuals and organisations generalises across their entire relationship. Yet, many studies on trust have identified various facets of trust, which defy such generalisations (Mayer et al., 1995). Although trust is generally conceptualised as a prerequisite for knowledge exchange in online communities (Levin \& Cross, 2004; Porter \& Donthu, 2008; Almirall \& Casedesus-Masanell, 2010), people exhibit preferences for competence despite the benevolent intentions of others in a community (Ba, 2001; Clemons et al., 2002; Jarvenpaa \& Majchrzak, 2010)․․

Finally, and perhaps most interestingly, unidimensional models do not account for intra-aspect conflict in which differing subconstructs have opposing valences within the dimensions of trust (Kaplan, 1972). If an individual believes that an organisation is dependable and competent but has a slightly negative orientation towards the individual, he/she may have only moderate to low trust levels that may result in subsequent weak intentions to purchase from the organisation. However, if the perception of negative orientation increases, it is difficult to predict how the positive and negative perceptions will 'net out' in the unidimensional model: This is where ambivalence becomes an important concept to consider.

Unidimensional models further posit that low levels of trust have relatively little impact on intentions and behaviours (McKnight et al., 1998; McKnight et al., 2002), which undermines the predictions of trust-dependent online behaviours (e.g., joining a community, sharing information, buying an item or subscribing to RSS feeds). Instead, we argue that it is more logical to compare the relative magnitudes of the given trust subconstructs/beliefs, the reliabilities of these ratings and how these weighted magnitudes influence the overall decision to trust or distrust. Further, by supposing that low trust is in fact distrust, unidimensional models ignore the possibility that distrust may have a more powerful impact on intentions. By assuming trust and distrust are opposite ends of one continuum, unidimensional models place this relationship on a linear scale, which does not allow for differential effects. The bidimensional model, using two continua, would be able to present more complicated relationships because it can include second-order variables.

Table 1 summarises the literature on the unidimensional model of trust. We then show the core assumptions related to the unidimensional model that each study follows, along with our explanation.

\section{Strengths and Shortcomings of Bidimensional Models of Trust}

Researchers have identified limitations of unidimensional models of trust and distrust, and proposed that these approaches be modified to either include distrust in a more prominent role (McKnight \& Chervany, 2001) or acknowledge that trust and distrust can coexist (Lewicki et al., 1998; Kramer, 1999). A major strength of such models is that they support a multidimensional view of trust and distrust, which is lacking in many unidimensional models.

Despite the improvements made by the bidimensional models, they have two major shortcomings 
Table 1 Strengths and Limitations of Unidimensional Models of Trust and Distrust

\begin{tabular}{lll}
\hline $\begin{array}{l}\text { Model } \\
\text { Feature }\end{array}$ & Core Assumptions (Example Citations) & Support or Refutation of Assumptions \\
\hline $\begin{array}{l}\text { Single trust } \\
\text { construct }\end{array}$ & $\begin{array}{l}\text { Trust is specified as a single construct (McKnight et } \\
\text { al., 2002; Gefen \& Pavlou, 2012; Fang et al., 2014) }\end{array}$ & $\begin{array}{l}\text { Pro: Simplification of trust into one } \\
\text { construct allows its inclusion in many } \\
\text { models, which has greatly advanced trust } \\
\text { research (Tomlinson \& Mayer, 2009). }\end{array}$ \\
$\begin{array}{l}\text { Exclusability } \\
\text { of positive } \\
\text { and negative } \\
\text { dimensions }\end{array}$ & $\begin{array}{l}\text { Information that underlies an attitude or belief } \\
\text { cannot be both positive and negative (McKnight et } \text { (19) }\end{array}$ & $\begin{array}{l}\text { Con: The separation of underlying } \\
\text { information into positive and negative } \\
\text { components is not supported in attitudinal } \\
\text { research (Cacioppo \& Bernston, 1994). }\end{array}$
\end{tabular}

\section{Extensive nomological network}

Trust and distrust cannot coexist

Focus on trust at the expense of distrust

Generalised trust
The nomological network of trust has been of great interest and research on it is extensive (Mayer et al., 1995; Dennis et al., 2012; Lim et al., 2012; Liu \& Goodhue, 2012; Fang et al., 2014).

Basic assumption of the model is that trust is a continuum with high trust on one end and high distrust on the other. A trustee may thus feel only trust or distrust (Deutsch, 1958, 1960; Dennis et al., 2012; Lim et al., 2012; Liu \& Goodhue, 2012).

Model deals with the creation of trust and avoidance of distrust. Emphasis is given to trust at the expense of distrust. This emphasis creates the assumption that the positive effect size of trust is equal to or greater than the effect size of distrust (McKnight et al., 1998; McKnight et al., 2002; Dennis et al., 2012; Lim et al., 2012; Liu \& Goodhue, 2012).

Model treats trust as a general attitude one has toward another that holds for all aspects of the relationship (Ba \& Pavlou, 2002).
Conflicts between trust and distrust
Because trust is proposed to not coexist with distrust, it is unable to predict what outcomes would result when both trust and distrust are present in a relationship (Deutsch, 1958, 1960).
Pro: The larger nomological network has greatly expanded our understanding of trust and highlighted its importance (Mayer et al., 1995).

Con: Empirical studies have found that a truster is able to feel both trust and distrust toward the same trustee (Dimoka, 2010; Lowry et al., 2014; Moody et al., 2014).

Con: Research on negatively-valenced attitudes has found that their effect sizes are greater than those of positivelyvalenced attitudes. Thus, research should focus on distrust as the potentially more influential attitude (Kahneman \& Tversky, 1979).

Con: Trust research has found that trust is multi-faceted and that several aspects of trust can be found in one relationship. The truster counts on one or more specific outcomes from the trustee (Hardin, 1993; Lewicki et al., 2006).

Con: Ambivalence literature shows that the coexistence of oppositely valenced attitudes may result in ambivalence (Kaplan, 1972).

on which this study's hybrid model capitalises. The first is that bidimensional models have ignored ambivalence in organisational trust relationships, despite the important role it may play (Jonas et al., 1997; Petty et al., 2006; Petty et al., 2007) and recent calls to examine the construct in managerial research (Lewicki et al., 2006; Jarvenpaa \& Majchrzak, 2010). The coexistence of trust and distrust naturally leads to an instantiation of ambivalence, which informs the debate between the bidimensional and unidimensional camps. Ambivalence has largely been overlooked in managerial research despite its prominent role in psychological models, which recognised that positive and negative attitudes often 
coexist and can be modelled independently (Kaplan, 1972; Kahneman \& Tversky, 1979). However, taking into account more recent, highly salient attitudinal work in psychology (Jonas et al., 1997; Petty et al., 2006; Petty et al., 2007), the absence of ambivalence in trust models is all the more conspicuous.

The second shortcoming is that these models assume that the core beliefs which form trust and distrust are simultaneously positive and negative. Kaplan (1972) originally proposed differentiating between positive and negative attitudes as separable constructs, rather than ends of one continuum. Although this perspective was eventually adopted by trust researchers in the bidimensional camp, bidimensional models do not incorporate trusting and distrusting beliefs in the manner suggested by Kaplan and other attitudinal researchers. This research stream posits that while positive and negative attitudes can be separated from each other, the underlying beliefs that form these attitudes are not as separable (Kaplan, 1972; Cacioppo \& Bernston, 1994; Priester \& Petty, 1996). Unlike an attitude, a single belief cannot vary from positive to negative for an individual; rather, a belief will be positive or negative - a single fact about one thing (Kaplan, 1972; Cacioppo \& Bernston, 1994; Petty et al., 2006). Accordingly, an individual may hold some positive and some negative trust/distrust beliefs, but a single belief will not be simultaneously positive and negative ${ }^{\mathrm{vi}}$.

Table 2 summarises the literature that is based on the bidimensional model of trust, along with its assumptions and empirical support. Notably, not all of the assumptions of this model have been supported to date.

\section{A Hybrid Conceptualisation of Trust and Distrust: Overall Trust-Based Beliefs}

This study addresses the limitations of both the unidimensional and bidimensional approaches by proposing a new construct that reconciles trust and distrust, namely overall trusting intentions, or distrusting intentions when the negative distrust beliefs outweigh the positive trusting beliefs. Distrusting intentions are precipitated when an individual perceives one or more of the belief subconstructs to be negative. Likewise, trusting intentions are induced when an individual perceives one or more of the three beliefs subconstructs to be positive. Thus, overall intentions are formed from six belief subconstructs: the three subconstructs of trust and the three subconstructs of distrust. Figure 1 shows the hybrid formation of overall trusting intentions from trust and distrust beliefs, adopting concepts and assumptions from both the unidimensional and bidimensional perspectives and from attitudinal research.

First, in conceptualising overall intentions, both trust and distrust are modelled using the generally accepted three dimensions from both the unidimensional and bidimensional conceptualisations that form trust, namely ability ${ }^{\text {vii }}$, orientation ${ }^{\text {viii }}$ and dependability ${ }^{\text {ix }}$. Thus, we propose that overall trustbased intentions is a multidimensional construct comprising positive and negative belief continua. Second, building on the bidimensional model of trust, the subdimensions enable trust and distrust to coexist in a relationship between an individual and an online organisation. Each of the three trust belief 
subdimensions (ability, orientation and dependability) might exhibit either a negative or a positive instantiation on that belief dimension. These three dimensions are then aggregated to form overall trust, a second-order formative belief construct of trust or distrust. Based on these two belief constructs, an overall trust-based attitude would be formed when arriving at an intention or behaviour. This attitude is based on the trust and distrust-based beliefs depicted in Figure 1.

\section{Table 2 Strengths and Limitations of the Bidimensional Models of Trust and Distrust}

\begin{tabular}{|c|c|}
\hline Model Feature & Explanation (Example Citations) \\
\hline $\begin{array}{l}\text { Separation of } \\
\text { trust and } \\
\text { distrust }\end{array}$ & $\begin{array}{l}\text { Trust and distrust coexist and are } \\
\text { separable constructs (McKnight et al., } \\
\text { 2004; McKnight \& Choudhury, 2006). }\end{array}$ \\
\hline $\begin{array}{l}\text { Multidimension } \\
\text { ality of trust and } \\
\text { distrust }\end{array}$ & $\begin{array}{l}\text { Trust and distrust are composed of many } \\
\text { subconstructs and dispositional antecedent } \\
\text { constructs (McKnight et al., 2004; } \\
\text { McKnight \& Choudhury, 2006). Further, } \\
\text { it is not about trusting a trustee in all } \\
\text { situations, but trust is between two people } \\
\text { regarding a specific behavior (Lewicki et } \\
\text { al., 2006). }\end{array}$ \\
\hline
\end{tabular}

Conflicts between trust and distrust

Conflicts within the same subconstruct
Although trust and distrust are proposed to exist, current models do not explain or predict ambivalence from possible conflicts between them (Dimoka, 2010).

Models propose and measure the concurrent positive and negative attitude toward the trustee on the same dimension. The truster holds both a positive and a negative valence belief of the same subconstruct (McKnight et al., 2004; McKnight \& Choudhury, 2006).
Empirical Support

Empirical support found in (Xiao \& Benbasat, 2007; Dimoka, 2010; Ou \& Sia, 2010; Riedl et al., 2010; Gefen \& Pavlou, 2012; Fang et al., 2014; Lowry et al., 2014).

Empirical support found in (McKnight et al., 2004; McKnight \& Choudhury, 2006).

Not investigated empirically within the IS trustdistrust literature. Ambivalence literature shows that coexistence of opposite valenced attitudes may result in ambivalence (Kaplan, 1972).

Not investigated empirically within the IS trustdistrust literature. Empirical work on trust and distrust has found that although they coexist, they do not coexist within the same subconstruct (Cacioppo \& Bernston, 1994; Priester et al., 2007; van Harreveld et al., 2009). This is further proposed and described as a basic underlying feature of bidimensional models in the attitude and ambivalence literature.

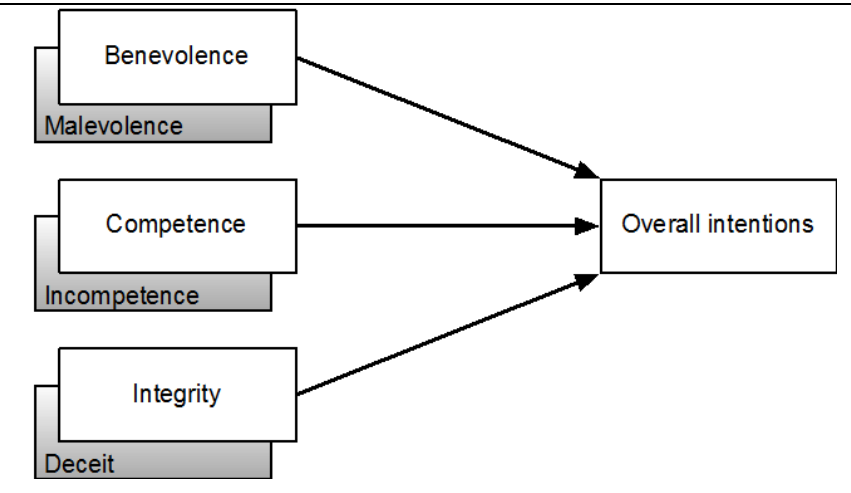

Figure 1 Proposed hybrid conceptualisation of overall trust-based beliefs

Third, building on the unidimensional approach, we propose that although trust and distrust can coexist, only one instantiation (e.g., competence or incompetence) can exist for each specific, independent 
belief subdimension, which may include a wide variety of specific beliefs for each of these subdimensions when an intention is formed by the truster. For instance, errors can be made in packaging, addressing, billing or many other details of an online order. Such errors could then create their own respective beliefs. We assume that even one major shortcoming can affect a consumer's judgment of overall competence in a negative way. Even if a vendor packages the correct item, sends it to the right address and uses the agreed-upon shipping method, these competent acts will not make up for an item arriving broken because of careless packaging. That is, we do not postulate that a consumer would conceptualise that the vendor was "mostly" correct by demonstrating three competent acts and one incompetent act. Consequently, the seriousness or pervasiveness of a single incompetent act will affect the magnitude of the consumer's overall judgment of competence due to its salience. Consistent with the work of Gefen (2002) and Simon (1957, 1991), the alternative would be to store, periodically process and keep salient a notion of competence regarding each individual step in the shipping process, which would be a needlessly wasteful process. Thus, when forming the final trusting or distrusting intention, depending on the direction of the intention, the truster will recall all relevant beliefs, and the subdimensions will be assessed and result in either a positive or negative assessment for the trustee's ability, orientation and dependability. These judgements, based on the beliefs are used to create the overall intention.

We believe that this same property holds for each subdimension. If a seller deceives the buyer and charges his or her credit card for twice the advertised price, the seller would not be thought to “mostly" have integrity, even if the seller shipped the expected SKU, quantity, and condition. Likewise, providing several caring communications during the sale will not be salient if the consumer encounters hostile service or support afterwards.

We assume that it is most likely that consumers form summary judgments for each of the three trusting belief dimensions, simplifying the contradictory information that underlies the dimensions. Thus, the weakest link in each trusting belief dimension will negatively anchor the person's overall judgment for the dimension in general. Besides conserving effort in storing and processing information, a summary or 'net' judgment leads more directly to a dichotomous attitude of whether or not to trust an organisation and engage in trust-related behaviours (e.g., joining an online community, sharing information or experiences or purchasing a product). Ultimately, the trusting or distrusting intention is formed by considering the various trusting and distrusting beliefs, which are stored in memory.

We propose that the truster who is engaging in the transaction may believe or perceive that the trustee has provided inconsistent or contradictory signals. The truster needs to process those contradictory signals to result in a single behavioural response (i.e., buy or not buy), and it has been unclear in our reading of the literature how or when this processing takes place. We propose that during the online shopping experience it is possible that contradictory signals are perceived, stored, and processed in 
greater detail than a single summary impression would imply. These signals could result in positive and negative beliefs, which may engender ambivalence. Current research in e-commerce is scant on ambivalence and thus we seek to further understand how it is created and how it impacts the trust-distrust relationship between the buyer and seller in online markets.

\section{Methodologies}

Prior to actual data collection, anomalous cues to be used in the study were generated and tested with two pilot studies to ascertain the following: (1) the expected buying process that a consumer needed to complete to purchase an item from an online vendor and (2) cues, signals, and errors on a website that would foment feelings of distrust from an online consumer.

\section{Pilot 1. Verification of a 'Normal' Online Shopping Process}

The first pilot ascertained the expected buying process that a consumer would experience when purchasing a product online from a vendor. Forty graduate students in an e-commerce course with extensive online shopping experience from a private university located in the northeastern United States were invited to participate in the pilot study; 20 volunteered (response rate=50\%).

Participants were asked to provide responses to the following open-ended question regarding a typical online transaction: 'List the steps that you would expect to follow in a typical online transaction'. Participants were able to freely respond to this question and submit their responses through an online survey tool. Two coders familiar with online shopping categorised data separately. After initial coding, the coders compared their results and discussed each discrepancy until they could agree on the categorisation. Initial inter-rater reliability was 95\%. The coded responses were counted and categorised. Items with high counts represented aspects of the buying process which buyers expected to experience. Table 3 summarises the expected steps in an online buying episode.

Table 3 Expected Shopping-Scenario Process

\begin{tabular}{llr}
\hline Category & Examples & Count \\
\hline Item selection & 'Search/browse items', 'Browse the goods' & 14 \\
Add to cart & 'Click on buy', 'Check out' & 10 \\
Create an account & 'Create a username and password', 'Login' & 6 \\
Begin transaction & 'Make purchase', 'Make the transaction' & 13 \\
Enter order/billing information & 'Enter credit card and shipping info', 'Decide payment info' \\
Review purchase/invoice & 'Review order confirmation', 'Confirm the purchase' & 15 \\
Confidentiality & 'Expect confidentiality' & 13 \\
Seller follow-through & 'Receive an e-mail' & 2 \\
\hline
\end{tabular}

The Table 3 categorisations indicate the general online consumer expects that a product should first be described on the company's webpage. Next, a consumer enters information required to ship the item, and purchasing information is requested. Finally, a confirmation page is displayed summarising the order. If it is correct, the consumer submits the order and is shown an invoice or receipt. Given these expectations, we used this process in the creation of treatment scenarios for final data collection. 


\section{Pilot 2. Abnormal Features on Online Shopping Websites}

Having established the expected store process, we then sought to discover good examples of unexpected, abnormal features of online transactions that trigger distrust. These features would then serve as abnormality cues in the full experiment. We also modified and validated customer reviews of online merchants for use as customer ratings in the final data collection.

We invited 74 students ${ }^{\mathrm{x}}$ to identify abnormal features, signals, cues and errors during online transactions to test the study's created scenarios; 44 individuals participated (response rate=59.5\%). They were asked to identify cues and signals that would cause to distrust an online seller given atypical or abnormal features on a website. We used the following prompts based on the tripartite view of beliefs (Bagozzi et al., 1979):

- $\quad$ How would you describe your feelings about a trustworthy online merchant?

- What key characteristics do you believe are shared by trustworthy online merchants?

- $\quad$ How would you behave when interacting with a trustworthy online merchant?

- $\quad$ How would you describe your feelings about an untrustworthy online merchant?

- What key characteristics do you believe are shared by untrustworthy online merchants?

- $\quad$ How would you behave when interacting with an untrustworthy online merchant?

The same two coders also coded these data, producing a similar level of inter-rater reliability (96\%). Based on the key characteristics of trustworthy and untrustworthy vendors, Table 4 reports the categorised list of cues or signals that would typically be considered abnormal and thus trigger distrust.

Table 4 Expected Shopping-Scenario Process

\begin{tabular}{llr}
\hline Category & Count \\
\hline Known deceitfulness & 'Bad review', 'Word of mouth' & 7 \\
Unusual information & 'Unusual question', 'Incorrect product information' & 5 \\
Poor design & 'Poor website design', 'Contradictory information' & 12 \\
Missing information & 'Limited or no information', 'Unclear representations' & 9 \\
Abnormal pricing & 'Too good to be true', 'Extremely different price' & 5 \\
Insecure & 'Lax security standards', 'Missing security components' & 13 \\
Small/unknown seller & 'Smaller company', 'No reviews' & 2 \\
\hline
\end{tabular}

We also presented to the participants the proposed customer reviews to be used in the experiment to manipulate the perceived ability, orientation and dependability of the online seller. They were based on actual reviews from Amazon.com and modified for our context. The feedback of these customer reviews provided support (100\% in favour) that such reviews were entirely believable and true. The participants also made some minor suggestions regarding specific wording in some of the reviews, which we found useful in developing the final materials.

\section{Final Data Collection}

Participants were recruited to participate in a free-simulation experiment. This methodology is similar to experimental simulation in that, in both cases, the researcher designs a realistic but closed setting and 
measures the response of human subjects as they interact within such a system. However, in the freesimulation experiment, events and their timing are determined by both the researcher and the behaviour of the human subject. This is particularly useful for increasing realism in website experimentation, such as that for this study, because the user chooses to interact and 'surf' with the experimental website in a naturalistic manner, as seen in various other studies (Gefen et al., 2003; Vance, 2008; Lowry et al., 2012). This study's free-simulation experiment consisted of various treatments for buying a commodity, a lowcost consumer good (i.e., an 8-pack of AA batteries). All participants viewed a product information page, a page that reviewed the seller, an order entry page and a final summary or invoice of the staged, experimental purchase. Participants were randomly assigned to one of three basic types of treatment scenarios, some with several variations, to increase the variations of trust, distrust and ambivalence within the dataset. These scenario types are as follows:

1. Control or trusting treatment (see Online Appendix 2 for screenshots): The entire buying process proceeded without any intentional signals meant to increase distrust or ambivalence;

2. Distrusting treatments (see Tables A1.2-A1.5 for screenshots): The entire buying process contained several errors and anomalous cues that were meant to increase distrusting beliefs.

3. Ambivalence treatments (see Tables A1.6-A1.8 for screenshots): The entire buying process contained roughly one third of the number of distrusting cues as the trusting treatments in an effort to evoke distrusting and trusting beliefs, increasing the likelihood for ambivalence.

Table 5 summarises the design manipulations explored and validated in the pilot study that were included in the treatments. Specifically, each treatment consisted of a varying portfolio of the available design treatments that were identified in the second pilot study.

Table 5 Summary of Experimental Treatments by Portfolio of Design Manipulations

\begin{tabular}{|c|c|c|c|c|c|c|c|c|c|}
\hline \multirow{3}{*}{ Design manipulation } & & \multicolumn{8}{|c|}{ Treatment goal and number } \\
\hline & & \multirow{2}{*}{$\begin{array}{l}\text { Trust } \\
1\end{array}$} & \multicolumn{4}{|c|}{ Distrust } & \multicolumn{3}{|c|}{ Ambivalence } \\
\hline & & & 2 & 3 & 4 & 5 & 6 & 7 & 8 \\
\hline \multirow[t]{3}{*}{ Price } & High & & $\mathrm{X}$ & & & $\mathrm{X}$ & & $\mathrm{X}$ & $\mathrm{X}$ \\
\hline & Normal & $\mathrm{X}$ & & & & & $\mathrm{X}$ & & \\
\hline & Low & & & $\mathrm{X}$ & $\mathrm{X}$ & & & & \\
\hline \multirow[t]{2}{*}{ Site look and feel } & Consistent & $\mathrm{X}$ & & $\mathrm{X}$ & $\mathrm{X}$ & & $\mathrm{X}$ & & \\
\hline & Inconsistent & & $\mathrm{X}$ & & & $\mathrm{X}$ & & & \\
\hline \multirow[t]{4}{*}{ Customer ratings } & None & & $\mathrm{X}$ & & & & & & \\
\hline & Normal & $\mathrm{X}$ & & & & & & & \\
\hline & Extremely negative & & & $\mathrm{X}$ & $\mathrm{X}$ & $\mathrm{X}$ & $\mathrm{X}$ & $\mathrm{X}$ & $\mathrm{X}$ \\
\hline & Targeted dimension & & & I & $\mathrm{M}$ & $\mathrm{D}$ & $\mathrm{D}$ & I & M \\
\hline \multirow[t]{2}{*}{ Information requested } & Normal & $\mathrm{X}$ & $\mathrm{X}$ & & & $\mathrm{X}$ & $\mathrm{X}$ & & \\
\hline & Additional info requested & & & $\mathrm{X}$ & $X$ & & & $\mathrm{X}$ & $\mathrm{X}$ \\
\hline \multirow{5}{*}{ Presentational errors } & None & $\mathrm{X}$ & & & & & & $\mathrm{X}$ & $\mathrm{X}$ \\
\hline & Wrong product picture & & $\mathrm{X}$ & & & $\mathrm{X}$ & $\mathrm{X}$ & & \\
\hline & Wrong product description & & $\mathrm{X}$ & & & $\mathrm{X}$ & & & \\
\hline & Missing product description & & & $\mathrm{X}$ & $\mathrm{X}$ & & & & \\
\hline & Misspellings & & $\mathrm{X}$ & $\mathrm{X}$ & $\mathrm{X}$ & & $\mathrm{X}$ & & \\
\hline
\end{tabular}

Key: I=incompetence (negative ability); $\mathrm{M}=$ Malevolence (negative orientation); $\mathrm{D}=$ Deceit (negative dependability) 


\section{Participants}

For the main study, 521 participants were recruited from both introductory psychology and information systems courses at a large public eastern university in the United States ${ }^{x i}$. Eight participants provided unusable or missing data, which were subsequently deleted from the dataset, resulting in an actual sample size of 513. The sample consisted of 280 males (55.7\%) and 223 females (44.3\%) with the average age of 20.9 years ( $\mathrm{SD}=3.2$ years). The average education level of the participants was 2.1 years of college $(\mathrm{SD}=1.3$ years $)$.

\section{Task, Procedures and Controls}

Participants were asked to imagine that they were buyers of a battery pack, to review various screenshots and to respond to several questions concerning their expected attitudes and intentions when making such a purchase. The sequence of events included viewing product pages, customer reviews, order summaries, billing information and shipping information.

The main page for the product contained an item picture, price and description as they conventionally appear online. An overall view of the page was presented, and then additional zoomed-in portions of the page were provided to ensure that participants were familiar with the product description, price and seller information. Customer reviews and ratings were also displayed, along with several comments from previous customers such as those commonly found on Amazon.com. Portions of the customer ratings were extracted and enlarged to increase the likelihood of participants' familiarity with those portions of the page. Participants were then shown a buyer's information page that requested personal and shipping information, a page in which buyers entered credit card and billing information and a product confirmation page that summarised the order along with price, shipping and billing information. After participants reviewed their randomly assigned buying scenario, they completed instruments to measure the constructs in the model (see Appendix 1).

\section{Analysis and Results}

Extensive pre-analysis and data validation were conducted according to the latest standards to accomplish four goals, as follows (see Appendix 3) (e.g., Gefen \& Straub, 2005; Cenfetelli \& Bassellier, 2009; Lowry \& Gaskin, 2014): (1) to establish factorial validity, (2) to establish that multicollinearity was not a problem with any of the measures, (3) to establish strong reliabilities and (4) to check for commonmethod bias. To establish factorial validity, we used partial least-squares (PLS) structural equation modelling (SEM), which has been used similarly in other behavioural research for strong factorial validity validation (e.g., Howell \& Hall-Merenda, 1999; McCormack et al., 2009). Because all constructs were reflective ${ }^{x i i}$, we established reliability by applying the two most conservative criteria - both the composite reliability and the Cronbach's $\alpha$ coefficients should be $\geq 0.7$ (Fornell \& Larcker, 1981; Nunnally \& Bernstein, 1994). Table 6 summarises these values, which indicate acceptable reliabilities. 
Table 6 Reliability Results for Reflective Subconstructs

\begin{tabular}{llrr}
\hline Construct & Subconstruct & $\begin{array}{c}\text { Composite } \\
\text { reliability }\end{array}$ & $\begin{array}{l}\text { Cronbach's } \\
\text { alpha }(\alpha)\end{array}$ \\
\hline Ambivalence & n/a & 0.820 & 0.789 \\
Distrusting beliefs & Malevolence & 0.911 & 0.853 \\
& Incompetence & 0.945 & 0.921 \\
& Deceit & 0.955 & 0.937 \\
Trusting beliefs & Benevolence & 0.911 & 0.853 \\
& Competence & 0.936 & 0.907 \\
Trusting intentions & Integrity & 0.944 & 0.920 \\
& Follow advice & 0.942 & 0.922 \\
& Give information & 0.743 & 0.686 \\
& Make purchase & 0.867 & 0.701 \\
& Willing to disclose information & 0.931 & 0.900 \\
\hline
\end{tabular}

The reflective constructs exhibit strong factorial validity and reliability and a lack of mono-method bias. These results show that the dataset meets or exceeds the rigorous validation standards expected in behavioural research, particularly for PLS analysis (Diamantopoulos \& Winklhofer, 2001; Podsakoff et al., 2003; Straub et al., 2004; Gefen \& Straub, 2005; MacKenzie et al., 2011; Lowry \& Gaskin, 2014). We note that the constructs are not as highly divergent as is often found in IS research. This is due to the fact that trust and distrust subdimensions are not unrelated constructs; rather, they have the same underlying core meanings in their respective definitions. Despite their similarities, we do find them to be divergent enough, and have their own differential impacts. Further, we note that their correlations are less than .90 , which is identified as the threshold for constructs that are too highly correlated (Pavlou et al., 2007).

Next, we tested the fit of the data within the covariance-based SEM STATA 12.1SE. Unlike PLSbased data confirmation for convergent and divergent validity, the model was assessed using fit indices. Unlike in the PLS model, we included only first-order reflective constructs. Second-order formative constructs were avoided to avoid the identification problem that often results when creating second-order formative constructs in a covariance-based SEM (Kenny \& Milan, 2011). All subdimensions of the second-order formative constructs were thus directly associated with all first-order dimensions of related constructs in the theoretical model. The fit indices indicated an adequate model fit, especially given the established nature of the theoretical model $\left(\chi^{2}{ }_{56}=4381.22\right.$, $\mathrm{p}=0.000$; RMSEA $=0.108$; CFI $=0.972$;

TLI=0.951; SRMR=0.032; CD=1.000).

\section{Manipulation Checks}

Two approaches were used for manipulation checks: (1) in the post-test survey, we asked the participants if they noticed the manipulations and (2) we tested to see if the treatments provided the desired effects. Appendix 3 provides full details for these checks, which are summarised here. The manipulation check ascertained whether the participants had noticed the process abnormalities, website design abnormalities and informational abnormalities. Most participants were aware of the manipulations, but a substantial portion of the manipulations were not perceived or remembered by the participants. Nevertheless, these 
data were retained because they provide a more realistic test of the data (Straub et al., 2004).

Given that large portions of the participant sample were not aware of specific manipulations, this study also relied upon mean comparisons between treatment groups to assess the effectiveness of the manipulations. We conducted several rounds of comparative analyses to establish whether the treatments mainly worked in the directions intended, using polynomial regression analysis (PRA).

\section{Robustness Check}

We performed all of the analyses in the paper after dropping all subjects who did not perceived the manipulations within the experiment. We find that all results are within $4 \%$ of the full dataset. Further, we tested whether these differences were statistically significant and found that all such differences were insignificant. We thus assert that the failure to perceive the manipulations did not alter our results.

\section{Polynomial Regression Analysis}

We used STATA 12.1SE to conduct PRA. After fitting the data to the theoretical model, the extracted scores for each of the first-order reflective constructs based upon the factor scores were extracted from the model estimation, resulting in one score for each subdimension, or 13 latent construct variables. Table 7 summarises the descriptive statistics for these constructs. PRA involves three steps: 1) showing a direct regression of the belief subdimensions on overall intentions and the differences between these subdimensions; 2) a regression of the combined dimensions (ability, orientation and dependability) on overall intentions; and 3) a full factored regression of subdimensions (see equation 1) on overall intentions. We describe each of these steps below.

Table 7 Descriptive Statistics of Extracted Latent Construct Scores

\begin{tabular}{llrrrc}
\hline Construct & Subconstruct & Mean & SD & Min. & Max. \\
\hline Ambivalence & n/a & 0.057 & 1.006 & -2.244 & 2.245 \\
Distrusting beliefs & Malevolence & 0.002 & 0.735 & -1.470 & 1.381 \\
& Incompetence & 0.019 & 0.898 & -1.546 & 1.446 \\
& Deceit & 0.015 & 0.849 & -1.596 & 1.429 \\
Trusting beliefs & Benevolence & -0.005 & 0.594 & -0.809 & 2.002 \\
& Competence & -0.242 & 0.689 & -1.013 & 1.856 \\
& Integrity & 0.035 & 1.577 & -3.308 & 2.453 \\
Trusting intentions & Follow advice & 0.038 & 1.082 & -2.429 & 1.994 \\
& Give information & 0.007 & 1.152 & -2.630 & 2.830 \\
& Make purchase & 0.004 & 1.043 & -2.128 & 1.779 \\
& Willing to disclose information & 0.044 & 1.332 & -3.559 & 2.312 \\
& General & 4.470 & 1.148 & 1.727 & 7.000 \\
\hline
\end{tabular}

We now demonstrate how PRA can provide a richer understanding of trust and distrust and their joint effects on trusting intentions and ambivalence (Klein et al., 2009) in three steps. First, we show the results of the unidimensional view of trust by regressing the results for the three trust dimensions. We then compare the predictive power of these results to that of the model produced by including distinct distrust dimensions. Finally, we compare this bidimensional view of trust and distrust to the PRA of trust and distrust, which accounts for the joint effects that occur when both trust and distrust are present. 
The first step, computing difference scores between the three trust-distrust dimensions (ability, competence-incompetence; orientation, benevolence-malevolence; and dependability, integrity-deceit), examines the dimensional approach to assessing trust and distrust. We regressed these variables onto trusting intentions and ambivalence. Table 8 summarises these results, which indicate that this model is highly predictive of both trust and ambivalence. Further, with the exception of honesty, the dimensions are significant predictors of both trust and ambivalence.

\begin{tabular}{|c|c|c|c|c|c|c|}
\hline \multirow[t]{2}{*}{ Variable } & \multicolumn{3}{|c|}{ Trusting intentions (general) } & \multicolumn{2}{|c|}{ Ambivalence } & \multirow[b]{2}{*}{$p$} \\
\hline & $\beta$ & $t$ & $p$ & $\beta$ & $t$ & \\
\hline Ability & -0.480 & 11.95 & 0.000 & -0.211 & 3.21 & 0.001 \\
\hline Orientation & -0.198 & 4.07 & 0.000 & 0.162 & 2.03 & 0.043 \\
\hline Honesty & -0.072 & 1.36 & 0.176 & -0.139 & 1.58 & 0.114 \\
\hline Constant & 4.445 & 173.64 & 0.000 & 0.004 & 1.05 & 0.296 \\
\hline $\mathrm{R}^{2}$ & 0.740 & 500.28 & 0.000 & 0.109 & 20.82 & 0.000 \\
\hline
\end{tabular}

The second step was to model the subdimensions as separate components, reflecting the bidimensional view of trust and distrust. These results show how the subdimensions of trust and distrust regress onto trusting intentions in general and ambivalence. Again, we note that most of the antecedents are significant predictors of the dependent variables for trust, but not for ambivalence, in which only incompetence is found to significantly predict ambivalence. Table 9 details these regression results. Comparing the adjusted $\mathrm{R}^{2}$ scores from the difference score model (Table 8 ) to the separate-componentscores model (Table 9), slight improvements are observed, which are significant based on the Chow test ( $\Delta$ Adj. $\mathrm{R}_{\text {trusting intentions }}^{2}=0.007, \mathrm{~F}=4.56, p=0.000 ; \Delta$ Adj. $\mathrm{R}^{2}$ Ambivalence $=0.010, \mathrm{~F}=2.194, p=0.041$ ). These results indicate that the bidimensional view of trust and distrust more accurately reflects the underlying data. Further, the effects of the dimensions are more highly varied in the bidimensional model, which reflects how opposing trust and distrust subdimensions produce differential impacts on both overall trusting intentions and ambivalence. Further, the effects of the distrust subdimensions tend to be stronger on the dependent variable, as indicated by the larger beta coefficients in the respective models.

Table 9 Results of Separate Component Scores Regressed on Trusting Intentions and Ambivalence

\begin{tabular}{|c|c|c|c|c|c|c|}
\hline \multirow[t]{2}{*}{ Variable } & \multicolumn{3}{|c|}{ Trusting intentions (general) } & \multicolumn{2}{|c|}{ Ambivalence } & \multirow[b]{2}{*}{$p$} \\
\hline & $\beta$ & $t$ & $p$ & $\beta$ & $t$ & \\
\hline Competence & 0.437 & 5.59 & 0.000 & 0.207 & 1.61 & 0.107 \\
\hline Integrity & 0.141 & 1.50 & 0.133 & 0.091 & 0.59 & 0.554 \\
\hline Benevolence & 0.173 & 2.13 & 0.034 & 0.208 & 1.56 & 0.120 \\
\hline Incompetence & -0.507 & 8.53 & 0.000 & -0.207 & 2.12 & 0.035 \\
\hline Deceit & -0.026 & 0.34 & 0.734 & -0.169 & 1.35 & 0.176 \\
\hline Malevolence & -0.220 & 3.03 & 0.003 & -0.113 & 0.95 & 0.342 \\
\hline Constant & 4.445 & 173.24 & 0.000 & 0.045 & 1.06 & 0.290 \\
\hline $\mathrm{R}^{2}$ & 0.747 & 249.25 & 0.000 & 0.119 & 10.59 & 0.000 \\
\hline
\end{tabular}


Given that the separate components for trust and distrust had a significant predictive improvement for both trusting intentions and ambivalence, we then took the third step of conducting PRA analysis for each trust dimension. Notably, it is important to perform the prior steps, because they show that the additional variables within the model are in fact significant, improving the predictability of the model. If either of these conditions fails, it is unlikely that a PRA-based model will produce results that are both more highly predictive of the data and demonstrative of the differential impacts found by the opposing constructs (Klein et al., 2009).

To perform a PRA, the opposing dimensions are included, along with the squared and interactive terms for both of these dimensions. We do this for all of the included dimensions within the model (i.e., competence-incompetence, benevolence-malevolence and integrity-deceit). The following is an example of using PRA equation (1) for the trust-distrust ability (competence-incompetence) dimension:

Trusting Intentions $=b_{0}+b_{1}$ Competence $+b_{2}$ Incompetence $+b_{3}$ Competence $^{2}+$

$b_{4}$ Competence $*$ Incompetence $+b_{5}$ Incompetence ${ }^{2}+e$.

Table 10 summarises the results of the PRA for each trust dimension on overall trusting intentions and ambivalence. The preponderance of the terms, including many of the interactive and higher-order ones, are significant, which indicates the benefit of this analysis in understanding these complex relationships. Comparing the adjusted $\mathrm{R}^{2}$ scores from the separate components model to this one, we again see slight improvements which are significant based on the Chow test $\left(\Delta\right.$ Adj. $\mathrm{R}^{2}$ trusting intentions $=0.014, F=2.905$, $p=0.002 ; \Delta$ Adj. $\mathrm{R}^{2}$ Ambivalence $=0.223, F=16.810, p=0.000$ ). Further, an analysis of the results shows that several of the nonlinear coefficients are significant, with moderate-to-large effect sizes. This supports the proposition of our research that the relationship between trust and distrust is quite complex, and therefore better analysed with PRA, which also produces better predictive power for the model. The results of these analyses can then be used to understand the complex interactions of the various subdimensions of trust and distrust in general trusting intentions and ambivalence.

\section{Response Surface Analysis}

Given that the nature of the PRA for each trust dimension includes two higher-order terms and an interaction term, the suggested method for understanding the relationship is to rely on RSA for graphical depiction of the results, alongside important pivotal points within the relationship that provide a more indepth understanding regarding its complexity (Edwards, 2002). RSA was developed to understand complex higher-order relationships and interactions among multiple variables, graphically and mathematically. We explain these results in more detail in the discussion section.

MYSTAT version 12 was used to create response surfaces for each of the trust dimensions with both overall trusting intentions and ambivalence. The response surfaces are based on the regression results obtained from the PRA for each of the two dependent variables (z), with the trust-based side of the 
Table 10 Results of PRA by Trust Dimension

\begin{tabular}{|c|c|c|c|c|c|c|}
\hline \multirow[t]{2}{*}{ Variable } & \multicolumn{3}{|c|}{ Trusting intentions (general) } & \multicolumn{2}{|c|}{ Ambivalence } & \multirow[b]{2}{*}{$p$} \\
\hline & $\beta$ & $t$ & $p$ & $\beta$ & $t$ & \\
\hline Competence & 0.487 & 5.93 & 0.000 & 0.109 & -0.91 & 0.361 \\
\hline Incompetence & -0.495 & 8.35 & 0.000 & -0.188 & 2.19 & 0.029 \\
\hline Competence $^{2}$ & 0.079 & 1.07 & 0.287 & -0.154 & -1.43 & 0.155 \\
\hline Incompetence $^{2}$ & 0.205 & 3.43 & 0.001 & -0.302 & -3.49 & 0.001 \\
\hline Competence*Incompetence & 0.161 & 1.73 & 0.084 & 0.057 & 0.42 & 0.674 \\
\hline Integrity & 0.141 & 1.40 & 0.161 & 0.074 & -0.51 & 0.612 \\
\hline Deceit & -0.027 & 0.35 & 0.724 & -0.025 & 0.23 & 0.822 \\
\hline Integrity $^{2}$ & -0.067 & 0.71 & 0.478 & 0.106 & 0.78 & 0.437 \\
\hline Deceit $^{2}$ & -0.249 & 3.52 & 0.000 & -0.102 & -0.99 & 0.322 \\
\hline Integrity*Deceit & -0.300 & 2.56 & 0.011 & 0.258 & 1.51 & 0.131 \\
\hline Benevolence & 0.199 & 2.27 & 0.023 & 0.176 & 1.39 & 0.166 \\
\hline Malevolence & -0.197 & 2.67 & 0.008 & -0.081 & 0.76 & 0.450 \\
\hline Benevolence $^{2}$ & 0.134 & 1.57 & 0.118 & -0.013 & -0.11 & 0.916 \\
\hline Malevolence $^{2}$ & 0.147 & 1.97 & 0.050 & 0.019 & 0.18 & 0.859 \\
\hline Benevolence*Malevolence & 0.296 & 2.50 & 0.013 & 0.066 & 0.39 & 0.699 \\
\hline Constant & 4.351 & 104.76 & 0.000 & 0.523 & 8.67 & 0.000 \\
\hline $\mathrm{R}^{2}$ & 0.761 & 105.32 & 0.000 & 0.342 & 17.24 & 0.000 \\
\hline
\end{tabular}

continuum assigned as the $x$ variable and the distrust-based side assigned as the $y$ variable. Figure 2 depicts the response surface graphs for overall trusting intentions ${ }^{\text {xiii }}$, while Figure 3 depicts ambivalence.

There are three basic types of figures for response surfaces, namely concave (dome-shaped); convex (bowl-shaped); and saddle, which combines upward and downward curves to produce a saddlelike shape. All of the shapes for the trust dimensions for overall trusting intentions appear as concave (integrity-deceit) or convex (competence-incompetence, benevolence-malevolence). The response surfaces for the trusting dimensions for ambivalence appear as concave (competence-incompetence) or saddle shaped (integrity-deceit, benevolence-malevolence).

Edwards (2002) recommended that the response surfaces can be better understood by analysing the stationary points and varying axes that pinpoint interesting aspects of the surfaces. The stationary point reflects the point on the surface for which the slope in all directions is zero. Thus for the concave or convex surfaces, the stationary point identifies the maximum and minimum points, respectively, while it represents the intersection of the upward and downward curves for the saddle shape. We followed the equations in Edwards (2002) and summarise them in Table 11 to calculate these coordinates and lines of interest related to the response surface.

The principle axes help to determine the shape and direction of the slopes for each of the response surfaces. Each is perpendicular to the others, and passes through the stationary point. The first principle axis describes the overall surface orientation in relation to the XY coordinate plane; the second principle axis defines the major surface plane. Each axis provides additional insight, given the nature of the surface in which it is found. For the concave response surface, the primary axis is the line along which the 

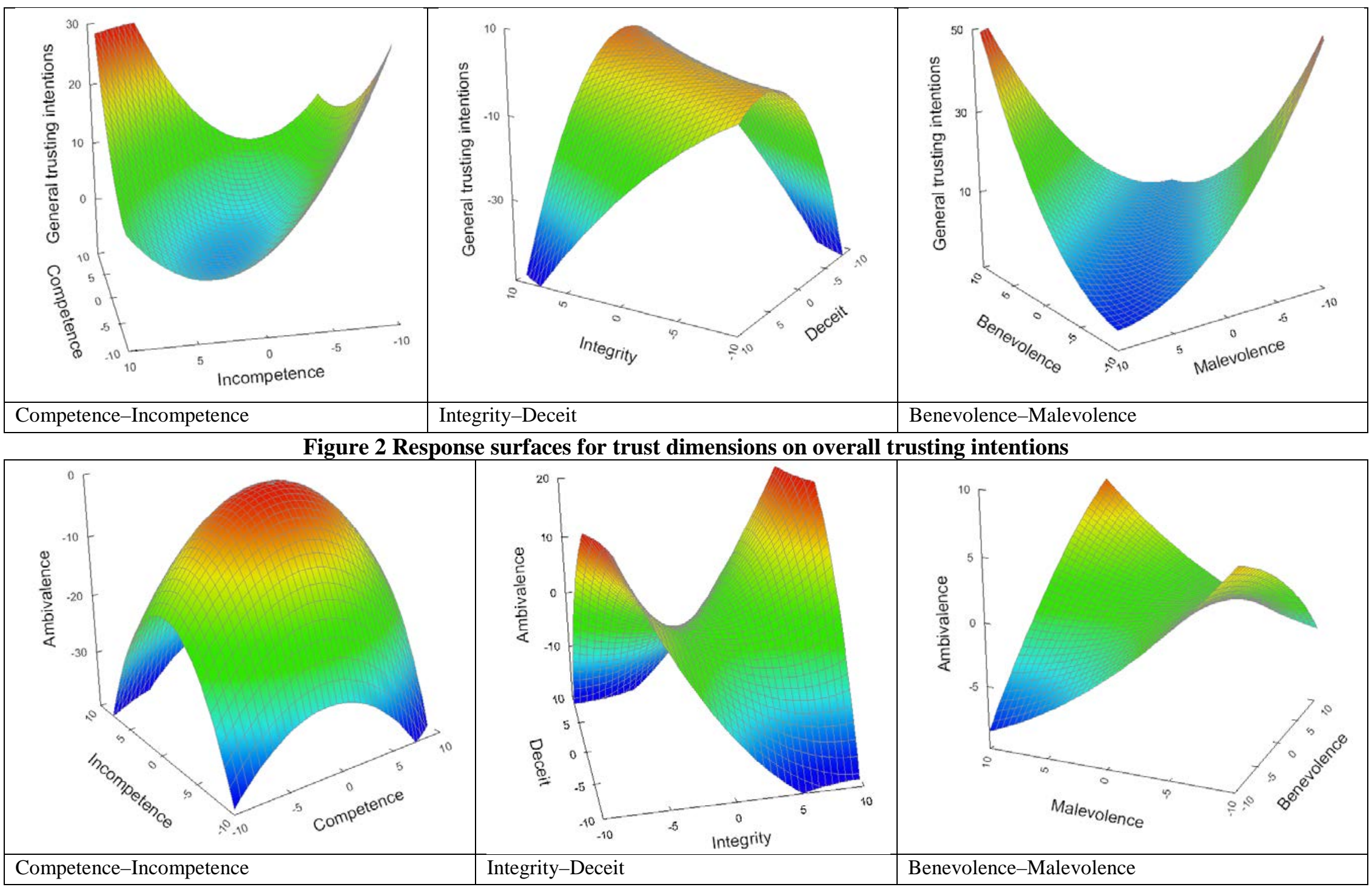

Figure 3 Response surfaces for trust dimensions on ambivalence 
Table 11 Key Metrics for Response Surfaces

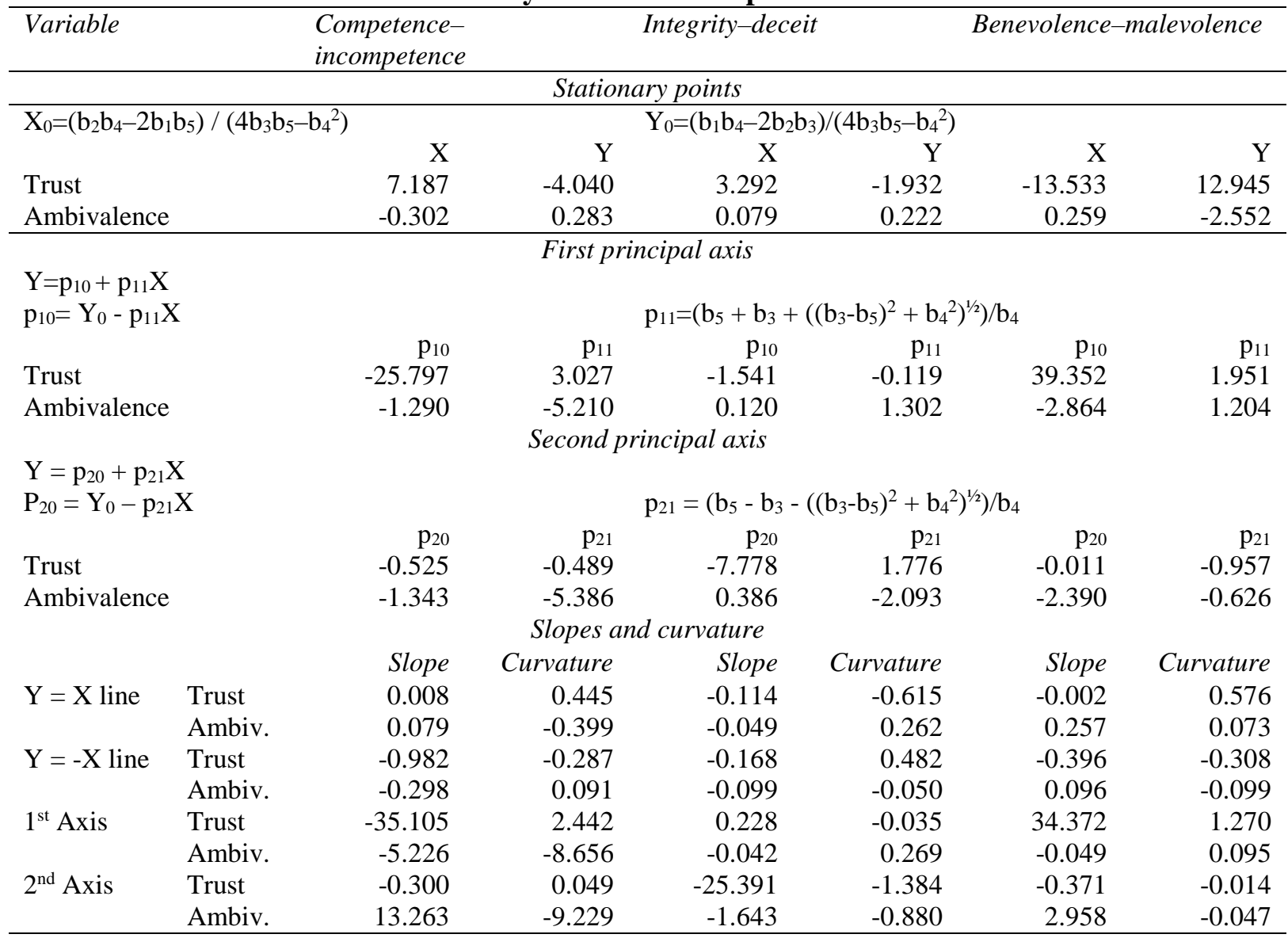

Note: Betas for the equation calculations are based on the beta positions in Equation 1, in the methodology section.

$\mathrm{P}_{10}$ : intercept of the first principle axis

$\mathrm{P}_{11}$ : slope of the first principle axis

$\mathrm{P}_{20}$ : intercept of the second principle axis

$\mathrm{P}_{21}$ : slope of the second principle axis

Slope: the slope of the surface along the line at $\mathrm{X}=0$

Curvature: the curvature of the surface along the indicated line

downward curvature of the surface is minimised; the secondary axis is the line along which the downward curvature is maximised. For the convex response surface, the principle axis is the line along which the upward curvature is maximised; the secondary axis is the line along which the downward curvature is minimised. For the saddle-shaped response surface, the principle axis is the line along which the upward curvature is maximised; the secondary axis is the line along which the downward curvature is maximised.

\section{Discussion}

Much research has focussed on the critical roles that trust and distrust play in the success of online transactions. Yet, the relationship between them has been the subject of substantial theoretical debate.

Further adding to the potential complexity of the trust-distrust relationship is the creation of ambivalence, which has not been examined in online transactions and relationships (Jarvenpaa \& Majchrzak, 2010). Unfortunately, current models of trust and distrust have limitations which impede their ability to explain 
how, or even if, ambivalence is generated by trust and distrust, and how these two constructs can best coexist. We thus propose a hybrid model of trust-distrust that addresses the limitations and strengths of previous models. Trust and distrust can in fact coexist as separate components, but with related continua. Inspired by Klein et al.'s (2009) call for behavioural researchers to better test and understand complex constructs using more appropriate analysis techniques such as PRA, we use PRA and RSA to better investigate these complex relationships.

Given the complexity of the difference-scores regression, PRA and related response surfaces, we first briefly interpret the results of the analysis reported in the previous section, summarise the theoretical and methodological contributions of this work and conclude by discussing the limitations and implications for future research. Given the complexity of these various analyses and findings, we summarize all of our results in our last section. Table 12 summarises all of our analyses, by constructs. As far as we know, each of the findings that we report here have not been reported in prior research, because this is the first attempt to examine the joint and interactive effects of the trust and distrust subdimensions when forming trust, distrust and ambivalence.

\section{Summary of the Results of Difference Scores and PRA}

Table 8 reports the analysis of the difference scores based on the assumption that trust and distrust occupy opposite ends of the same single continuum. The difference scores were effective in predicting overall trusting intentions, and weakly predicted ambivalence. However, the analysis of the separate components - based on the assumption that trust represents a distinct continuum apart from distrust - revealed that overall trusting intentions and ambivalence were significantly more predictable than the difference scores (see Table 9). Hence, by separating trust from distrust, the predictive power of the models increased. This empirical evidence provides further support for the notion that trust and distrust are most likely separate components rather than opposite ends of the same spectrum.

We then analysed the same models with PRA, under the assumption that distrust and trust lie upon separate but related continua (see Table 10). This analysis revealed that the higher-order and interactive terms introduced from the PRA equation significantly increased the predictive power of both models, particularly the ambivalence model, which increased explained variance by $287 \%$. The findings reported in Table 11 support this study's research objective of exploring the relationship between trust and distrust on overall trusting intentions and ambivalence. We show that the relationship between the two constructs is likely more complicated than reported in extant trust-distrust literature. Our analyses support the conclusion that trust and distrust cannot be simply pitted against each other; rather, it is important to consider their elements and how they jointly affect trusting intentions and ambivalence. The canonical correlations show that they have about 70\% shared variance, but 30\% distinctness between them, which supports the assumption that distrust and trust lie on separable but related continua. 
Table 12 Summary of Analyses and Findings by Construct

\begin{tabular}{|c|c|c|c|}
\hline Construct & Outcome & Meth & Finding \\
\hline \multirow[t]{3}{*}{ Benevolence } & Positive influence on trust & PRA & Moderate influence on the creation of trust-equal impact as malevolence. \\
\hline & Positive influence on trust & RSA & $\begin{array}{l}\text { Largest influence on the generation of trust, with equal and large amounts of benevolence and malevolence } \\
\text { (positive or negative). }\end{array}$ \\
\hline & $\begin{array}{l}\text { Positive influence on } \\
\text { ambivalence }\end{array}$ & RSA & $\begin{array}{l}\text { Can moderately create ambivalence with high amounts of benevolence and malevolence. Somewhat less } \\
\text { ambivalence is created with negative, equal amounts of the two constructs }\end{array}$ \\
\hline \multirow{3}{*}{$\begin{array}{l}\text { Benevolence } \\
\& \\
\text { malevolence }\end{array}$} & Interactive trust influence & PRA & The two orientation subdimensions interact and have a medium large effect on trust. Given their equal \\
\hline & Inability to detract from trust & RSA & Analysis reveals that the lowest point on the response surface will only minimally reduce trust. \\
\hline & Potential for ambivalence & RSA & $\begin{array}{l}\text { High positive levels of benevolence and malevolence results in low levels of ambivalence; however, negative } \\
\text { extremes of the two subdimensions results in minimal levels of ambivalence. }\end{array}$ \\
\hline \multirow[t]{4}{*}{ Malevolence } & Negative influence on trust & PRA & Moderate influence on the creation of trust-equal impact as benevolence. \\
\hline & Higher order trust effect & PRA & Binomial term for malevolence is shown to exert a moderately weak influence on trust. \\
\hline & Positive influence on trust & RSA & Like benevolence, malevolence has the greatest potential for creating trust with equal amounts of benevolence. \\
\hline & Weak ambivalence effect & RSA & Response surface reveals that malevolence is minimally able to increase or decrease ambivalence. \\
\hline \multirow[t]{4}{*}{ Competence } & Positive influence on trust & PRA & Large effect on the generation of trust—greater impact on trust than incompetence. \\
\hline & & RSA & \\
\hline & Positive influence on trust & RSA & Greatest amounts of trust result from high competence and moderate incompetence. \\
\hline & Positive influence on trust & RSA & Moderately large effect on the generation of trust. \\
\hline \multirow{2}{*}{$\begin{array}{l}\text { Competence } \\
\& \\
\text { incompetence }\end{array}$} & Inability to detract from trust & RSA & Analysis reveals that the lowest point on the response surface will only minimally reduce trust. \\
\hline & $\begin{array}{l}\text { Detrimental potential on } \\
\text { ambivalence }\end{array}$ & RSA & $\begin{array}{l}\text { Both ability subdimensions are shown to have no potential for the generation of ambivalence, but potentially } \\
\text { reducing ambivalence when either subdimension reaches a high magnitude. }\end{array}$ \\
\hline \multirow[t]{6}{*}{ Incompetence } & Negative influence on trust & PRA & Large influence on the generation of trust-less impactful than competence. \\
\hline & Higher-order trust effect & PRA & Binomial term for incompetence is shown to exert a medium influence on trust. \\
\hline & Negative ambivalence effect & PRA & Medium effect on the generation of ambivalence. \\
\hline & $\begin{array}{l}\text { Higher-order influence on } \\
\text { ambivalence }\end{array}$ & PRA & Binomial term for incompetence is shown to exert a medium effect on ambivalence. \\
\hline & Best predictor of ambivalence & PRA & Incompetence, with its direct and binomial term, is shown to be the best predictor of ambivalence. \\
\hline & Positive influence on trust & RSA & $\begin{array}{l}\text { Incompetence is shown to positively influence trust when it is extreme; moderately positive amounts of } \\
\text { incompetence result in lowest levels of trust. }\end{array}$ \\
\hline Integrity & Neglible influence on trust & PRA & Integrity is not shown to positively influence trust. \\
\hline \multirow[t]{3}{*}{$\begin{array}{l}\text { Integrity \& } \\
\text { deceit }\end{array}$} & Detrimental influence on trust & RSA & $\begin{array}{l}\text { Integrity is shown to have a negative effect on trust when it is of high magnitude, and deceit is of equal } \\
\text { magnitude. }\end{array}$ \\
\hline & Potential for ambivalence & RSA & $\begin{array}{l}\text { High positive levels of integrity and deceit results in moderate levels of ambivalence, however negative } \\
\text { extremes of the two subdimensions results in moderately weak levels of ambivalence. }\end{array}$ \\
\hline & Interactive effect on trust & $\begin{array}{l}\text { PRA } \\
\text { RSA }\end{array}$ & $\begin{array}{l}\text { The two honesty subdimensions interact and have a medium large effect on trust. Given the significant deceit } \\
\text { binomial the response surface shows that the interaction creates a large potential for deterring trust, rather than } \\
\text { positively affecting trust. }\end{array}$ \\
\hline Deceit & Higher-order influence on trust & $\begin{array}{l}\text { PRA } \\
\text { RSA }\end{array}$ & $\begin{array}{l}\text { Binomial term for deceit is shown to exert a medium effect on ambivalence. Response surface reveals that this } \\
\text { term reverses the direction of the equation, thus producing a maximum potential for trust at a low level. }\end{array}$ \\
\hline
\end{tabular}




\section{Explaining the Results of the RSA}

This section will briefly explain the results of the RSA, based on PRA, to provide a better understanding of the relationship of trust with distrust and their joint effects on overall trusting intentions and ambivalence. Here, we are able to highlight more precisely how trust and distrust components interact, which has not been shown in any previous study.

Overall trusting intention results from the RSA. First, the effects of competence and incompetence on overall trusting intentions are more complex than has been found previously. Conceptualisations of trust have focussed on trust as precipitated when overall trust is high or distrust is low. The response surface supports those assumptions, but also demonstrates that moderately high levels of trust can be achieved when competence is high, regardless of the level of incompetence. This finding indicates that incompetence has only weak effects on trusting intentions, and only if the competence of the seller is low. Interestingly, the stationary point reveals that the lowest point on the surface is a moderately high level of incompetence (7.187) and a moderately low level of competence (-4.040). This indicates that the combination of competence that is likely to result in the lowest levels of trust is moderately high levels of incompetence paired with low levels of competence. Even higher levels of incompetence of competence result in higher amounts of trust. This finding has not been reported in the extant literature on trust and distrust.

We also report that trust is more likely to be highly instantiated when competence and incompetence are not of equal magnitudes. Our results reveal that high competence and low incompetence equally arouse high trust alongside high incompetence and low competence. This result is puzzling, but highlights that the participants were more likely to trust when either competence or incompetence was clearly of a greater magnitude than its opposing subdimension. Further, given the slopes of the principle and secondary axis for this analysis, we reveal that the effects of each subdimension are relatively equal in predicting trust.

The impact of competence and incompetence on ambivalence is even more revealing. We report that the potential for creating ambivalence is relatively negligible for these dimensions. The highest level of ambivalence from these subdimensions is still less than zero. Further, the slope of the principle and secondary axis reveal that ambivalence is quickly reduced by increasing either competence or incompetence. We report that the highest levels of ambivalence are created with a small amount of increased incompetence and a small amount of decreased incompetence.

Last, the ability dimension of trust (competence and incompetence) only modestly impedes online transactions, because the lowest levels of trusting intentions reported in this relationship reach nearly -10 , while high levels of competence and low levels of incompetence can reach levels of nearly 30 . This shows that lack of competence does not strongly inhibit overall trusting intentions, but has greater 
available potential impact on overall trust. This may be because of the fundamental attribution error (Ross, 1977). Online buyers may be extending positive attributions towards sellers that overcome perceived competency failures by assuming that the seller is still benevolent or honest and that the fault is beyond the seller's control.

Given the inability of these dimensions to affect ambivalence, we conclude that the impact of the ability dimension within the online relationship is at best a modest asset or at worst relatively no deterrent from shopping online, highlighting that buyers are likely relying upon the trust afforded by a third party and are not as interested in the ability of the online merchant to complete the transaction as expected.

Unexpected results regarding the surface response for integrity and deceit. Rather than higher levels of integrity and lower levels of deceit related to high levels of overall trusting intentions, opposing yet equal magnitudes of integrity and deceit result in high levels of overall trusting intentions, which has never been proposed or found in any extant literature on trust or distrust. For example, if high integrity were perceived (e.g., 10), then for the individual to also have high trusting intentions, moderate levels of deceit would need to be detected (e.g., -3). The highest trusting intention level is obtained when low levels of integrity (3.292) and moderately low levels of deceit are perceived (-1.932).

Further based on the estimates of the axes for integrity and deceit indicate that the highest levels of trust afforded in these relationships is actually quite minimal, indicating that being perceived with high levels of integrity and low levels of deceit does little to greatly increase trust. Of more interest is that when the participants perceived equally high levels of deceit and integrity, they had extremely low levels of trust. The curvatures of the axes reveal that as the magnitudes of these components become uneven, trust is quickly reduced. This highlights that the orientation dimension of trust is most likely to quickly reduce and result in low levels of trust if a buyer perceives that signals regarding deceit and integrity are imbalanced.

We find that high levels of overall trusting intentions can be achieved without having high levels of integrity or low levels of deceit. The response surface indicates that moderate levels of deceit result in high trusting intentions, excepting high scores for the absence of integrity (i.e., -7 or lower). If this finding holds, then it would indicate that trusting intentions could be achieved towards an online seller as long as the vendor is not perceived as being modestly to strongly deceitful and gives minimal perceptions of integrity. That is, in an online setting, buyers might be more product-driven and more personally distanced from the seller, and thus, as long as they receive their desired product without being defrauded, they do not expect or need the seller to have high levels of integrity.

The magnitude of trust shows that integrity and deceit only have a modest influence on the potential for positive trusting intentions. However, if high levels of deceit or a high lack of integrity are perceived, extremely negative scores for trusting intentions are instigated. This could be explained by 
attribution theory (Kelley, 1973): When buyers attribute internal motivations for behaviours on the part of a seller, they believe that such behaviours are common, which results in extremely low levels of trusting intentions. In other words, a deceitful seller is expected to continuously seek ways to harm buyers, which will cause them to form negative trusting intentions towards that seller.

\section{Benevolence and malevolence have the highest potential for positively affecting trusting}

intentions. By achieving high levels of trusting intentions through high levels of benevolence or low levels of malevolence, a buyer can form the most positively-valued trusting intentions among any of the other trust dimensions. Although the benevolence-malevolence response surface is similar to competence-incompetence, the trough of the surface is more flat rather than sloped as indicated by the almost zero slope of the principal component and the increased curvature. This shows that similarly opposing levels of equal magnitude between benevolence and malevolence are equally valued and result in zero to slightly negative levels of negative trusting intentions.

Moreover, this is the only trust dimension in which the high amounts of the positive benevolence subdimension alongside of equally low levels of the negative malevolence subdimension result in the most trust. The other two dimensions require an uneven amount of the opposing subdimensions, but not for benevolence and malevolence. Alongside the highest potential for trust, this indicates that the most important signals for the online merchant to promote are those that indicate their desire for the well-being of the buyer, and to remove those that signal any amount of malevolence.

Ambivalence results of response surface analysis. First, the RSA for competenceincompetence concerning ambivalence yields unexpected results. Rather than high levels of competence and incompetence creating conflicting attitudes, resulting in ambivalence, we find that the condition resulting in minimal ambivalence has only small levels of the two. Specifically, we find that slightly negative competence (-0.302) and slightly positive incompetence (0.283) result in the highest level of ambivalence. Contrary to both recent and classic work on ambivalence (Kaplan, 1972; Sparks et al., 1992; Priester \& Petty, 1996; Jonas et al., 1997; Conner et al., 2002; Petty et al., 2006; van Harreveld et al., 2009). This is partially explained by the magnitude of ambivalence being predicted by this response surface.

The highest scores equate to roughly a maximum of 0 ( $\left.\mathrm{p}_{10}=-1.290\right)$. Thus, it appears that the lack of competence or a show of incompetence is sufficient to reduce the possibility of ambivalence, but that buyers do not view both simultaneously, and thus precipitate ambivalence. Thus, if sellers are perceived as capable in terms of listing product information, they will be perceived as able to enact a transaction and ship the correct product to the correct address. Competence and incompetence do not appear likely to engender any significant amount of ambivalence that would impact the online trust relationship.

Second, we find that both the integrity-deceit and benevolence-malevolence response surfaces 
predict ambivalence in accordance with the expectations in traditional ambivalence literature. When a certain magnitude of the trusting component is matched with an equally opposing magnitude of the distrusting component, ambivalence is fomented. This effect only holds for the extreme magnitudes of the components, and not for low levels, in contrast to the case of competence and incompetence.

Finally, we note that the combination of equal magnitudes in terms of integrity and deceit resulted in the greatest potential for ambivalence. This is followed by a weaker effect on ambivalence by malevolence and benevolence. However, these results highlight that the greatest potential cause of ambivalence occurs when the buyer perceives conflicting cues about the seller that imply the seller is equally likely to help and harm the buyer. Even moving to moderate amounts of both deceit and integrity would result in roughly the same amount of ambivalence created by large amounts of benevolence and malevolence. Thus, online merchants should carefully review or modify signals that specifically depict their orientation towards the seller, as this dimension has the strongest implications for the generation of ambivalence, which may negatively influence trusting intentions.

\section{Contributions}

The primary contributions of this research are both methodological and conceptual, pointing to theoretical contributions for current and future research in online transactions involving trust, distrust and ambivalence. We have been able to contribute to the research conversation about online trust-distrust by using novel methods to analyse already-established relationships of trust and distrust. We have shown how to use PRA and RSA to analyse the complex constructs of trust and distrust. PRA provided an increase in explained variance as compared to regression results, especially for the prediction of ambivalence. We were able to yield several theoretical insights that would not have been possible through the traditional approaches used in the literature. We note that although these improvements are marginal, they are practically significant given their context. E-commerce sites have recognized low rates of turning website visitors into buyers. Given that trust is crucial for these online transactions, if we are able to increase trust by even a small amount, it would likely have a practical impact on these websites.

Previous literature on trust and distrust has focussed on their overall effects, or joint effects, on some mediating or dependent variable. Our work focusses instead on showing how the established dimensions of trust and distrust influence each other, and how these interactions alter the general trust within the relationship. Previous work has stressed that the impact of distrust has a greater magnitude than trust. We extend this work and further explore how the subdimensions between trust and distrust work together and specify the ideal conditions to increase trust. Surprisingly, we show that it is not only about having high amounts of the trust subdimensions and reducing the distrust subdimensions. The relationships are more nuanced and required PRA and RSA to understand the intricacies involved. This study also reveals that there is likely a greater theoretical complexity amongst the continua of trust- 
distrust than has been represented in the literature. These results indicate that more research using advanced analysis techniques is necessary to refine these constructs and associated theories.

Previous work has done little to explore whether the beliefs of the truster regarding the trustee's ability, orientation or honesty are of equal importance. Our work has thoroughly explored the effects of these dimensions and how they work together to influence trust and ambivalence. We specifically highlight that the most important combination of subdimensions for generating general trust is a high amount of benevolence, a low amount of malevolence and a high amounts of competence, along with a minimal amount of incompetence. Deceit and integrity simply do not have the wherewithal to create a high amount of trust. However, a low level of trust is more likely due to either high evidence of integrity or deceit. Although signals of high integrity would not be expected to generate low trust, the truster might believe that the signals are unreliable or "too good to be true." Such findings, unreported to date, are not possible to identify under SEM or regression-based methods found in the extant trust-distrust literature.

In this study's context, we find that the orientation (benevolence-malevolence) of the seller matters more than any other dimension for creating trust, whereas the dependability of the seller in terms of lack of integrity or the presence of deceit will most greatly detract from trusting intentions. We also show that the seller's ability (competence and incompetence) will not strongly detract from trust. It does, however, have the potential to increase overall trusting intentions. Previous research has not determined which dimensions influence trust or in which ways, which suggests abundant further directions for research and practice. We also find that the general ideas of high trust and low distrust hold for ability (competence-incompetence) and orientation (benevolence-malevolence), but not for dependability (integrity-deceit). In fact, only moderate levels of integrity and modestly low levels of deceit produce the highest levels of trusting intentions. Perhaps most shoppers expect a small amount of deceitful signals or the site might be perceived as deceptive. This can be particularly true in an online transaction context, in which consumers generally expect websites to try to get something from them.

The final key theoretical contribution of this study is that by using advanced analysis techniques, we have been able to introduce the ambivalence construct to the trust/distrust literature, thereby responding to Jarvenpaa and Majchrzak’s (2010) call for this construct. If ambivalence is indeed the result of trust and distrust (usually at the same magnitude), traditional analysis cannot be used to test it. Thus, ambivalence is a natural extension to the work proposed by McKnight et al. (2003) and Dimoka et al. (2010), who initially found that trust and distrust are distinct. If they are in fact separable, then what occurs if both are found to be engendered? We find support that ambivalence can be created by the existence of strongly opposing attitudes, but interestingly, not involving the ability subdimension. Rather, competence and incompetence were merely found to reduce ambivalence, but not to instigate ambivalence, no matter their levels of the two. We also show that ambivalence is most strongly aroused 
by dependability (integrity-deceit), and then by the contrast between orientations (benevolencemalevolence), especially when both are at high and not low levels. Understanding what does or does not create ambivalence is particularly important because ambivalence has a strong effect on trusting intentions. Website vendors need to create positive, trust-generating experiences for potential consumers, not those that generate unexpected ambivalence.

This study's ambivalence results provide another interesting theoretical and empirical source of support for the claim that trust and distrust are separate components. If they occupy opposite ends of the same continuum, ambivalence cannot be created by manipulating them at the same time because they cannot coexist under this conceptualisation. Hence, the fact that this study's trust-distrust manipulations resulted in the creation of ambivalence supports the assertion that they are indeed separate. Table 13 summarises the key contributions of the analysis to the trust-distrust literature.

\section{Limitations and Future Research}

This study has several limitations that present future research opportunities. First, the results show support for the direct effect of ambivalence on trusting intentions, contrary to the more traditionally predicted moderation of the relationships of trust and distrust with trusting intentions. This finding is inconsistent with most ambivalence research, but in accordance with Jonas et al.'s (1997) work. Future empirical work needs to replicate and extend these results to explore these relationships further.

This research also has limited generalisability. As in Jonas et al. (1997), these results are based on small, inexpensive, standardised products. Future research should explore whether these findings hold for products or services that require higher levels of involvement or experience prior to purchase. The key difference with costly purchases is that increased processing of information would be more beneficial because it could reduce the risks inherent in such purchases. Hence, adding risk to the model could be potentially useful to understand its role in producing ambivalence.

Regarding student subjects, we highlight three factors that minimise this potential threat against generalisability. First, a meta-analysis by King and He (2006) found that the use of student subjects in technology use contexts, as compared to other subjects, results in no statistical difference. Second, leading IS and behavioural researchers have proposed that if the context and phenomenon being investigated are familiar to them, then the use of students is appropriate (Gordon et al., 1986; Compeau et al., 2012). In our case, students are experienced online users and shoppers and are thus good representatives of the general population of online shoppers. Third, many other online studies in similar contexts have relied upon student subjects for the same reasons, thereby making our work more comparable to their results (e.g., Lowry et al., 2008; Parboteeah et al., 2009; Dimoka, 2010; Wells et al., 2011).

Finally, the results are based on the intention to trust a fictitious third party rather than actual shopping or browsing behaviours. Although other leading online transaction studies have typically 
Table 13 Summary of the Key Contributions to Online Trust-Distrust Literature

\begin{tabular}{|c|c|c|}
\hline Analysis approach & Key result & Interpretation and contribution \\
\hline $\begin{array}{l}\text { Regression with trust- } \\
\text { distrust difference } \\
\text { scores (Table 9) vs. } \\
\text { regression with trust- } \\
\text { distrust separate } \\
\text { components (Table 10) }\end{array}$ & $\begin{array}{l}\text { Separating trust from distrust } \\
\text { increases the predictive power of the } \\
\text { models. }\end{array}$ & $\begin{array}{l}\text { Supports theory and empirical research } \\
\text { claiming that trust and distrust are separate } \\
\text { components, not opposite ends of the same } \\
\text { spectrum. }\end{array}$ \\
\hline \multirow[t]{2}{*}{$\begin{array}{l}\text { PRA (Table } 11)+ \\
\text { canonical correlation }\end{array}$} & $\begin{array}{l}\text { Adding higher-order and interactive } \\
\text { terms in the PRA equation increases } \\
\text { predictive power of the separate } \\
\text { components analysis from Table } 10 .\end{array}$ & $\begin{array}{l}\text { (1) supports trust and distrust as separate } \\
\text { components, but suggests they have related } \\
\text { continua; (2) that the continua have a more } \\
\text { complex relationship than in the literature; and } \\
\text { (3) that the relationship between the two is not } \\
\text { a mere interaction or linear combination, but } \\
\text { rather a third-order relationship due to the } \\
\text { engenderment of ambivalence. }\end{array}$ \\
\hline & $\begin{array}{l}\text { Introduction of ambivalence to the } \\
\text { literature. }\end{array}$ & $\begin{array}{l}\text { PRA and canonical correlation indicates that } \\
\text { trust and distrust have distinct components and } \\
\text { variance. Increased the explanatory power of } \\
\text { ambivalence by almost } 300 \% \text { above the } \\
\text { predictive power of trust and distrust } \\
\text { components alone. }\end{array}$ \\
\hline
\end{tabular}

RSA of the PRA equation
If competence, integrity and benevolence are high, trusting intentions are high.

Competence strongly affects trusting intentions, but incompetence weakly affects them.

Opposing, equal magnitudes of integrity and deceit result in minimal increases to levels of trusting intentions, but have the potential for greatly reducing them.

High levels of benevolence and low levels of malevolence result in high trusting intentions.

Only low to no levels of competence and low to no levels of incompetence create ambivalence.
Supports basic assumption in the literature of trusting intentions occurring when overall trust is high and distrust is low.

Competence is more important than incompetence.

High levels of trusting intentions do not require high levels of integrity or low levels of deceit; integrity can be satisficed. Rather, high levels of either integrity or deceit will result in lower levels of trust. Signals of extremes in orientation will reduce trust.

Benevolence and lack of malevolence have the strongest potential for increasing trusting intentions.

Contrary to the findings in the ambivalence literature, ambivalence can be created by weakly to moderately invoked competence and incompetence attitudes or relatively equal magnitudes. The ambivalence literature proposes that the magnitudes need to be at least moderate.

When a certain magnitude of integrity is matched with deceit, or malevolence is matched with benevolence, ambivalence is invoked.
Equal magnitudes of integrity-deceit or benevolence-malevolence create ambivalence. The orientation (integrity, deceit) of the seller raises the greatest potential for ambivalence. 
focussed on the truster's intentions as the ultimate dependent variable (Dinev \& Hart, 2006; Lowry et al., 2008; Porter \& Donthu, 2008; Qiu \& Benbasat, 2009), the influence of trust and distrust on actual behaviours might be dissimilar to their effects on intentions. Further, the research on ambivalence has focussed on the moderation of beliefs with behaviours, not intentions. Thus, future research should explore whether these results and model hold for actual behaviour.

\section{Conclusions}

Substantial research has focussed on the critical roles that trust and distrust play in the success of online transactions and relationships. Unfortunately, current models of trust and distrust have limitations that impede the ability to explain how ambivalence is generated by them (or if ambivalence can even be generated) and how all three can best coexist. We thus proposed a hybrid model of trust-distrust to address the limitations and strengths of previous trust-distrust models. We posited that trust and distrust could in fact coexist as separate components, but with related continua. We used PRA and RSA to investigate these complex relationships. This confirmed that indeed, trust and distrust are most likely separate components, not opposite ends of the same continuum, with related continua. We also found that the continua within the subconstructs of trust and distrust likely have more complex and interesting relationships than has been considered in the literature. These findings lead to interesting future research opportunities on trust, distrust and ambivalence using advanced techniques such as PRA and RSA.

\section{References}

ALMIRALL E and CASEDESUS-MASANELL R (2010) Open versus closed innovation: A model of discovery and divergence. Academy of Management Review 35(1), 27-47.

ARROW KJ (1974) Limited knowledge and economic analysis. American Economic Review 61(1), 1-10. BA SL (2001) Establishing online trust through a community responsibility system. Decision Support Systems 31(3), 323-336.

BA SL and PAVLOU PA (2002) Evidence of the effect of trust building technology in electronic markets: Price premiums and buyer behavior. MIS Quarterly 26(3), 243-268.

BAGOZZI RP (1994) Structural equation models in marketing research: Basic principles. In Principles of Marketing Research (BAGOZZI RP, Ed.), pp 317-385, Blackwell, Oxford.

BAGOZZI RP, TYBOUT AM, CRAIG CS and STERNTHAL B (1979) The construct validity of the tripartite classification of attitudes. Journal of Marketing Research 16(1), 88-95.

BARBER B (1983) The Logic and Limits of Trust. Rutgers University Press, New Brunswick, NJ.

BENAMATI J, SERVA MA and FULLER MA (2006) Are trust and distrust distinct constructs? An empirical study of the effects of trust and distrust among online banking users. In 39th Annual Hawaii International Conference on System Sciences (HICSS'06), IEEE, Kauai, HI.

BOLLEN K and LENNOX R (1991) Conventional wisdom on measurement: A structural equation perspective. Psychological Bulletin 110(2), 305-314.

BROOKS ME, HIGHHOUSE S, RUSSELL SS and MOHR DC (2003) Familiarity, ambivalence, and firm reputation: Is corporate fame a double-edged sword? Journal of Applied Psychology 88(5), 904-914.

CACIOPPO JT and BERNSTON GG (1994) Relationship between attitudes and evaluative space: A critical review, with emphasis on the separability of positive and negative substrates.

Psychological Bulletin 115(3), 401-423.

CENFETELLI RT and BASSELLIER G (2009) Interpretation of formative measurement in information 
systems research. MIS Quarterly 33(4), 689-707.

CHIN WW, MARCOLIN BL and NEWSTED PR (1996) A partial least squares latent variable modeling approach for measuring interaction effects: Results from a Monte Carlo simulation study and voice mail emotion/adoption study. In 17th International Conference on Information Systems (DEGROSS JI, JARVENPAA S and SRINIVASAN A, Eds.), pp 21-41, AIS, Cleveland, OH.

CHIN WW, MARCOLIN BL and NEWSTED PR (2003) A partial least squares latent variable modeling approach for measuring interaction effects: Results from a Monte Carlo simulation study and an electronic-mail emotion/adoption study. Information Systems Research 14(2), 189-217.

CLEMONS EK, HANN I-H and HITT LM (2002) Price dispersion and differentiation in online travel: An empirical investigation. Management Science 48(4), 534-549.

COMPEAU DR, MARCOLIN HK and HIGGINS CA (2012) Generalizability of information systems research using student subjects - A reflection on our practices and recommendations for future research. Information Systems Research 23(4), 1093-1109.

CONNER M, SPARKS P, POVEY R, JAMES R, SHEPHERD R, et al. (2002) Moderator effects of attitudinal ambivalence on attitude-behaviour relationships. European Journal of Social Psychology 32(5), 705-718.

COOK TD and CAMPBELL DT (1979) Quasi-Experimentation: Design and Analysis for Field Settings. Rand McNally, Chicago, IL.

DELLAROCAS C (2003) The digitization of word of mouth: promise and challenges of online feedback mechanisms. Management Science 49(10), 1407-1424.

DELLAROCAS C (2006) How often should reputation mechanisms update a trader's reputation profile? Information Systems Research 17(3), 271-285.

DENNIS AR, ROBERT JR LP, CURTIS AM, KOWALCZYK ST and HASTY BK (2012) Research note: Trust is in the eye of the beholder: A vignette study of postevent behavioral controls' effects on individual trust in virtual teams. Information systems research 23(2), 546-558.

DEUTSCH M (1958) Trust and suspicion. Journal of Conflict Resolution 2(4), 265-279.

DEUTSCH M (1960) The effect of motivational orientation upon trust and suspicion. Human Relations 13(2), 123-139.

DIAMANTOPOULOS A and SIGUAW JA (2006) Formative versus reflective indicators in organizational measure development: A comparison and empirical illustration. British Journal of Management 17(2006), 263-282.

DIAMANTOPOULOS A and WINKLHOFER HM (2001) Index construction with formative indicators: An alternative to scale development. Journal of Marketing Research 38(2), 269-277.

DIMOKA A (2010) What does the brain tell us about trust and distrust? Evidence from a functional neuroimaging study. MIS Quarterly 34(2), 373-396.

DINEV T and HART P (2006) An extended privacy calculus model for e-commerce transactions. Information Systems Research 17(1), 61-80.

EDWARDS JR (2002) Alternatives to difference scores: Polynomial regression analysis and response surface methodology. In Advances in Measurement and Data Analysis (DRASGOW F and SCHMITT NW, Eds.), pp 350-400, Jossey-Bass, San Francisco, CA.

EVERARD A and GALLETTA D (2005) How presentation flaws affect perceived site quality, trust, and intentions to purchase from an on-line store. Journal of Management Information Systems 22(3), 55-95.

FANG Y, QURESHI I, SUN H, MCCOLE P, RAMSEY E, et al. (2014) Trust, satisfaction, and online repurchase intention: The moderating role of perceived effectiveness of e-commerce institutional mechanisms. MIS Quarterly 38(2), 407-427.

FESTINGER L (1957) A Theory of Cognitive Dissonance. Stanford University Press, Stanford, CA.

FORNELL C and LARCKER DF (1981) Evaluating structural equation models with unobservable variables and measurement error. Journal of Marketing Research 18(1981), 39-50.

GEFEN D (2002) Customer loyalty in e-commerce. Journal of the Association for Information Systems $3(2), 27-51$. 
GEFEN D, KARAHANNA E and STRAUB DW (2003) Trust and TAM in online shopping: An integrated model. MIS Quarterly 27(1), 51-90.

GEFEN D and PAVLOU PA (2012) The boundaries of trust and risk: The quadratic moderating role of institutional structures. Information Systems Research 23(3-part-2), 940-959.

GEFEN D and STRAUB DW (2004) Consumer trust in B2C e-commerce and the importance of social presence: Experiments in e-products and e-services. Omega: The International Journal of Management Science 32(6), 407-424.

GEFEN D and STRAUB DW (2005) A practical guide to factorial validity using PLS-Graph: Tutorial and annotated example. Communications of the AIS 16(5), 91-109.

GORDON ME, SLADE LA and SCHMITT N (1986) The 'Science of the sophomore' revisited: From conjecture to empiricism. Academy of Management Review 11(1), 191-207.

GRAEBNER ME (2009) Caveat venditor: Trust asymmetries in acquisitions of entrepreneurial firms. Academy of Management Journal 52(3), 435-472.

HANN I-H, HUI K-L, LEE S-YT and PNG IPL (2007) Overcoming online information privacy concerns: An information-processing theory approach. Journal of Management Information Systems 24(2), $13-42$.

HARDIN R (1993) The street-level epistemology of trust. Politics \& Society 21, 505-529.

HOWELL JM and HALL-MERENDA KE (1999) The ties that bind: The impact of leader-member exchange, transformational and transactional leadership, and distance on predicting follower performance. Journal of Applied Psychology 84(5), 680-694.

JARVENPAA SL and MAJCHRZAK A (2010) Research commentary-Vigilant interaction in knowledge collaboration: Challenges of online user participation under ambivalence. Information Systems Research 21(4), 773-784.

JARVENPAA SL and TRACTINSKY N (1999) Consumer trust in an Internet store: A cross-cultural validation. Journal of Computer-Mediated Communication 5(2), 1-35.

JONAS K, DIEHL M and BROMER P (1997) Effects of attitudinal ambivalence on information processing and attitude-intention consistency. Journal of Experimental Social Psychology 33(2), 190-210.

KACHADOURIAN LK, FINCHAM F and DAVILA J (2005) Attitudinal ambivalence, rumination, and forgiveness of partner transgressions in marriage. Personality and Social Psychology Bulletin 31(5), 334-342.

KAHNEMAN D and TVERSKY A (1979) Prospect theory: An analysis of decision under risk. Econometrica 47(2), 263-291.

KAPLAN KJ (1972) On the ambivalence-indifference problem in attitude theory and measurement: A suggested modification of the semantic differential technique. Psychological Bulletin 77(5), 361372.

KELLEY HH (1973) The process of causal attribution. American Psychologist 28(2), 107-128.

KENNY DA and MILAN S (2011) Identification: A non-technical discussion of a technical issue. In Handbook of Structural Equation Modeling (HOYLE R, KAPLAN D, MARCOULIDES G and WEST S, Eds.), Guilford Press, New York, NY.

KING WR and HE J (2006) A meta-analysis of the technology acceptance model. Information \& Management 43(6), 740-755.

KLEIN G, JIAN JJ and CHENEY P (2009) Resolving difference score issues in information systems research. MIS Quarterly 33(4), 811-826.

KOMIAK S and BENBASAT I (2008) A two-process view of trust and distrust building in recommendation agents: A process-tracing study. Journal of the Association for Information Systems 9(12), 727-747.

KRAMER RM (1999) Trust and distrust in organizations: Emerging perspectives, enduring questions. Annual Review of Psychology 50(1), 569-598.

KRISHNAN R, MARTIN X and NOORDERHAVEN NG (2006) When does trust matter in alliance performance? Academy of Management Journal 49(5), 894-917. 
LEVIN DT and SIMONS DJ (1997) Failure to detect changes to attended objects in motion pictures. Psychonomic Bulletin and Review 4(4), 501-506.

LEVIN DZ and CROSS R (2004) The strength of weak ties you can trust: The mediating role of trust in effective knowledge transfer. Management Science 50(11), 1477-1490.

LEWICKI RJ and BUNKER BB (1996) Developing and maintaining trust in work relationships. In Trust in Organizations (KRAMER RM and TYLER TR, Eds.), pp 114-139, Sage, Thousand Oaks, CA.

LEWICKI RJ, MCALLISTER DJ and BIES RJ (1998) Trust and distrust: New relationships and realities. Academy of Management Review 23(3), 438-458.

LEWICKI RJ, TOMLINSON EC and GILLESPIE N (2006) Models of interpersonal trust development: Theoretical approaches, empirical evidence, and future directions. Journal of Management 32(6), 991-1022.

LEWIS JD and WEIGERT A (1984) Trust as a social reality. Social Forces 63(4), 967-984.

LIANG H, SARAF N, HU Q and XUE Y (2007) Assimilation of enterprise systems: The effect of institutional pressures and the mediating role of top management. MIS Quarterly 31(1), 59-87.

LIM ET, TAN C-W, CYR D, PAN SL and XIAO B (2012) Advancing public trust relationships in electronic government: The Singapore e-filing journey. Information Systems Research 23(4), 1110-1130.

LIU BQ and GOODHUE DL (2012) Two worlds of trust for potential e-commerce users: Humans as cognitive misers. Information Systems Research 23(4), 1246-1262.

LOWRY PB and GASKIN J (2014) Partial least squares (PLS) structural equation modeling (SEM) for building and testing behavioral causal theory: When to choose it and how to use it,. IEEE Transactions on Professional Communication 57(2), 123-146.

LOWRY PB, MOODY G, VANCE A, JENSEN M, JENKINS JL, et al. (2012) Using an elaboration likelihood approach to better understand the persuasiveness of website privacy assurance cues for online consumers. Journal of the American Society for Information Science and Technology 63(4), 755-766.

LOWRY PB, ROMANO NC, JENKINS JL and GUTHRIE RW (2009) The CMC interactivity model: How interactivity enhances communication quality and process satisfaction in lean-media groups. Journal of Management Information Systems 26(1), 159-200.

LOWRY PB, SCHUETZLER RM, GIBONEY JS and GREGORY TA (2015) Is trust always better than distrust? The potential value of distrust in newer virtual teams engaged in short-term decision making. Group Decision and Negotiation 24(4), 723-752.

LOWRY PB, VANCE A, MOODY G, BECKMAN B and READ A (2008) Explaining and predicting the impact of branding alliances and Web site quality on initial consumer trust of e-commerce Web sites. Journal of Management Information Systems 24(4), 201-227.

LOWRY PB, WILSON DW and HAIG WL (2014) A picture is worth a thousand words: Source credibility theory applied to logo and website design for heightened credibility and consumer trust. International Journal of Human-Computer Interaction 30(1), 63-93.

LOWRY PB, ZHANG D, ZHOU L and FU X (2010) Effects of culture, social presence, and group composition on trust in technology-supported decision-making groups. Information Systems Journal 20(3), 297-315.

LUHMANN N (1979) Trust and Power. John Wiley, New York, NY.

MACDONALD TK and HYNIE M (2008) Ambivalence and unprotected sex: Failure to predict sexual activity and decreased condom use. Journal of Applied Social Psychology 38(4), 1092-1107.

MACDONALD TK and ZANNA MP (1998) Cross-dimension ambivalence toward social groups: Can ambivalence affect intentions to hire feminists? Personality and Social Psychology Bulletin 24(4), 427-441.

MACKENZIE SB, PODSAKOFF PM and PODSAKOFF NP (2011) Construct measurement and validation procedures in MIS and behavioral research: Integrating new and existing techniques. MIS Quarterly 35(2), 293-334.

MAIO GR, BELL DW and ESSES VM (1996) Ambivalence and persuasion: The processing of messages 
about immigrant groups. Journal of Experimental Social Psychology 32(6), 512-536.

MARAKAS GM, JOHNSON RD and CLAY PF (2007) The evolving nature of the computer selfefficacy construct: An empirical investigation of measurement construction, validity, reliability, and stability over time. Journal of the Association for Information Systems 8(1), 16-46.

MAYER R, DAVIS J and SCHOORMAN F (1995) An integrative model of organizational trust. The Academy of Management Review 20(3), 709-734.

MCALLISTER DJ (1995) Affect- and cognition-based trust as foundations for interpersonal cooperation in organizations. Academy of Management Journal 38(1), 24-59.

MCCORMACK D, CASIMIR G, DJURKOVIC N and YANG L (2009) Workplace bullying and intention to leave among schoolteachers in China: The mediating effect of affective commitment. Journal of Applied Social Psychology 39(9), 2106-2127.

MCKNIGHT DH and CHERVANY NL (2001) While trust is cool and collected, distrust is fiery and frenzied: A model of distrust concepts. In 7th Americas Conference on Information Systems, pp 883-888, Association for Information Systems, Boston, MA.

MCKNIGHT DH and CHOUDHURY V (2006) Distrust and trust in B2C e-commerce: Do they differ? In Proceedings of the Eighth International Conference on Electronic Commerce (ICEC'06) (SPENCER B, FOX MS, DU W, DU D and BUFFETT S, Eds.), pp 482-491, Fredericton, New Brunswick, Canada.

MCKNIGHT DH, CHOUDHURY V and KACMAR CJ (2002) Developing and validating trust measures for e-commerce: An integrative typology. Information Systems Research 13(3), 334-359.

MCKNIGHT DH, CUMMINGS L and CHERVANY N (1998) Initial trust formation in new organizational relationships. Academy of Management Review 23(3), 473-490.

MCKNIGHT DH, KACMAR C and CHOUDHURY V (2003) Whoops... did I use the wrong concepts to predict e-commerce trust? Modeling the risk-related effects of trust versus distrust concepts. In 36th Hawaii International Conference on System Sciences (HICSS'36), pp 182-191, Big Island, HI.

MCKNIGHT DH, KACMAR C and CHOUDHURY V (2004) Dispositional trust and distrust distinctions in predicting high- and low-risk Internet expert advice site perceptions. E-Service Journal 3(2), 35-58.

MOODY GD, GALLETTA DF and LOWRY PB (2014) When trust and distrust collide: The engendering and role of ambivalence in online consumer behavior. Electronic Commerce Research and Applications 13(4), 266-282.

NAQUIN CE and PAULSON GD (2003) Online bargaining and interpersonal trust. Journal of Applied Psychology 88(1), 113-120.

NUNNALLY JC and BERNSTEIN IH (1994) Psychometric Theory. McGraw-Hill, New York, NY.

OREG S and SVERDLIK N (2011) Ambivalence toward imposed change: The conflict between dispositional resistance to change and the orientation toward the change agent. Journal of Applied Psychology 96(2), 337-349.

OU CX and SIA CL (2010) Consumer trust and distrust: An issue of website design. International Journal of Human-Computer Studies 68(12), 913-934.

PARBOTEEAH DV, VALACICH JS and WELLS JD (2009) The influence of website characteristics on a consumers' urge to buy impulsively. Information Systems Research 20(1), 60-78.

PAVLOU P, LIANG H and XUE Y (2007) Understanding and mitigating uncertainty in online exchange relationships: A principal-agent perspective. MIS Quarterly 31(1), 105-136.

PAVLOU PA and FYGENSON M (2006) Understanding and predicting electronic commerce adoption: An extension of the theory of planned behavior. MIS Quarterly 30(1), 115-143.

PETTER S, STRAUB DW and RAI A (2007) Specifying formative constructs in information systems research. MIS Quarterly 31(4), 623-656.

PETTY RE, BRINOL P and DEMARREE KG (2007) The meta-cognitive model (MCM) of attitudes: Implications for attitude measurement, change, and strength. Social Cognition 25(5), 657-686.

PETTY RE, TORMALA ZL, BRINOL P, JARVIS W and BLAIR G (2006) Implicit ambivalence from 
attitude change: An exploration of the PAST model. Journal of Personality and Social Psychology 90(1), 21-41.

PODSAKOFF PM, MACKENZIE SB, LEE JY and PODSAKOFF NP (2003) Common method biases in behavioral research: A critical review of the literature and recommended remedies. Journal of Applied Psychology 88(5), 879-903.

PORTER CE and DONTHU N (2008) Cultivating trust and harvesting value in virtual communities. Management Science 54(1), 113-128.

PRIESTER JR and PETTY RE (1996) The gradual threshold model of ambivalence: Relating the positive and negative bases of attitudes to subjective ambivalence. Journal of Personality and Social Psychology 71(3), 431-449.

PRIESTER JR, PETTY RE and PARK K (2007) Whence univalent ambivalence? From the anticipation of conflicting reactions. Journal of Consumer Research 34(1), 11-21.

PURANAM P and VANNESTE BS (2009) Trust and governance: Untangling a tangled web. Academy of Management Review 34(1), 11-31.

QIU L and BENBASAT I (2009) Evaluating anthropomorphic product recommendation agents: A social relationship perspective to designing information systems. Journal of Management Information Systems 25(4), 145-181.

RIEDL R, HUBERT M and KENNING P (2010) Are there neural gender differences in online trust? An fMRI study on the perceived trustworthiness of eBay offers. MIS Quarterly 34(2), 397-428.

RINGLE CM, WENDE S and WILL S (2005) SmartPLS 2.0 (M3) Beta. September 17, 2010, http://www.smartpls.de.

ROSENBERG M and HOVLAND CI (1960) Cognitive, affective and behavioral components of attitudes. In Attitude Organization and Change (ROSENBERG M, Ed.), pp 1-14, Yale University Press, New Haven, CT.

ROSS L (1977) The intuitive psychologist and his shortcomings: Distortions in the attribution process. In Advances in Experimental Social Psychology (BERKOWITZ L, Ed.), Vol 10, pp 173-220, Academic Press, New York, NY.

ROTTER JB (1980) Interpersonal trust, trustworthiness, and gullibility. American Psychologist 35(1), 17.

SCHOORMAN FD, MAYER RC and DAVIS JH (2007) An integrative model of organizational trust: Past, present, and future. Academy of Management Review 32(2), 344-354.

SCHUL Y, MAYO R and BURNSTEIN E (2008) The value of distrust. Journal of Experimental Social Psychology 44(5), 1293-1302.

SILVERMAN M and MACK A (2006) Priming by change blindness: When it does and does not occur. Consciousness and Cognition 15(2), 409-422.

SIMON H (1957) A behavioral model of rational choice. In Models of Man: Social and Rational: Mathematical Essays on Rational Human Behavior in a Social Setting (SIMON H, Ed.), pp 99118, Wiley, New York, NY.

SIMON H (1991) Bounded rationality and organizational learning. Organization Science 2(1), 125-134.

SPARKS P, HEDDERLEY D and SHEPHERD R (1992) An investigation into the relationship between perceived control, attitude variability and the consumption of two common foods. European Journal of Social Psychology 22(1), 55-71.

STRAUB DW (1989) Validating instruments in MIS research. MIS Quarterly 13(2), 147-169.

STRAUB DW, BOUDREAU MC and GEFEN D (2004) Validation guidelines for IS positivist research. Communications of the AIS 14, 380-426.

THOMPSON MM and ZANNA MP (1995) The conflicted individual: Personality-based and domainspecific antecedents of ambivalent social attitudes. Journal of Personality 63(2), 259-288.

TOMLINSON EC and MAYER RC (2009) The role of causal attribution dimensions in trust repair. Academy of Management Review 34(1), 85-104.

TRAFIMOW D and SHEERAN P (1998) Some tests of the distinction between cognitive and affective beliefs. Journal of Experimental Social Psychology 34(4), 378-397. 
VAN HARREVELD F, VAN DER PLIGT J and DE LIVER YN (2009) The agony of ambivalence and ways to resolve it: Introducing the MAID model. Personality and Social Psychology Review 13(1), 45-61.

VANCE A (2008) Trusting IT artifacts: How trust affects our use of technology. Unpublished, doctoral dissertation, Computer Information Systems Department, Georgia State University.

WELLS JD, VALACICH JS and HESS TJ (2011) What signals are you sending? How website quality influences perceptions of product quality and purchase intentions. MIS Quarterly 35(2), 373-396.

WILLIAMS M (2001) In whom we trust: Group membership as an affective context for trust development. Academy of Management Review 26(3), 377-396.

WILLIAMS P and AAKER JL (2002) Can mixed emotions peacefully coexist? Journal of Consumer Research 28(3), 636-649.

WU B, GOEL V and DAVISON BD (2006) Propagating trust and distrust to demote web spam. In Models of Trust for the Web Workshop (MTW06) of 15th International World Wide Web Conference, pp 1-9, Edinburgh, Scotland, UK.

XIAO B and BENBASAT I (2007) E-Commerce product recommendation agents: Use, characteristics, and impact MIS Quarterly 31(1), 137-209.

YAKOVLEVA M, REILLY RR and WERKO R (2010) Why do we trust? Moving beyond individual to dyadic perceptions. Journal of Applied Psychology 95(1), 79-91.

ZIEGLER R, HAGEN B and DIEHL M (2012) Relationship between job satisfaction and job performance: Job ambivalence as a moderator. Journal of Applied Social Psychology 42(8), 20192040. 


\section{Appendix 1. Instrument Detail}

\section{Table A1 Instrument Detail}

\begin{tabular}{|c|c|c|}
\hline Construct & Subconstruct & Items \\
\hline \multirow{17}{*}{$\begin{array}{l}\text { Trusting intentions } \\
\text { (Second-order } \\
\text { formative; } \\
\text { McKnight et al. } \\
\text { (2002) }\end{array}$} & $\begin{array}{l}\text { Willingness to } \\
\text { depend }\end{array}$ & $\begin{array}{l}\text { WD1. When an important issue or problem arises, I would feel comfortable depending on the information provided } \\
\text { by the seller. }\end{array}$ \\
\hline & & WD2. I could always rely on the seller in a tough situation. \\
\hline & & WD3. I feel that I could count on the seller to help with a crucial problem. \\
\hline & & WD4. Faced with a difficult situation that required me to buy a given product right now, I would use the seller. \\
\hline & Willingness to & FA1. If I had a challenging problem, I would want to use the seller again. \\
\hline & follow advice & FA2. I would feel comfortable acting on the information given to me by the seller. \\
\hline & & FA3. I would not hesitate to use the information the seller supplied me. \\
\hline & & FA4. I would confidently act on the information I was given by the seller. \\
\hline & & FA5. I would feel secure in using the information from the seller. \\
\hline & & $\begin{array}{l}\text { FA6. Based on the scenario I just reviewed, I would buy the product, and be assured that the correct item, in good } \\
\text { condition would be sent to me. }\end{array}$ \\
\hline & $\begin{array}{l}\text { Willingness to } \\
\text { give } \\
\text { information }\end{array}$ & $\begin{array}{l}\text { "Suppose you wanted more specific information about a given product and you could consult (one time only) by } \\
\text { telephone with a salesman from the seller for 15-30 minutes (free of charge). For this service, please answer the } \\
\text { following:" }\end{array}$ \\
\hline & & $\begin{array}{l}\text { GI1. I would be willing to provide information like my name, address and phone number to the seller's } \\
\text { representative. }\end{array}$ \\
\hline & & GI2. I would be willing to provide my social security number to the seller’s representative. \\
\hline & & GI3. I would be willing to share the specifics of my product needs with the seller's representative. \\
\hline & Make purchase & $\begin{array}{l}\text { "Suppose the Amazon.com was not free, but charged to access product information on the site. Answer the } \\
\text { following questions:" }\end{array}$ \\
\hline & & MP1. Faced with a difficult situation, I would be willing to pay to access information about the product. \\
\hline & & MP2. I would be willing to provide credit card information to the seller. \\
\hline \multirow{11}{*}{$\begin{array}{l}\text { Trusting beliefs } \\
\text { (Second-order } \\
\text { formative; } \\
\text { McKnight et al. } \\
\text { (2002) }\end{array}$} & Benevolence & BEN1. I believe that the seller would act in my best interest. \\
\hline & & BEN2. If I required help, the seller would do his or her best to help me. \\
\hline & & BEN3. The seller is interested in my well-being, not just his or her own. \\
\hline & Competence & COMP1. The seller would be competent and effective in providing the product. \\
\hline & & COMP2. The seller would perform his or her role of providing opportunities for the product very well. \\
\hline & & COMP3. Overall, the seller would be a capable and proficient provider of the product. \\
\hline & & COMP4. In general, the seller would be very knowledgeable about the product. \\
\hline & Integrity & INT1. The seller would be truthful in his or her dealings with me. \\
\hline & & INT2. I would characterise the seller as honest. \\
\hline & & INT3. The seller would keep his or her commitments. \\
\hline & & INT4. The seller would be sincere and genuine. \\
\hline \multirow{2}{*}{$\begin{array}{l}\text { Distrusting beliefs } \\
\text { (Second-order }\end{array}$} & Malevolence & MAL1. I worry that the seller is only concerned about his or her own interests. \\
\hline & & MAL2. It concerns me a lot that the seller pretends to care more about me than he or she really does. \\
\hline
\end{tabular}


formative;

McKnight et al.

(2002); McKnight

and Choudhury

Ambivalence

Priester et al.

(2007)
Incompetence

MAL3. I fear that the seller inwardly dislikes putting himself or herself out to help other buyers.

INCOMP1. I am troubled that the seller is not as knowledgeable in his or her field as I would expect.

INCOMP2. I am cautious because I believe that the seller does a haphazard job at what he or she does.

INCOMP3. Concern is justified, since the seller is not really competent in his or her area of expertise.

DECT1. Unfortunately, the seller would tell a lie if he or she could gain by it.

DECT2. It's a troubling fact that the seller won't always hold to the standard of honesty he or she claims.

DECT3. Sadly, the seller would cheat on his or her financial statements if he or she thought he or she could get away with it.

"Indicate your agreement with the following statements:"

AMBIV1. Possessed reactions that were mixed versus one-sided.

AMBIV2. Felt conflict in their reactions.

AMBIV3. Experienced behavioural indecision.

AMBIV4. Felt tension in their thoughts and feelings.

AMBIV5. Felt ambivalence. 
Online Appendix 2. Detailed Experimental Methods

Note to editors and reviewers: because of length restrictions, theses appendices are intended to be used as online supplements to the main article and to support the review process.

The experimental webpages are shown by the treatment conditions below in Table A1.2-A1.9. 
Table A1.2 Control Treatment - No Distrust Signals

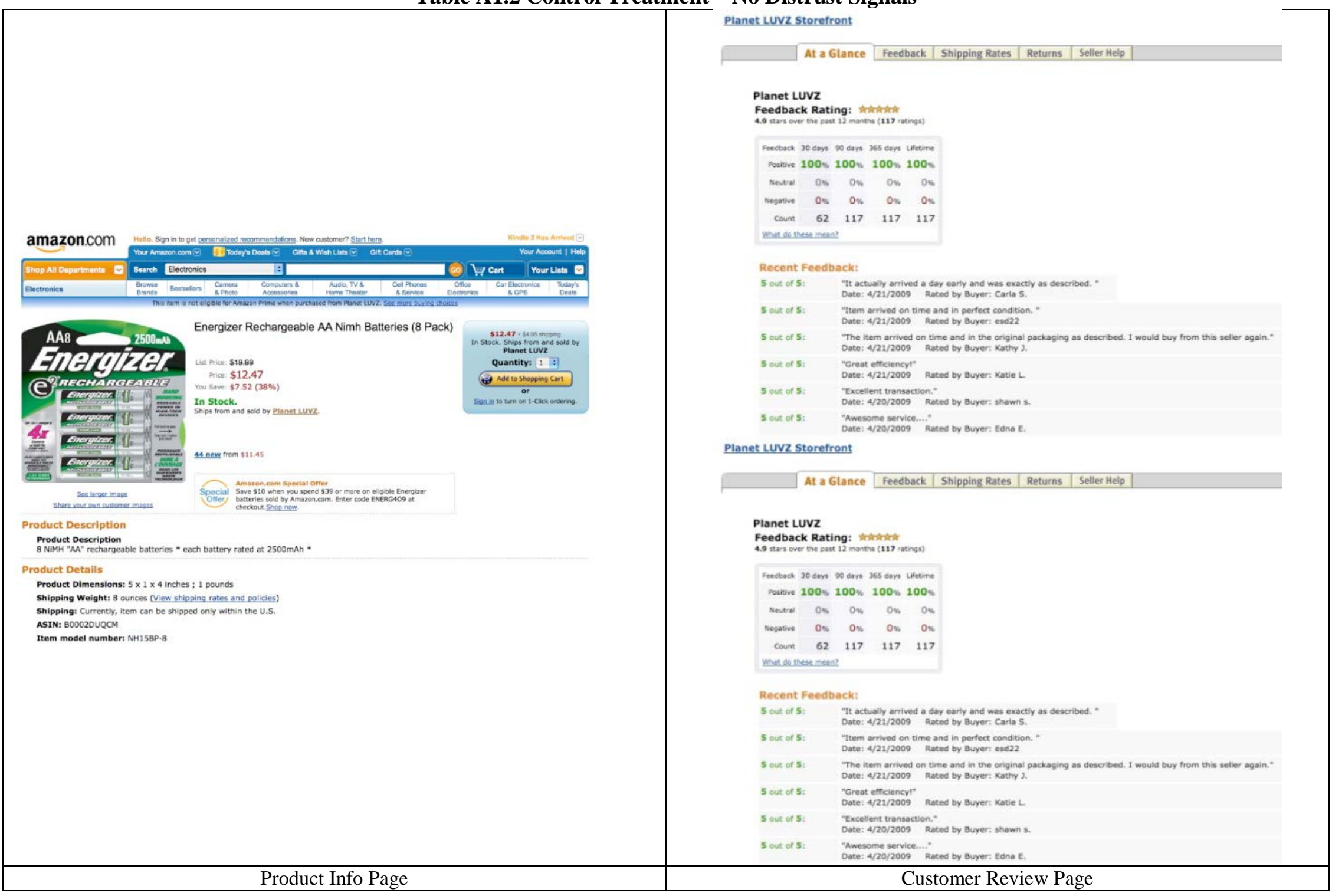




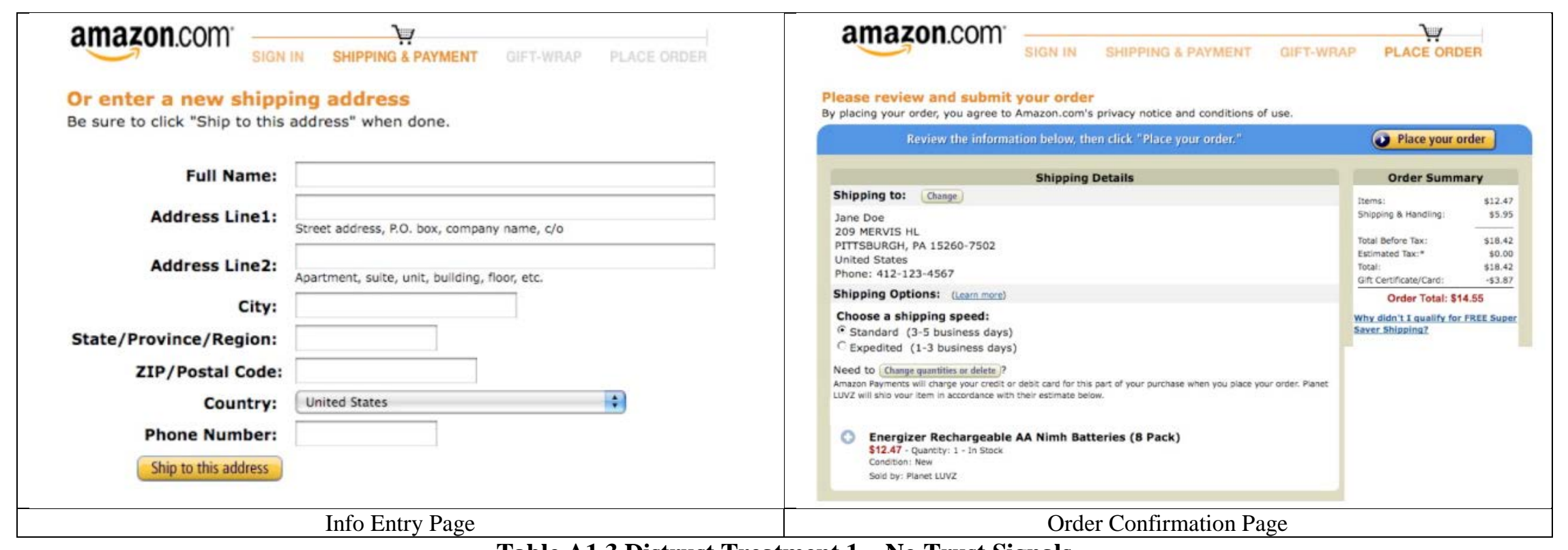

Table A1.3 Distrust Treatment 1 - No Trust Signals

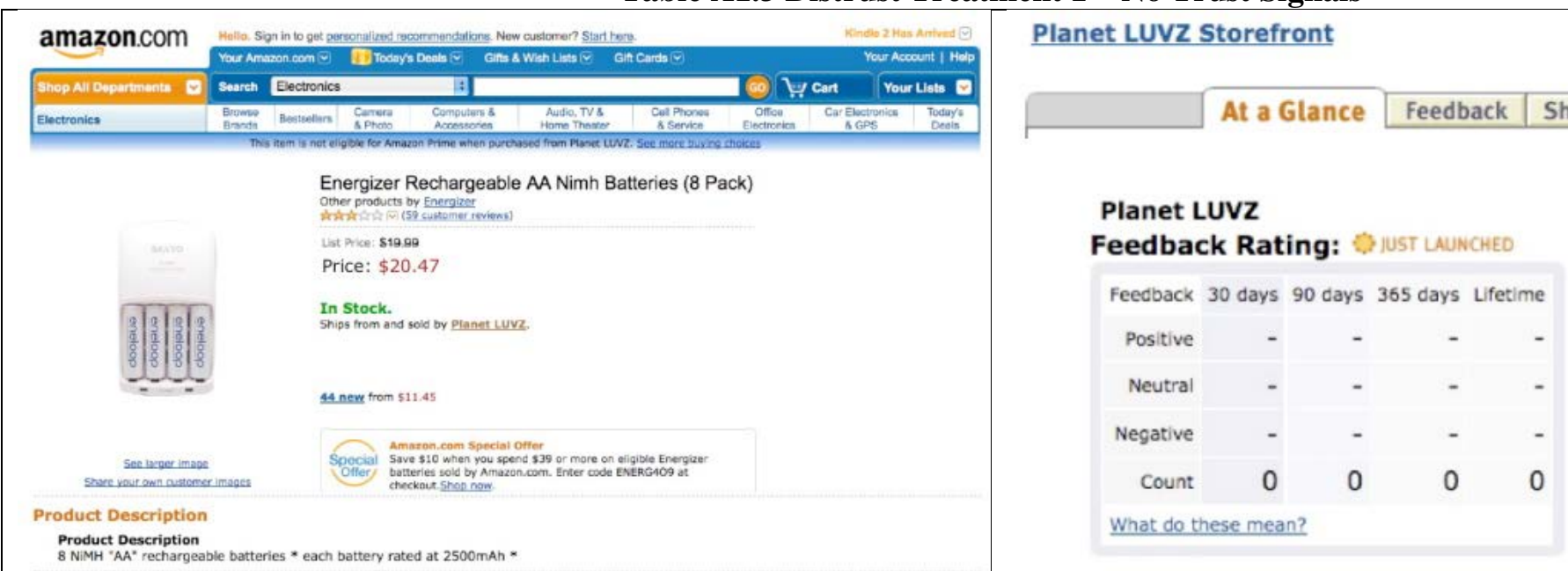

Product Details

Vew the Owner's Manual pron

× $11.5 \times 14.5$ inches ; 25 pounds

Shipping Weight: 32.6 pounds (View shipping rates and policies) 


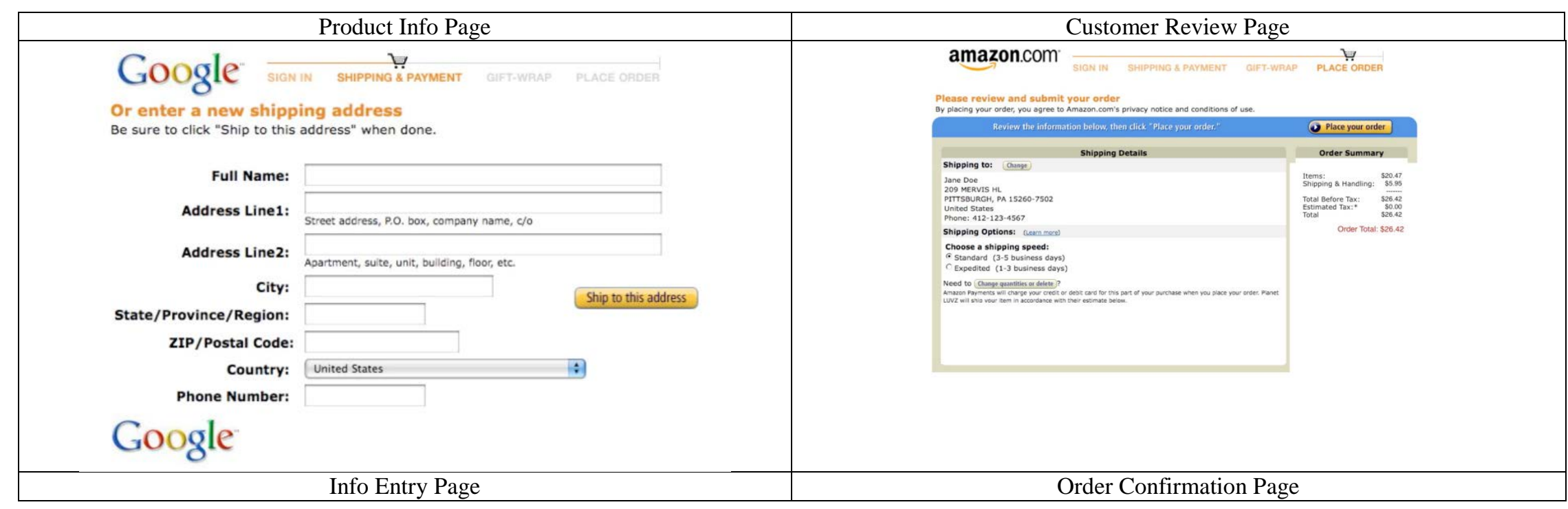


Table A1.4 Distrust Treatment 2 - Incompetence Signals

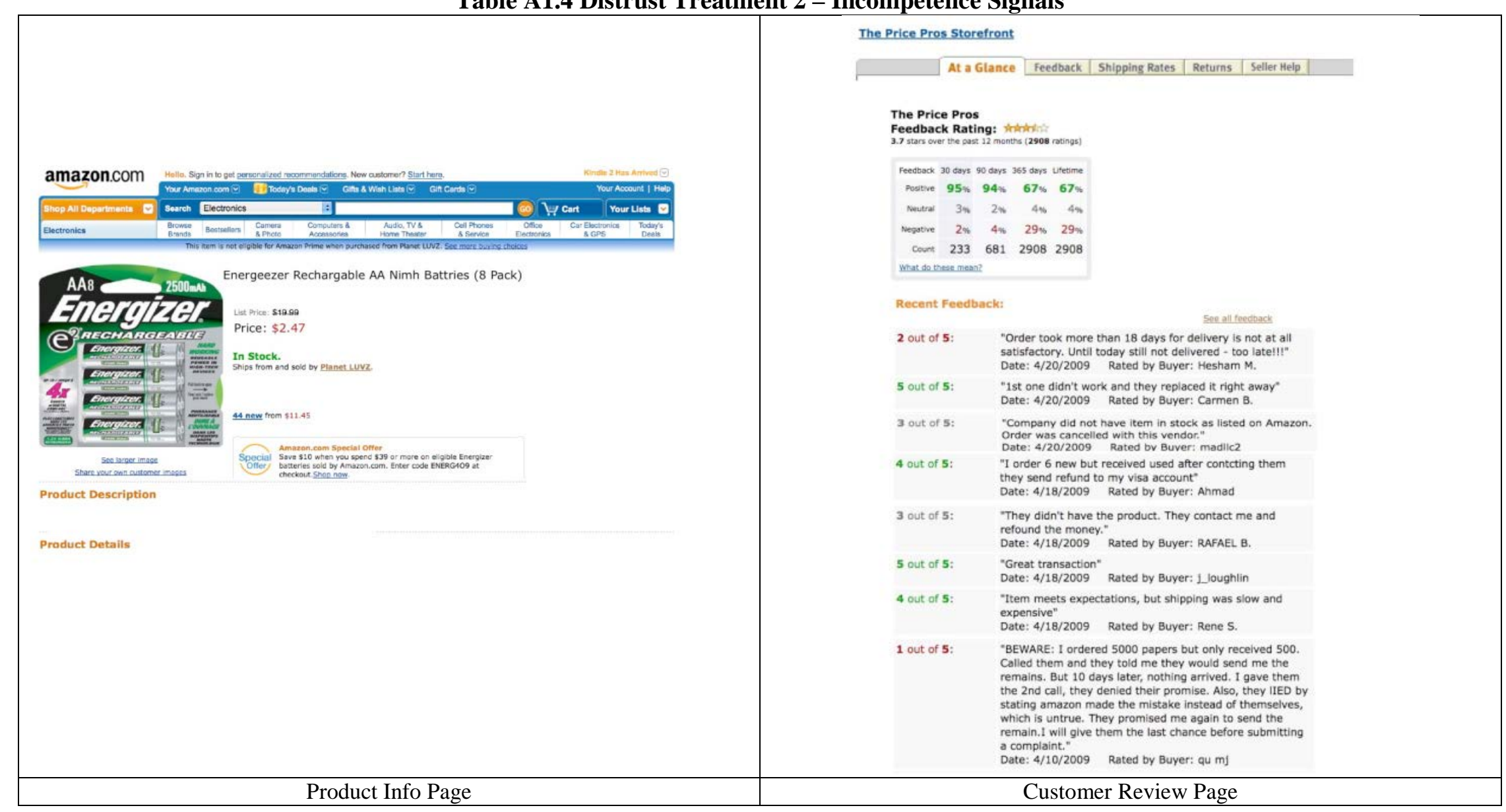




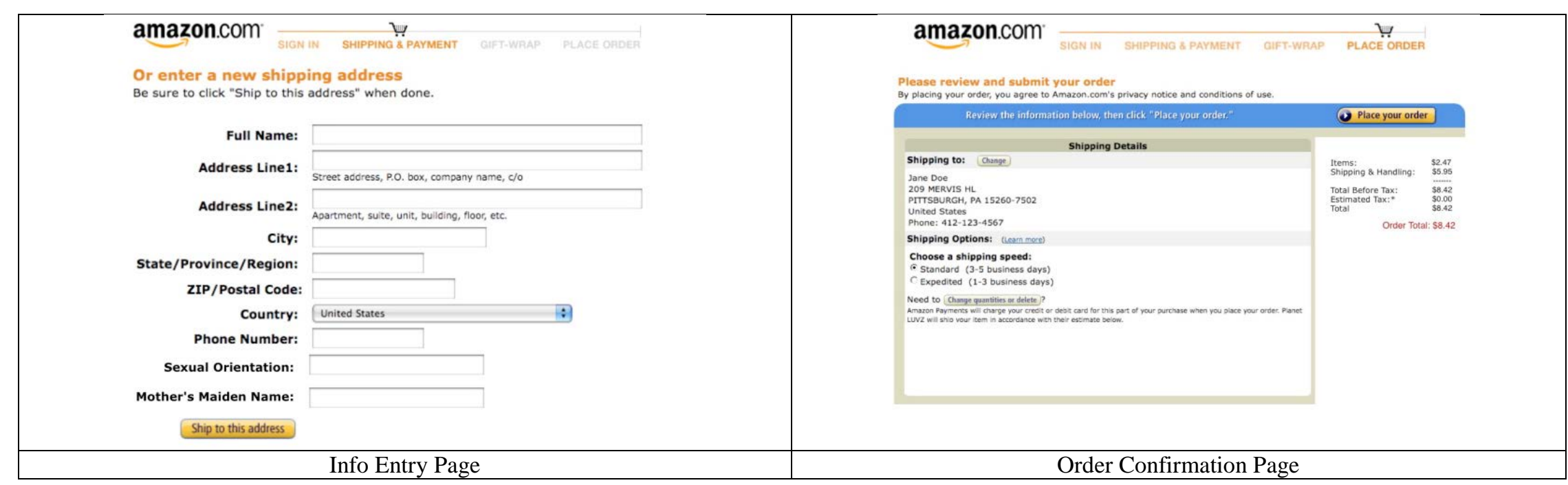


Table A1.5 Distrust Treatment 3 - Malevolence Signals

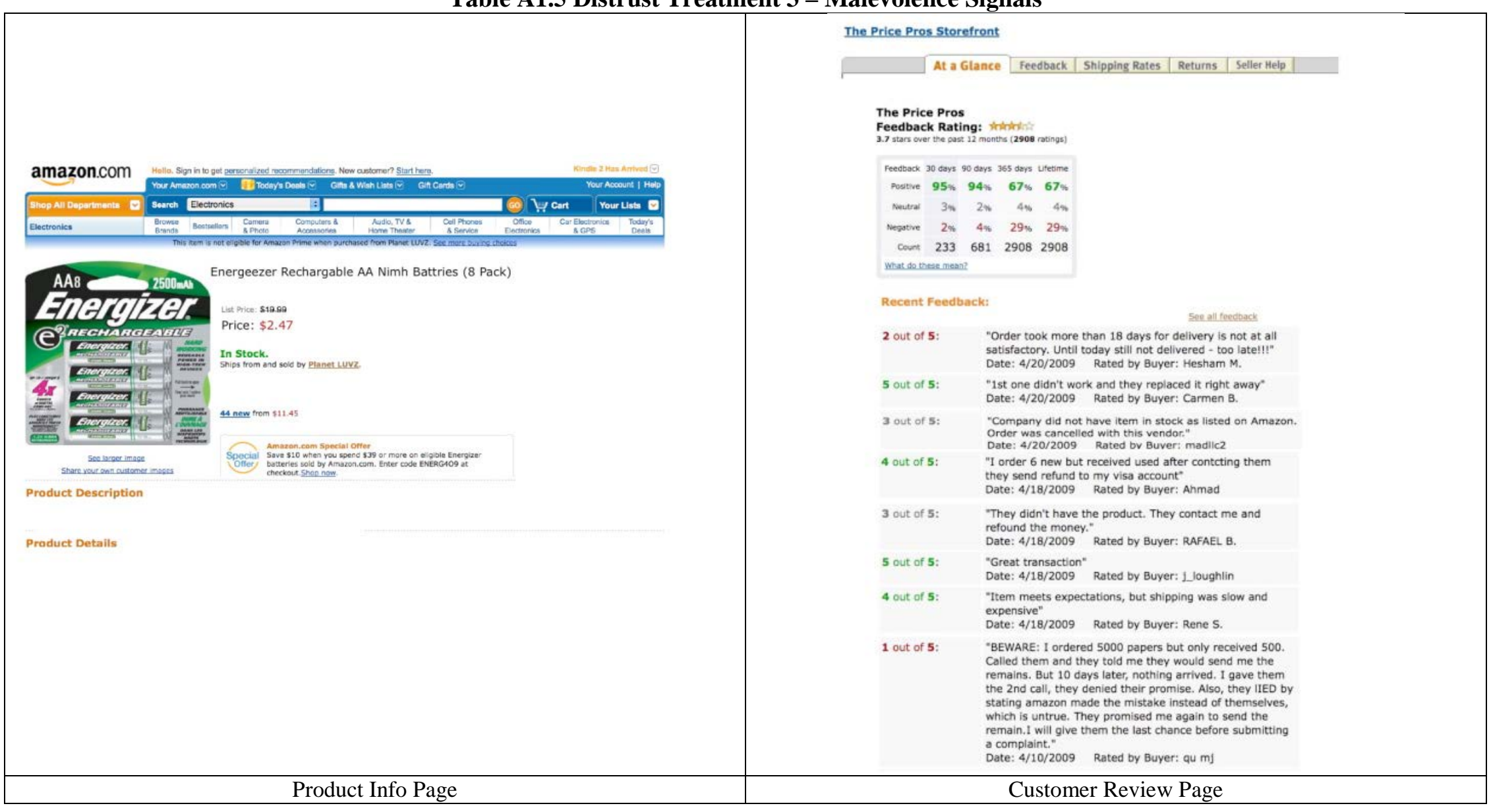




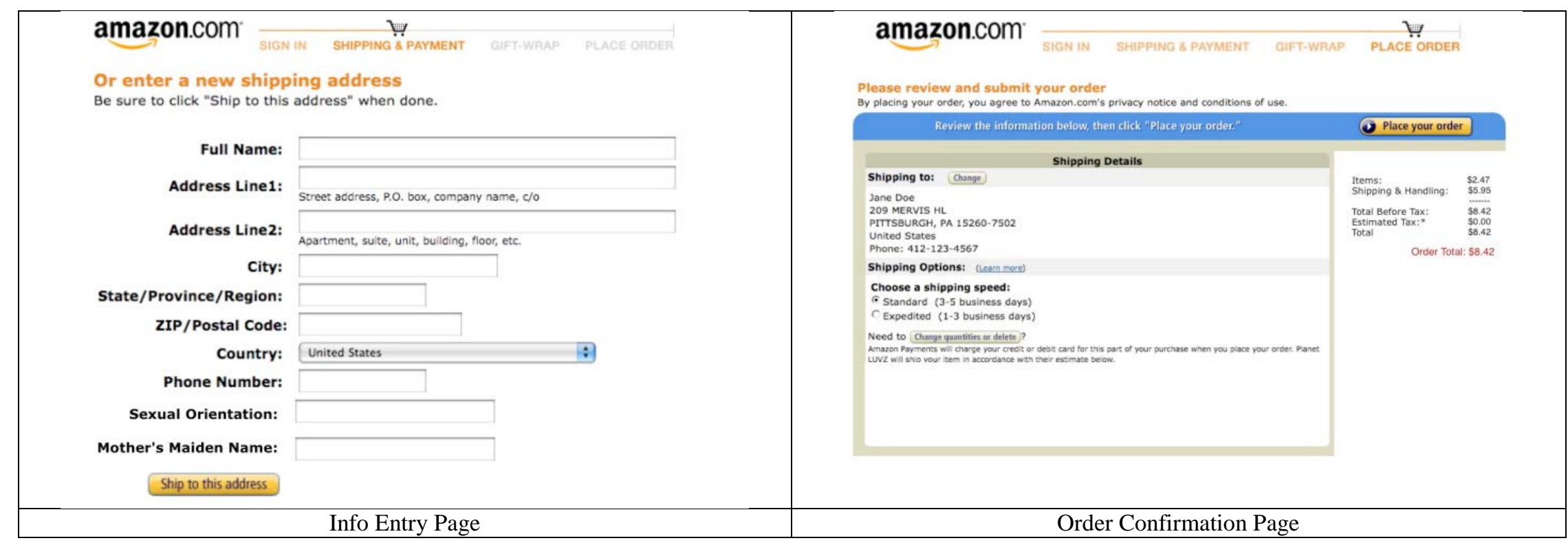


Table A1.6 Distrust Treatment 4 - Deceit Signals

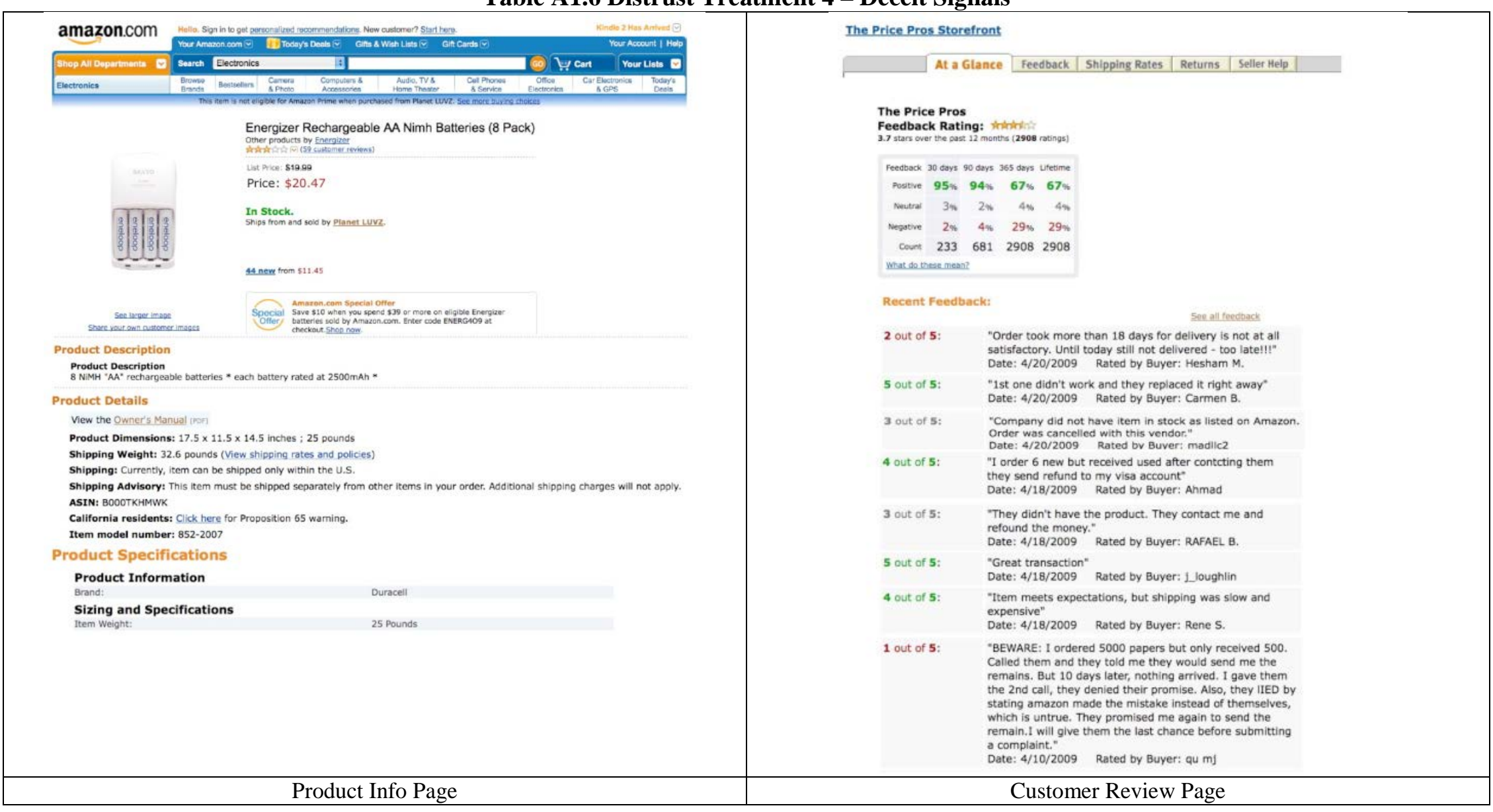




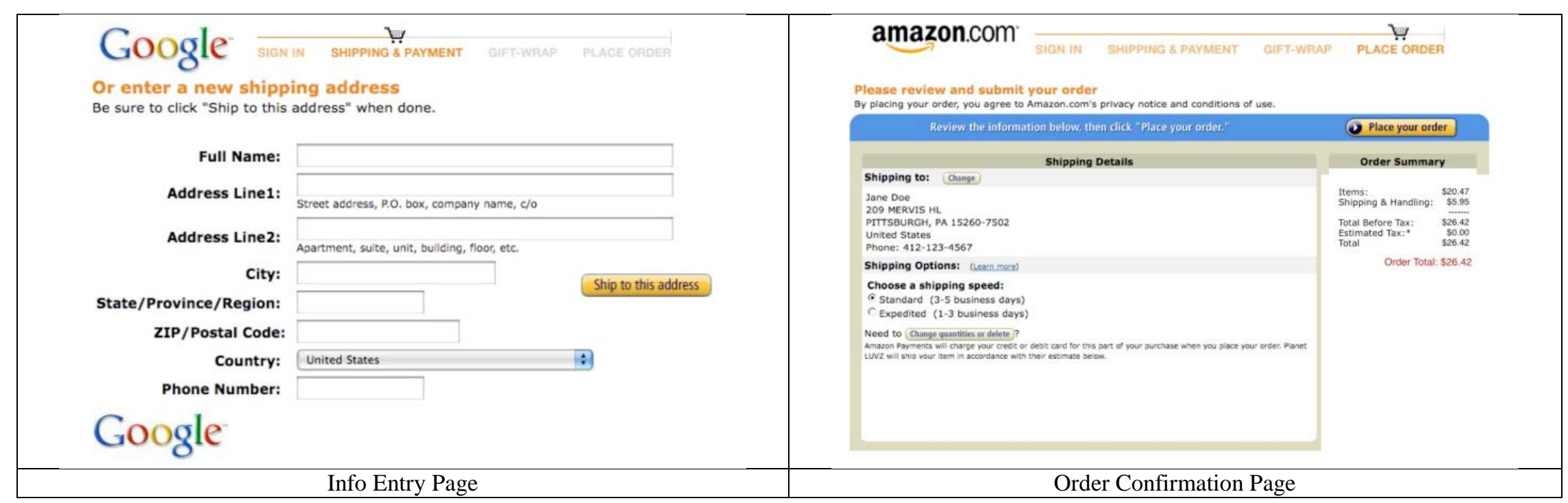




\section{Table A1.7 Ambivalence Treatment 1}

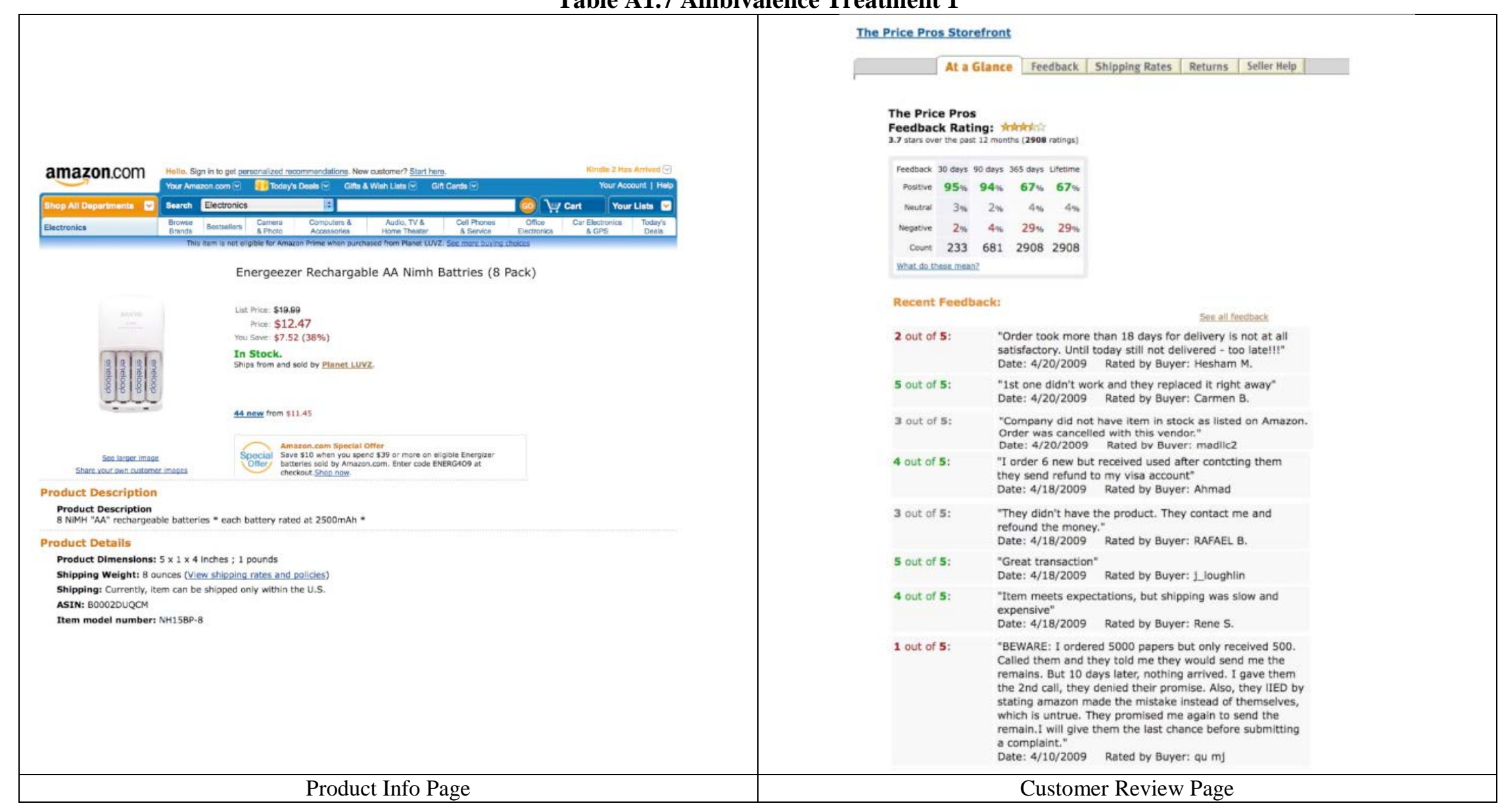




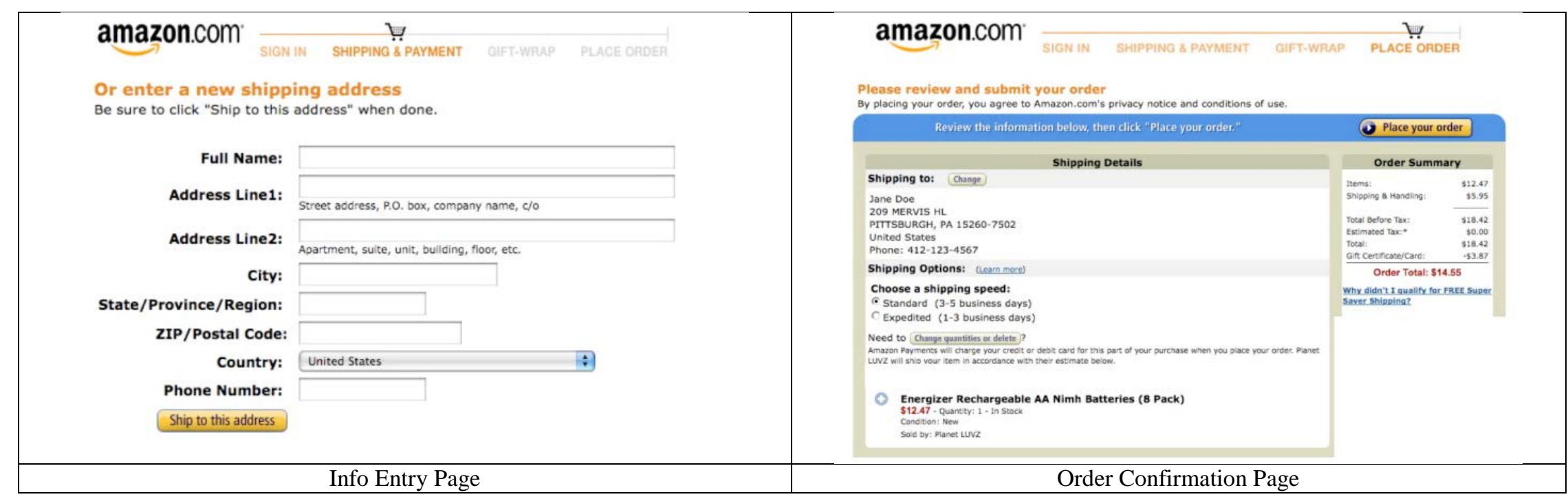


Table A1.8 Ambivalence Treatment 2

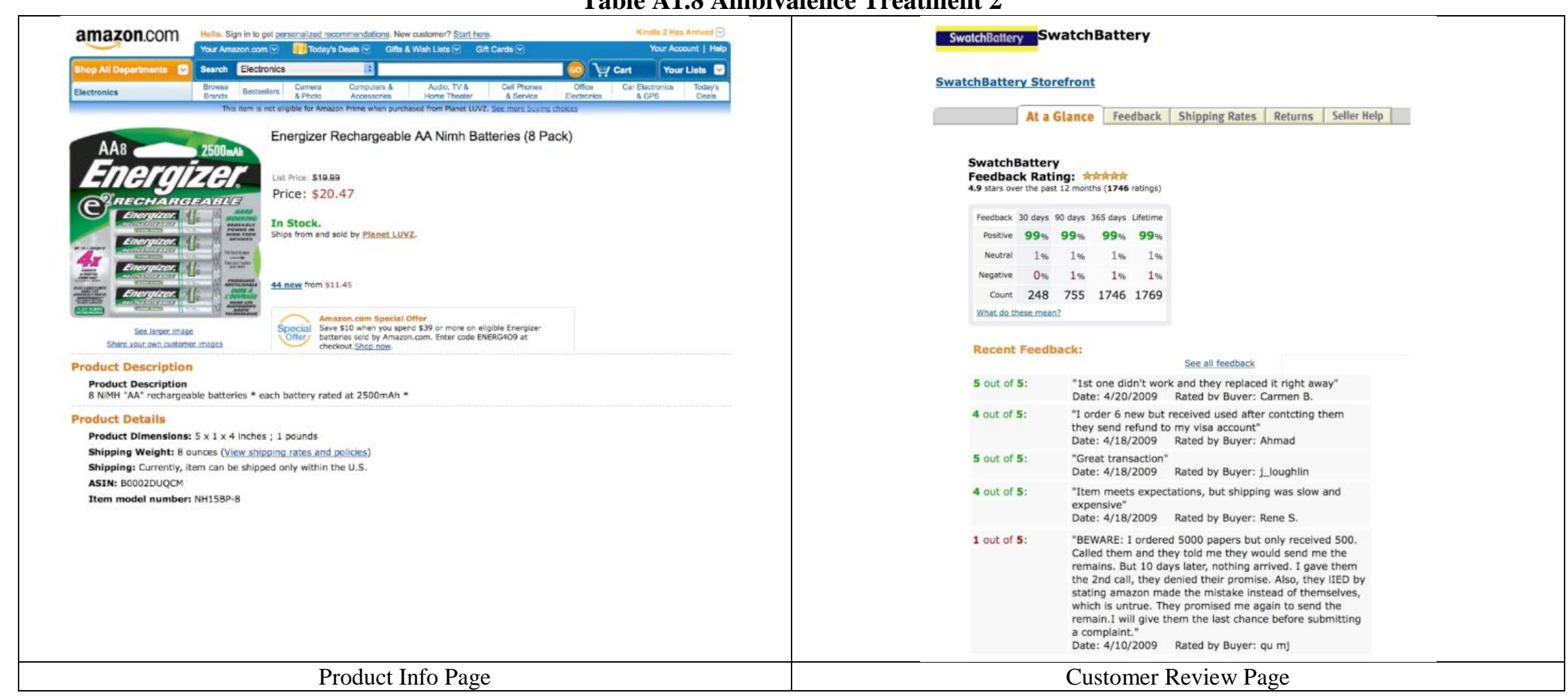




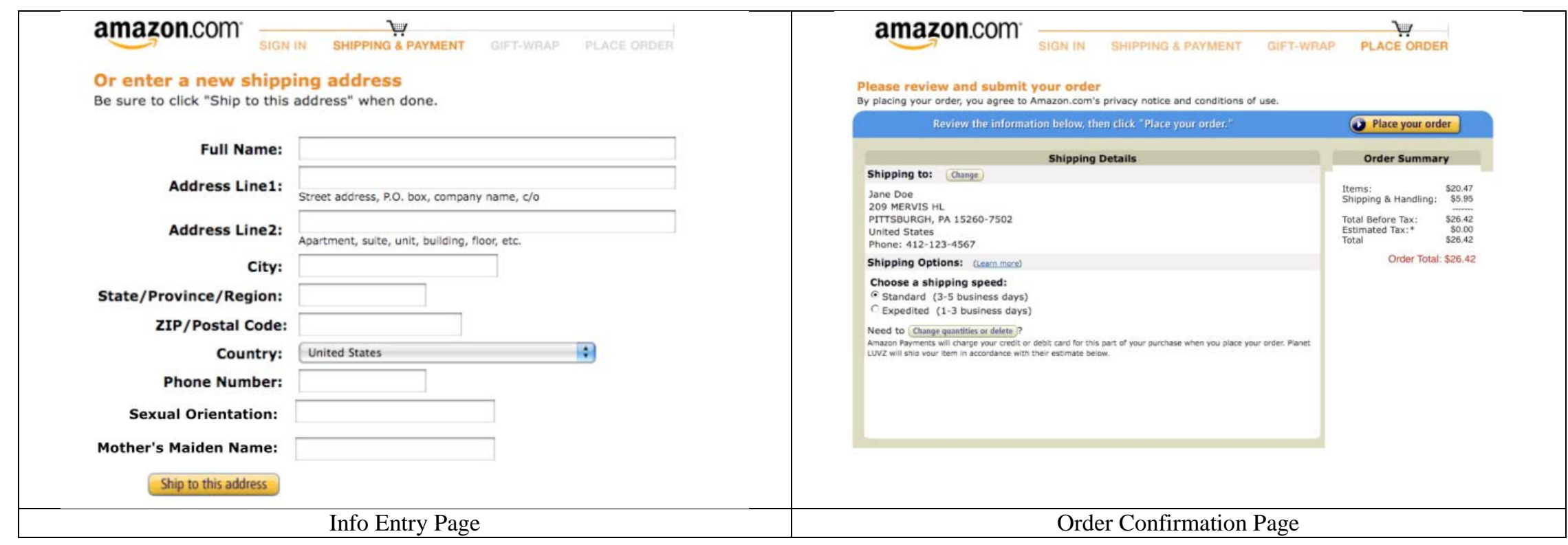


Table A1.9 Ambivalence Treatment 3

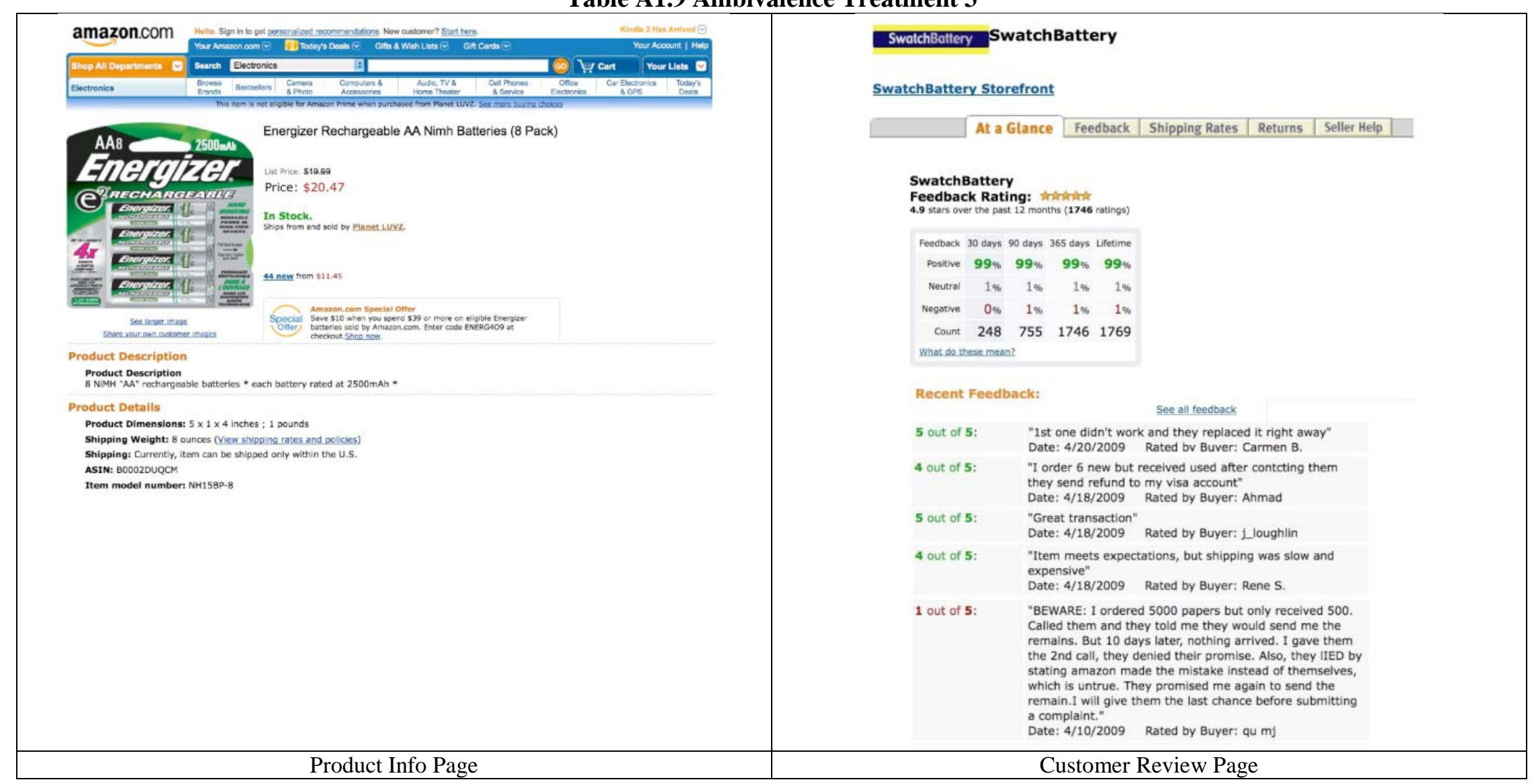




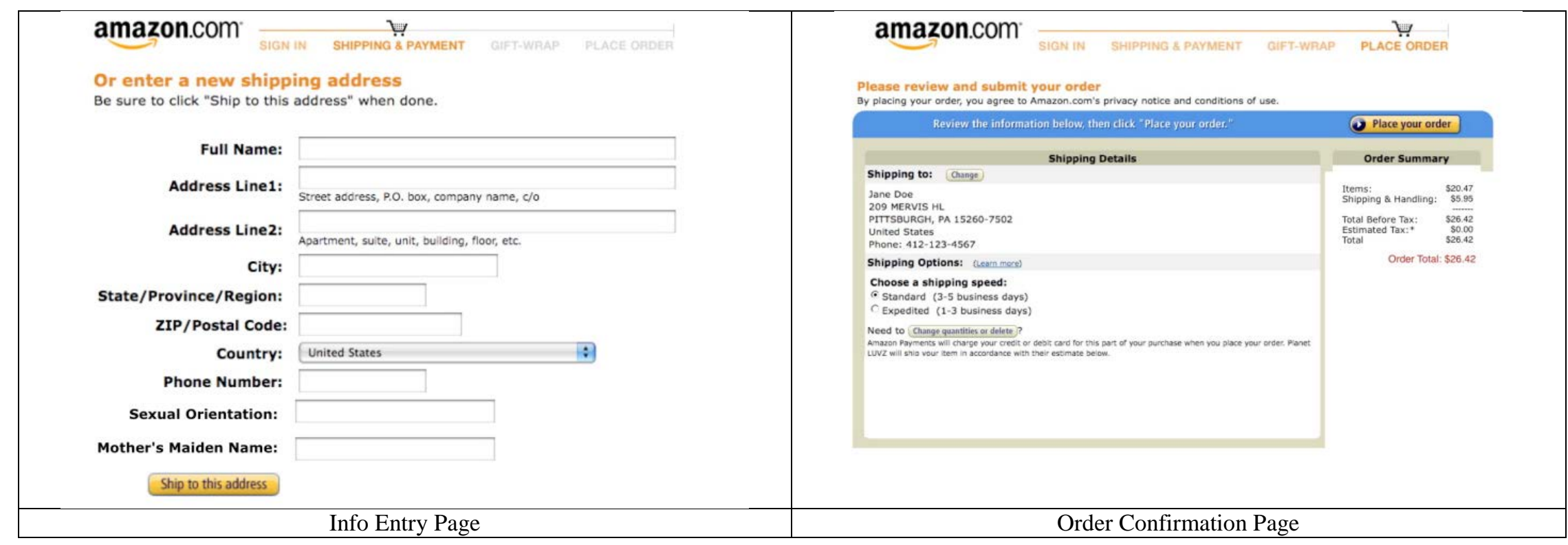




\section{Appendix 3. Factorial Validity and Analysis Support}

\section{Assessing Construct Validity}

In this section, we assess several key elements of construct validity, including determining which constructs are formative and which are reflective (Diamantopoulos \& Winklhofer, 2001); assessing factorial validity as determined by discriminant validity and convergent validity (Straub et al., 2004); evaluating multicollinearity (Cenfetelli \& Bassellier, 2009); and checking for common methods bias (Podsakoff et al., 2003). We used partial least squares (PLS), employing SmartPLS version 2.0 (Ringle et al., 2005) for model validation and analysis because PLS is especially adept at validation of mixed models of formative and reflective indicators (Chin et al., 1996; Diamantopoulos \& Winklhofer, 2001; Chin et al., 2003; Gefen \& Straub, 2005; Lowry \& Gaskin, 2014).

\section{Determining which Constructs are Formative and which are Reflective}

A key step of preparation for assessing factorial validity is to determine which constructs are formative and which are reflective (Diamantopoulos \& Winklhofer, 2001). The basic difference is that items within formative constructs are theoretically distinct, and thus cannot be replaced with other items in the same construct; meanwhile, the items in reflective constructs are theoretically similar, and thus are replaceable (Diamantopoulos \& Winklhofer, 2001). This theoretical and methodological distinction has recently become a serious issue in IS research, where it has been discovered that many previous IS studies were mis-specified because they did not distinguish between reflective and formative constructs (Petter et al., 2007). Such mis-specification can lead to problems in empirical results and theoretical interpretations, including a potential increase in both Type I and Type II errors (Petter et al., 2007).

We used the latest leading recommendations (Diamantopoulos \& Winklhofer, 2001; Petter et al., 2007; Cenfetelli \& Bassellier, 2009; Lowry \& Gaskin, 2014) to determine how to analyse our constructs. Notably, constructs are not inherently reflective or formative; it is up to the researcher and the literature to make that determination and to choose appropriate items for the conceptualisation (MacKenzie et al., 2011). Our conceptualisation and measurement, along with formal model specification, followed the latest conventions (e.g., MacKenzie et al., 2011) Trust and distrust beliefs and the dispositions to trust and distrust have previously been theorised, modelled and validated as second-order constructs, composed of first-order reflective subconstructs (McKnight et al., 1998; McKnight et al., 2004; McKnight \& Choudhury, 2006). We have neither theoretical nor methodological reasons to contradict these previous construct conceptualisations, and thus we have validated and modelled our constructs accordingly.

\section{Establishing Factorial Validity}

Factorial validity is established through both convergent and discriminant validity, which are two highly interrelated concepts which must coexist. Convergent validity is the basic idea that measurement items which should be related are related. It is established 'when items thought to reflect a construct converge, or show significant, high correlations with one another, particularly when compared to the convergence of items relevant to other constructs, irrespective of method' (Straub et al., 2004, p. 391). Discriminant validity is the basic idea that items that should not be related are in fact not related. Thus, it can be established when items thought to diverge show insignificant, low correlations with one another, particularly compared to items in other constructs (Straub et al., 2004). Importantly, factorial validity is established in different ways for reflective and formative constructs; thus, we address these analyses separately.

\section{Factorial Validity of Reflective Constructs}

To establish the factorial validity of our reflective constructs, we followed procedures by Gefen and Straub (2005) and Lowry et al. (2014), and further demonstrated in (Lowry et al., 2008; Lowry et al., 2009). For an especially conservative analysis, we used two established techniques to establish convergent validity and two established techniques to establish discriminant validity.

Convergent Validity of Reflective Constructs. First, we examined the outer model loadings. Convergent validity can be established when the $t$-values of the outer model loadings are significant. In all cases but one (one ambivalence item), each latent variable's indicators strongly converged on the latent variable and was highly significant, as summarised in Table A3.1. As a second check, we correlated the latent variable scores against the indicators as a form of factor loadings, and then examined the indicator loadings and cross-loadings to establish 
convergent validity. Although this approach is typically used to establish discriminant validity, convergent validity and discriminant validity are interdependent and help to establish each other. Convergent validity is also established when each loading for a latent variable is substantially higher than those for other latent variables. This is done by correlating the latent variable scores against the indicators as a form of factor loadings. Table A3.2 illustrates the loadings in grey. Based on this analysis, only the same indicator in ambivalence showed poor loading on its intended construct, in comparison to all other constructs.

Discriminant Validity of Reflective Constructs. We also used two approaches to establish discriminant validity. First, like with convergent validity, we examined the factor loadings, but this time, wanted to ensure significant that overlap did not exist between the constructs (see Table A3.2). All loadings, excluding an item from following advice, were appropriate, given the dropped ambivalence indicator in the previous step.

Second, we used the approach of examining the square roots of the average variances extracted (AVEs), as summarised in Table A3.3. The basic standard followed here is that the square root of the AVE for any given construct (latent variable) should be higher than any of the correlations involving the construct. The numbers are shown in the diagonal for constructs (bolded and underlined). Strong discriminant validity was shown for all constructs.

\section{Factorial Validity of Formative Constructs}

Establishing factorial validity for formative indicators is more challenging than validating reflective indicators, because the established procedures which exist to determine the validity of reflective measures do not apply to formative measures (Gefen \& Straub, 2004; Petter et al., 2007). Moreover, the procedures for validating formative measures are less known or well-established (Diamantopoulos \& Winklhofer, 2001), although standards are beginning to emerge in IS research (Cenfetelli \& Bassellier, 2009).

Validating items within formative measures is particularly challenging because these items can move in different directions from one another. Whereas reflective indicators must demonstrate considerably high correlations with each other (i.e., high conceptual overlap) to be valid internally, the indicators of a formative construct need not meet this criterion, and instead need to represent distinct facets of the overall construct being modelled (Bollen \& Lennox, 1991; Diamantopoulos \& Winklhofer, 2001; Petter et al., 2007). Reflective items are interchangeable, but formative items are not; hence, reliability measurements are not appropriate for formative constructs (Diamantopoulos \& Winklhofer, 2001). Specifically, internal consistency examinations of formative constructs with Cronbach's $\alpha$ and AVE calculations are not methodologically appropriate (Bagozzi, 1994; Marakas et al., 2007; Petter et al., 2007; Cenfetelli \& Bassellier, 2009).

Researchers have traditionally used theoretical reasoning alone to support the validity of formative constructs (Diamantopoulos \& Winklhofer, 2001). Over time, methodological approaches have emerged to improve the validation of formative constructs, such as the modified multitrait-multimethod approach and assessment of multicollinearity (Straub et al., 2004; Marakas et al., 2007; Petter et al., 2007). This foundation has been improved on in work by Cenfetelli and Bassellier (2009), which we follow for our validation process.

As an initial step, we assessed the absolute indicator contributions (i.e., zero-order correlations) of the individual items for service quality against the overall average of service quality. The idea is to improve internal validity by removing items not exhibiting a significant association with the overall construct (Diamantopoulos \& Winklhofer, 2001; Cenfetelli \& Bassellier, 2009). All of the items exhibited significant associations with the overall measure at the 0.05 level of significance. We also performed inter-item correlational diagnostics to assess whether there were high correlations among the formative indicators, as these can significantly weaken formative measures (Diamantopoulos \& Siguaw, 2006). However, the biggest potential issue that must be addressed is multicollinearity (Cenfetelli \& Bassellier, 2009). We thus we assessed the possibility of multicollinearity amongst all of the indicators (reflective and formative) in the model. Variance inflation factors (VIFs) less than 10 are traditionally viewed as justification for a model's lack of multicollinearity, with 5.0 being ideal, but formative methodologists have recently called for a more stringent cut-off of less than 3.3 (Diamantopoulos \& Siguaw, 2006; Petter et al., 2007; Cenfetelli \& Bassellier, 2009).

A number of concerns emerged from this analysis. While all of the reflective indicators had VIFs of 5.0 or less, a few of the formative indicators were above the more stringent 3.3 cut-off. All such instances were found in trusting beliefs and trusting intentions, but these were second-order formative constructs made up of reflective subconstructs. However, given the extensive use and theory backing the second-order formative nature of these two constructs, we retained them in the model as specified by research, noting that small amounts of multicollinearity may obfuscate the results. 


\section{Establishing a Lack of Common-Methods Bias}

To diminish the likelihood of common methods bias occurring in our data collection, we randomised items within the instrument so that participants would be less apt to detect underlying constructs, another potential source of common method bias (Cook \& Campbell, 1979; Straub et al., 2004). However, all data were collected using a similar-looking online survey; thus, we still needed to test for common methods bias to establish that it was not a likely negative factor in the data remaining for our analysis. We used two approaches to increase validity and rigor.

The traditional approach to establishing lack of common methods bias is to conduct a Harman's single factor test; however, the validity of this approach is increasingly under attack, and thus, we used a couple of stronger methods instead (Podsakoff et al., 2003; Pavlou et al., 2007).

The first approach was suggested by Podsakoff et al. (2003), and adapted for PLS by Liang et al. (2007). The objective of this technique is to measure the influence of a common latent method factor on each individual indicator in the model versus the influence of each indicator's corresponding construct. To perform this technique in PLS, constructs of the theoretical model and their relationships are modelled as is normally conducted with two major additions: (1) A single-indicator construct is created for each indicator in the measurement model. Each subconstruct is then linked to each of the single-indicator constructs which comprise the subconstruct. This effectively makes each subconstruct in the model a second-order reflective construct. (2) A construct representing the method is created, reflectively composed of all indicators of the instrument. The method construct (the latent method factor) is then linked to each single-item construct. Based on this analysis the average substantively explained variance of the items is .833, while the average method-based variance is -.001 . This results in a ratio of 637:1. In addition, most of the relationships between the items and the method-based construct were insignificantindicating a lack of common-methods bias.

However, this approach by Liang et al. (2007) is now under increase dispute as to its effectiveness. Thus, we used a second approach, which to simply examine a correlation matrix of the constructs and determine whether any of the correlations were above 0.90 , which would be evidence that common method bias may exist (Pavlou et al., 2007). To be conservative, we conducted this analysis for the constructs and for the subconstructs. All construct correlations were below this threshold.

\section{Manipulation Checks}

Two approaches were used for manipulation checks, as follows: (1) asking the participants if they noticed the manipulation and (2) statistical manipulation checks to see whether the treatments provided the desired manipulations. To assess the manipulation validity of the experiment, questions were added to the post-test to determine whether participants perceived their treatment manipulations. This elucidated whether the participants had noticed the process abnormalities, website design abnormalities and informational abnormalities. Table A3.4 shows the results of these manipulation questions. As can be seen, when asked whether participants perceived the manipulations, a majority was aware of it. However, a substantial portion of the manipulations were not perceived/remembered by the participants (see below). Nevertheless, these data were retained because they provide a more realistic test of our data. Straub et al. suggest that although unmanipulated participants add additional variance to results, data for these participants may profitably be retained in the dataset to provide 'a more robust testing of the hypotheses' (2004, p. 408).

Several of the manipulations were relatively weak in comparison to the majority that was correctly perceived (the highlights in grey indicate the manipulations that were perceived with less than $50 \%$ accuracy). The most frequently under-perceived manipulation was the request for sexual orientation and mother's maiden name (information abnormalities for treatments \#4, 7 and 8). This manipulation was only accurately recalled once (treatment \#3, 59\%). Interestingly, while participants largely did not recall this manipulation, later analysis revealed that this type of abnormality did produce changes in overall trust. This shows that several of our manipulations were subtle, but in the end effective, providing all the more reason to retain all data, not just data which were properly perceived. Perhaps other manipulations of this type of abnormality would be more blatant and produce stronger results (e.g., Everard \& Galletta, 2005). The downside of more blatant manipulations is giving up realism.

Two other treatments had less than expected perceived manipulations for informational abnormalities (\#5 and 6). For the fifth treatment group, participants did not perceived the subtle shift from an Amazon shopping cart to that of Google, which is akin to a finding in the literature on change blindness (e.g., Levin \& Simons, 1997; Silverman \& Mack, 2006). Change blindness refers to individuals' inability to notice changes in their current settings. Perhaps the change between two of the most major e-commerce shopping carts was too subtle for participants to perceive; again, later analysis indicates an effect from this manipulation despite the participants' 
inability to perceive it. Likewise, participants did not correctly recall that no informational abnormalities existed, potentially because various other abnormalities were present. It is possible that the mixed signals in other areas resulted in a faulty recall of this one area that was not anomalous.

Higher than market prices were also incorrectly perceived in two treatment groups (\#5 and 7), while they were correctly perceived in two other treatments (\#2 and 8). Perhaps since the manipulation of high price was only marginal in comparison to low price, participants incorrectly perceived this manipulation ( $50 \%$ of the total), whereas all low price manipulations were correctly perceived. In the instances where the high price manipulation was not perceived, it is possible that such a manipulation may be due to other abnormalities present in the process which may have interfered with participants' memories regarding price.

Finally, half of the treatment groups incorrectly recalled whether production-related information was being manipulated (treatments \#2, 3, 4 and 6). Treatments \#2, 3 and 4 incorrectly recalled that information was present about their products, despite the absence of such information (or the inclusion of information focussing deliberately on the wrong product- a car battery). Such inattention to detail may be attributed to the nature of the product being 'purchased' by the participants (i.e., rechargeable AA batteries). As participants are expected to be highly familiar with such items, it is possible that they largely ignored this information, as it would not factor into their buying decision.

Given that large portions of the participant sample were not aware of specific manipulations, this study also relies upon mean comparisons between treatment groups to assess the effectiveness of the manipulations. We conducted several rounds of comparative analysis, summarised in Tables A3.5, A3.6 and A3.7, which establish that the treatments mainly worked in the directions as intended.

The means of the relevant constructs that were manipulated by the treatment groups are shown in Table A3.5. Each of the treatments significantly altered the levels of situational abnormality, which followed the study design. Specifically, the abnormality treatments (\#2-5) reported even higher scores for situational abnormalities than the ambivalence treatments (\#6-8). Table A3.5 indicates that all abnormality manipulations were significant and in the correct direction.

The same procedure was used to verify the trust manipulations found in treatments \#3-5. These results are shown in Tables A3.6 and A3.7. Tables A3.6 and A3.7 indicate that all trust manipulations were significant and in the intended direction. For clarity, the trust dimension is highlighted with the corresponding manipulation, which is expected to be the lowest mean in the given column.

These results indicate that, with the notable exception of the deceit manipulation on integrity, the manipulations tended to produce the most pronounced results in their intended subdimensions of both trust and distrust. However, we note that all manipulations that contained some distrusting or negative cue (i.e., treatments \#2-8) resulted in higher levels of distrust when compared with the control treatment. This indicates that the effects of the manipulation for a specific subdimension of distrust tend to bleed over to other subdimensions. This supports the assumption that intra-attribute ambivalence is likely not to be present in such relationships, as trusters do not distinguish between the subdimensions in great detail required for such ambivalence.

A multivariate analysis of variance of our manipulations onto trust, distrust and ambivalence shows that the manipulations significantly affected each of the dimensions of trust, distrust and ambivalence at the $p=0.000$ level with the exception of price. Price showed significant results only with Roy's largest root on these constructs $(\mathrm{R}=0.032, F=6.0, p=0.016$ ), whereas all other estimates were insignificant (Wilks' lambda $=0.966, F=12.0, p=0.148$; Lawley-Hoteling trace $=0.0354, F=12.0, p=0.146$; Pillal's trace $=0.034, F=12.0, p=0.151$ ). Although price is not clearly shown to affect the results of trust, distrust or ambivalence, we retain it in our model due to the results shown above, and the significant effects it is found to have on the various dimensions in isolation.

We also regressed the effects of each manipulation of the study on the variables of interest to show the partial effects that each manipulation has on each dimension. The summarised results of these regressions are shown in Table A3.8. We note that the majority of the effects are highly significant. 
Table A3.1 Outer-Model Weights $t$ values of Reflective Items to Test Convergent Validity

\begin{tabular}{|c|c|c|c|c|}
\hline Latent construct & Subdimension & Items & $t$ stat & $p$ value \\
\hline \multirow[t]{5}{*}{ Ambivalence } & $\mathrm{nN} / \mathrm{A}$ & ambiv1* & 0.606 & 0.545 \\
\hline & & ambiv2 & 6.483 & 0.000 \\
\hline & & ambiv3 & 6.996 & 0.000 \\
\hline & & ambiv4 & 61.867 & 0.000 \\
\hline & & ambiv5 & 4.947 & 0.000 \\
\hline \multirow[t]{15}{*}{$\begin{array}{l}\text { Trusting intentions } \\
\text { (Second-order formative) }\end{array}$} & Follow advice & fa1 & 31.263 & 0.000 \\
\hline & & fa2 & 119.602 & 0.000 \\
\hline & & fa3 & 45.004 & 0.000 \\
\hline & & fa4 & 102.207 & 0.000 \\
\hline & & fa5 & 65.078 & 0.000 \\
\hline & & fa6 & 55.762 & 0.000 \\
\hline & Give information & gi1 & 66.045 & 0.000 \\
\hline & & gi2 & 14.346 & 0.000 \\
\hline & & gi3 & 12.202 & 0.000 \\
\hline & Make purchase & mp1 & 44.767 & 0.000 \\
\hline & & mp2 & 184.278 & 0.000 \\
\hline & $\begin{array}{l}\text { Willing to disclose } \\
\text { information }\end{array}$ & wd1 & 68.255 & 0.000 \\
\hline & & wd2 & 94.452 & 0.000 \\
\hline & & wd3 & 77.518 & 0.000 \\
\hline & & wd4 & 64.500 & 0.000 \\
\hline \multirow[t]{11}{*}{$\begin{array}{l}\text { Distrusting beliefs } \\
\text { (Second-order formative) }\end{array}$} & Incompetence & incomp1 & 130.447 & 0.000 \\
\hline & & incomp2 & 167.900 & 0.000 \\
\hline & & incomp3 & 144.472 & 0.000 \\
\hline & & incomp4 & 37.259 & 0.000 \\
\hline & Malevolence & mal1 & 104.814 & 0.000 \\
\hline & & mal2 & 79.079 & 0.000 \\
\hline & & mal3 & 77.303 & 0.000 \\
\hline & Deceit & dect1 & 115.653 & 0.000 \\
\hline & & dect2 & 98.363 & 0.000 \\
\hline & & dect3 & 122.894 & 0.000 \\
\hline & & dect4 & 120.108 & 0.000 \\
\hline \multirow[t]{2}{*}{$\begin{array}{l}\text { Trusting beliefs } \\
\text { (Second-order formative) }\end{array}$} & Benevolence & ben1 & 79.134 & 0.000 \\
\hline & & ben2 & 78.961 & 0.000 \\
\hline
\end{tabular}




\begin{tabular}{|c|c|c|c|}
\hline \multirow{2}{*}{ Competence } & ben3 & 51.032 & 0.000 \\
\hline & comp1 & 93.572 & 0.000 \\
\hline \multirow{7}{*}{ Integrity } & comp2 & 115.794 & 0.000 \\
\hline & comp3 & 135.397 & 0.000 \\
\hline & comp4 & 36.016 & 0.000 \\
\hline & int1 & 101.225 & 0.000 \\
\hline & int2 & 84.795 & 0.000 \\
\hline & int3 & 75.566 & 0.000 \\
\hline & int4 & 84.791 & 0.000 \\
\hline
\end{tabular}

* Poor loading 
Table A3.2 Items in Latent Variable Analysis for Discriminant Validity

\begin{tabular}{|c|c|c|c|c|c|c|c|c|c|c|c|c|}
\hline & 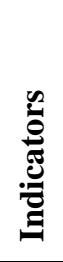 & 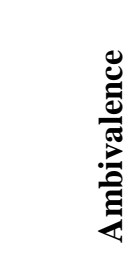 & 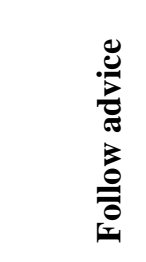 & 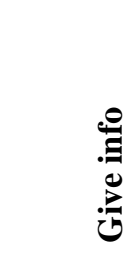 & 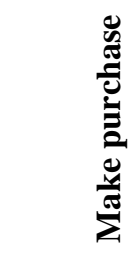 & 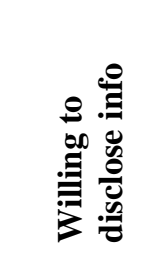 & 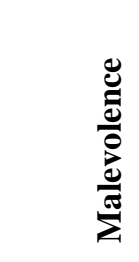 & 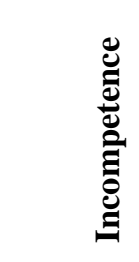 & 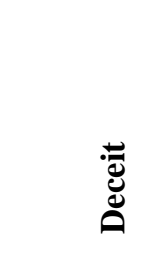 & 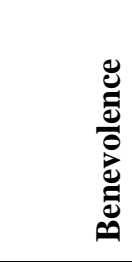 & نั & لَّ \\
\hline ambiv1 & & 0.083 & -0.115 & -0.162 & -0.116 & -0.073 & -0.129 & -0.058 & -0.073 & 0.097 & 0.069 & 0.112 \\
\hline ambiv2 & & 0.655 & 0.122 & -0.011 & 0.112 & 0.151 & 0.119 & 0.174 & 0.160 & -0.064 & -0.143 & -0.125 \\
\hline ambiv3 & & 0.659 & 0.137 & -0.051 & 0.062 & 0.133 & 0.112 & 0.159 & 0.147 & -0.087 & -0.137 & -0.130 \\
\hline ambiv4 & & 0.955 & 0.508 & 0.223 & 0.421 & 0.529 & 0.485 & 0.550 & 0.516 & -0.347 & -0.470 & -0.435 \\
\hline ambiv5 & & 0.518 & 0.072 & -0.031 & 0.063 & 0.088 & 0.110 & 0.128 & 0.138 & -0.038 & -0.092 & -0.066 \\
\hline fa1 & & 0.391 & 0.740 & 0.413 & 0.581 & 0.704 & 0.541 & 0.574 & 0.516 & -0.476 & -0.539 & -0.534 \\
\hline fa2 & & 0.396 & 0.919 & 0.513 & 0.683 & 0.784 & 0.615 & 0.695 & 0.645 & -0.549 & -0.647 & -0.593 \\
\hline fa3 & & 0.321 & 0.850 & 0.426 & 0.558 & 0.635 & 0.494 & 0.553 & 0.528 & -0.445 & -0.536 & -0.469 \\
\hline fa4 & & 0.391 & 0.909 & 0.462 & 0.615 & 0.707 & 0.568 & 0.636 & 0.593 & -0.501 & -0.606 & -0.537 \\
\hline fa5 & & 0.398 & 0.914 & 0.492 & 0.653 & 0.722 & 0.594 & 0.668 & 0.633 & -0.533 & -0.643 & -0.575 \\
\hline fa6 & & 0.484 & $0.851^{*}$ & 0.442 & 0.724 & 0.766 & 0.668 & 0.788 & 0.713 & -0.553 & -0.693 & -0.623 \\
\hline gi1 & & 0.172 & 0.479 & 0.864 & 0.579 & 0.451 & 0.446 & 0.450 & 0.420 & -0.333 & -0.370 & -0.349 \\
\hline gi2 & & 0.124 & 0.285 & 0.602 & 0.334 & 0.303 & 0.207 & 0.201 & 0.205 & -0.220 & -0.281 & -0.257 \\
\hline gi3 & & 0.079 & 0.331 & 0.620 & 0.276 & 0.242 & 0.235 & 0.206 & 0.191 & -0.300 & -0.282 & -0.251 \\
\hline mp1 & & 0.235 & 0.500 & 0.511 & 0.833 & 0.480 & 0.460 & 0.512 & 0.499 & -0.357 & -0.405 & -0.388 \\
\hline mp2 & & 0.403 & 0.757 & 0.527 & 0.916 & 0.718 & 0.639 & 0.728 & 0.668 & -0.573 & -0.670 & -0.626 \\
\hline wd1 & & 0.398 & 0.739 & 0.458 & 0.636 & 0.873 & 0.571 & 0.647 & 0.593 & -0.491 & -0.581 & -0.557 \\
\hline wd2 & & 0.430 & 0.719 & 0.411 & 0.589 & 0.894 & 0.615 & 0.630 & 0.613 & -0.541 & -0.604 & -0.590 \\
\hline wd3 & & 0.413 & 0.729 & 0.407 & 0.593 & 0.901 & 0.612 & 0.652 & 0.629 & -0.567 & -0.601 & -0.589 \\
\hline wd4 & & 0.427 & 0.736 & 0.432 & 0.645 & 0.841 & 0.557 & 0.648 & 0.584 & -0.497 & -0.640 & -0.564 \\
\hline mal1 & & 0.399 & 0.584 & 0.363 & 0.576 & 0.573 & 0.899 & 0.710 & 0.799 & -0.477 & -0.531 & -0.521 \\
\hline mal2 & & 0.439 & 0.629 & 0.424 & 0.580 & 0.632 & 0.874 & 0.717 & 0.754 & -0.499 & -0.523 & -0.505 \\
\hline mal3 & & 0.329 & 0.558 & 0.384 & 0.530 & 0.564 & 0.864 & 0.661 & 0.715 & -0.507 & -0.469 & -0.511 \\
\hline incomp1 & & 0.477 & 0.720 & 0.409 & 0.694 & 0.702 & 0.736 & 0.935 & 0.775 & -0.444 & -0.585 & -0.531 \\
\hline
\end{tabular}




\begin{tabular}{|c|c|c|c|c|c|c|c|c|c|c|c|}
\hline incomp2 & 0.483 & 0.704 & 0.387 & 0.687 & 0.702 & 0.732 & 0.936 & 0.783 & -0.458 & -0.600 & -0.538 \\
\hline incomp3 & 0.476 & 0.691 & 0.371 & 0.672 & 0.677 & 0.729 & 0.934 & 0.814 & -0.452 & -0.591 & -0.546 \\
\hline incomp4 & 0.360 & 0.606 & 0.396 & 0.543 & 0.556 & 0.656 & 0.790 & 0.683 & -0.423 & -0.545 & -0.488 \\
\hline dect1 & 0.448 & 0.654 & 0.398 & 0.636 & 0.634 & 0.785 & 0.797 & 0.916 & -0.505 & -0.567 & -0.587 \\
\hline dect2 & 0.416 & 0.645 & 0.376 & 0.607 & 0.628 & 0.790 & 0.766 & 0.919 & -0.493 & -0.538 & -0.573 \\
\hline dect3 & 0.446 & 0.610 & 0.349 & 0.627 & 0.628 & 0.787 & 0.777 & 0.908 & -0.501 & -0.564 & -0.568 \\
\hline $\operatorname{dect} 4$ & 0.429 & 0.661 & 0.380 & 0.616 & 0.637 & 0.796 & 0.774 & 0.923 & -0.485 & -0.583 & -0.558 \\
\hline ben1 & -0.292 & -0.534 & -0.380 & -0.497 & -0.531 & -0.505 & -0.438 & -0.491 & 0.902 & 0.705 & 0.748 \\
\hline ben2 & -0.292 & -0.530 & -0.373 & -0.502 & -0.549 & -0.484 & -0.457 & -0.467 & 0.885 & 0.698 & 0.741 \\
\hline ben3 & -0.235 & -0.490 & -0.310 & -0.442 & -0.494 & -0.494 & -0.404 & -0.470 & 0.850 & 0.619 & 0.707 \\
\hline comp1 & -0.397 & -0.651 & -0.430 & -0.568 & -0.625 & -0.527 & -0.585 & -0.562 & 0.692 & 0.901 & 0.772 \\
\hline comp2 & -0.431 & -0.651 & -0.394 & -0.578 & -0.642 & -0.559 & -0.613 & -0.597 & 0.698 & 0.930 & 0.781 \\
\hline comp3 & -0.409 & -0.665 & -0.400 & -0.600 & -0.654 & -0.519 & -0.596 & -0.575 & 0.714 & 0.926 & 0.787 \\
\hline comp4 & -0.267 & -0.533 & -0.345 & -0.496 & -0.520 & -0.439 & -0.480 & -0.429 & 0.612 & 0.778 & 0.647 \\
\hline int1 & -0.346 & -0.584 & -0.378 & -0.561 & -0.620 & -0.557 & -0.531 & -0.569 & 0.782 & 0.755 & 0.907 \\
\hline int2 & -0.390 & -0.599 & -0.359 & -0.545 & -0.586 & -0.515 & -0.548 & -0.561 & 0.734 & 0.763 & 0.910 \\
\hline int3 & -0.352 & -0.574 & -0.357 & -0.565 & -0.581 & -0.505 & -0.528 & -0.552 & 0.725 & 0.783 & 0.887 \\
\hline int4 & -0.357 & -0.551 & -0.377 & -0.474 & -0.566 & -0.516 & -0.492 & -0.558 & 0.751 & 0.738 & 0.890 \\
\hline
\end{tabular}

* Item has insignificant loading or higher loading on non-related construct 
Table A3.3 AVE Analysis to Establish Discriminant Validity

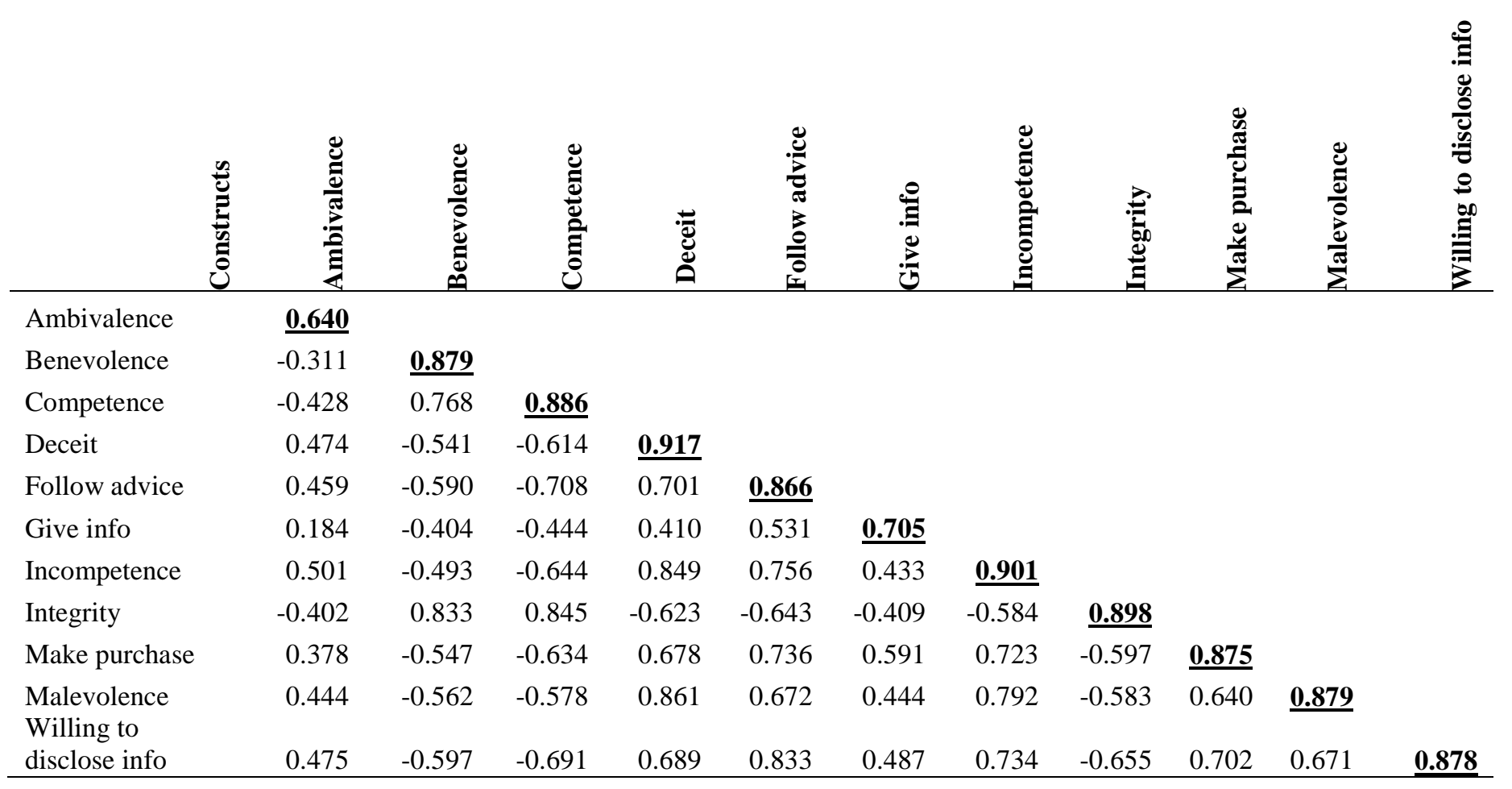


Table A3.4 Summary of Manipulation Checks - Qualitative Assessment

\begin{tabular}{|c|c|c|c|c|c|c|}
\hline Treatment \# & Manipulation & Expected & Correct? & Wrong? & Unsure? & Total \\
\hline \multirow[t]{5}{*}{1} & Product info & Normal & $81 \%(54)$ & $3 \%(2)$ & $16 \%(11)$ & 67 \\
\hline & Price & Normal & $81 \%$ (54) & $3 \%(2)$ & $16 \%$ & 67 \\
\hline & Reviews & $\begin{array}{l}\text { Positive } \\
\text { only }\end{array}$ & $96 \%(64)$ & $3 \%(2)$ & $1 \%(1)$ & 67 \\
\hline & Reviews & Absent & 73\% (49) & $7 \%(5)$ & $18 \%(12)$ & 66 \\
\hline & Information & Normal & $72 \%(48)$ & $16 \%(11)$ & $12 \%(8)$ & 67 \\
\hline \multirow[t]{5}{*}{2} & Product info & Abnormal & $27 \%(15)$ & $57 \%$ (32) & $16 \%(9)$ & 56 \\
\hline & Price & Abnormal & $54 \%(30)$ & $18 \%(10)$ & $29 \%(16)$ & 56 \\
\hline & Reviews & Absent & $86 \%$ (48) & $2 \%(1)$ & $13 \%(7)$ & 56 \\
\hline & Reviews & Absent & $88 \%$ (49) & $0 \%(0)$ & $13 \%(7)$ & 56 \\
\hline & Information & Normal & $55 \%(31)$ & $18 \%(10)$ & $27 \%$ (15) & 56 \\
\hline \multirow[t]{5}{*}{3} & Product info & Abnormal & $49 \%$ (31) & $38 \%$ (24) & $13 \%(8)$ & 63 \\
\hline & Price & Abnormal & $65 \%(41)$ & $24 \%(15)$ & $10 \%(6)$ & 62 \\
\hline & Reviews & $\begin{array}{l}\text { Positive } \\
\text { present }\end{array}$ & $76 \%(48)$ & $19 \%(12)$ & $5 \%(3)$ & 63 \\
\hline & Reviews & $\begin{array}{l}\text { Negative } \\
\text { present }\end{array}$ & $95 \%(60)$ & $0 \%(0)$ & $3 \%(2)$ & 62 \\
\hline & Information & Abnormal & $59 \%(37)$ & $24 \%$ (15) & $17 \%(11)$ & 63 \\
\hline \multirow[t]{5}{*}{4} & Product info & Abnormal & $48 \%$ (29) & $34 \%(21)$ & $18 \%(11)$ & 61 \\
\hline & Price & Abnormal & $59 \%$ (36) & $26 \%$ (16) & $15 \%(9)$ & 61 \\
\hline & Reviews & $\begin{array}{l}\text { Positive } \\
\text { present }\end{array}$ & $62 \%(38)$ & $30 \%(18)$ & $8 \%(5)$ & 61 \\
\hline & Reviews & $\begin{array}{l}\text { Negative } \\
\text { present }\end{array}$ & $93 \%(57)$ & $3 \%(2)$ & $3 \%(2)$ & 61 \\
\hline & Information & Abnormal & 48\% (29) & $28 \%$ (17) & $25 \%$ (15) & 61 \\
\hline \multirow[t]{5}{*}{5} & Product info & Abnormal & $52 \%(30)$ & $29 \%$ (17) & 19\% (11) & 58 \\
\hline & Price & Abnormal & $36 \%(21)$ & $41 \%(24)$ & $22 \%(13)$ & 58 \\
\hline & Reviews & $\begin{array}{l}\text { Positive } \\
\text { present }\end{array}$ & $88 \%(51)$ & $7 \%(4)$ & $7 \%(4)$ & 59 \\
\hline & Reviews & $\begin{array}{l}\text { Negative } \\
\text { present }\end{array}$ & $95 \%(55)$ & $2 \%(1)$ & $5 \%(3)$ & 59 \\
\hline & Information & Abnormal & $34 \%(20)$ & $40 \%(23)$ & $26 \%(15)$ & 58 \\
\hline \multirow[t]{5}{*}{6} & Product info & Normal & $49 \%$ (34) & $26 \%$ (18) & $25 \%(17)$ & 69 \\
\hline & Price & Normal & $72 \%(50)$ & $4 \%(3)$ & $23 \%$ (16) & 69 \\
\hline & Reviews & $\begin{array}{l}\text { Positive } \\
\text { present }\end{array}$ & $90 \%(62)$ & $4 \%(3)$ & $6 \%(4)$ & 69 \\
\hline & Reviews & $\begin{array}{l}\text { Negative } \\
\text { present }\end{array}$ & $91 \%(63)$ & $1 \%(1)$ & $7 \%(5)$ & 69 \\
\hline & Information & Normal & $48 \%(33)$ & $25 \%(17)$ & $28 \%(19)$ & 69 \\
\hline \multirow[t]{5}{*}{7} & Product info & Normal & $72 \%$ (49) & $12 \%(8)$ & 15\% (10) & 67 \\
\hline & Price & Abnormal & $45 \%(30)$ & $30 \%(20)$ & $25 \%$ (17) & 67 \\
\hline & Reviews & $\begin{array}{l}\text { Positive } \\
\text { present }\end{array}$ & $91 \%(61)$ & $7 \%(5)$ & $1 \%(1)$ & 67 \\
\hline & Reviews & $\begin{array}{l}\text { Negative } \\
\text { present }\end{array}$ & $94 \%(63)$ & $4 \%(3)$ & $1 \%(1)$ & 67 \\
\hline & Information & Abnormal & $48 \%(32)$ & $28 \%(19)$ & $24 \%(16)$ & 67 \\
\hline \multirow[t]{5}{*}{8} & Product info & Normal & $68 \%(48)$ & $17 \%(12)$ & $15 \%(11)$ & 71 \\
\hline & Price & Abnormal & $51 \%(36)$ & $28 \%(20)$ & $21 \%(15)$ & 71 \\
\hline & Reviews & $\begin{array}{l}\text { Positive } \\
\text { present }\end{array}$ & $93 \%$ (66) & $4 \%(3)$ & $3 \%(2)$ & 71 \\
\hline & Reviews & $\begin{array}{l}\text { Negative } \\
\text { present }\end{array}$ & $92 \%(65)$ & $4 \%(3)$ & $4 \%(3)$ & 71 \\
\hline & Information & Abnormal & $48 \%(34)$ & $24 \%(18)$ & $27 \%$ (19) & 71 \\
\hline
\end{tabular}


Table Key:

- Expected: the type of manipulation being employed for that part of the study.

- Correct: the percentage (number) of participants that correctly identified the manipulation in the expected direction.

- Wrong: the percentage (number) of participants that incorrectly specified the manipulation in the unexpected direction.

- Unsure: the percentage (number) of participants that indicated they were unsure of any manipulation of that particular type in the study

- Total: total number of responses.

- Highlighted row indicates a manipulation type which was not correctly identified by the majority of participants presented with that type of manipulation.

Table A3.5 Summary of Situational Abnormality Manipulation Tests

\begin{tabular}{rrrrrrrrrrrrr}
\hline$\#$ & \multicolumn{4}{c}{ SA-Design } & \multicolumn{3}{c}{ SA-Info } & \multicolumn{3}{c}{ SA-Product } & \multicolumn{3}{c}{ SA-General } \\
& Mean & SSD & $\boldsymbol{t}$ & Mean & SSD & $\boldsymbol{t}$ & Mean & SSD & t & Mean & SSD & $\boldsymbol{t}$ \\
\hline 1 & 2.985 & 1.089 & --- & 3.183 & 1.206 & --- & 2.817 & 1.145 & --- & 3.300 & 1.201 & --- \\
2 & 4.304 & 1.126 & 8.52 & 4.794 & 1.464 & 8.23 & 3.432 & 1.547 & 2.98 & 4.753 & 1.349 & 8.06 \\
3 & 4.501 & 1.248 & 9.64 & 4.625 & 1.302 & 8.79 & 4.042 & 1.387 & 7.01 & 5.118 & 1.209 & 11.93 \\
4 & 4.623 & 1.164 & 10.99 & 4.586 & 1.102 & 9.94 & 4.482 & 1.320 & 9.85 & 4.964 & 1.167 & 11.14 \\
5 & 3.899 & 1.281 & 5.38 & 4.559 & 1.388 & 7.61 & 3.856 & 1.458 & 5.48 & 4.982 & 1.391 & 9.28 \\
6 & 3.660 & 1.164 & 4.81 & 4.154 & 1.207 & 6.68 & 3.653 & 1.410 & 4.93 & 4.951 & 1.284 & 10.68 \\
7 & 3.792 & 0.945 & 8.04 & 3.898 & 1.220 & 4.79 & 3.920 & 1.240 & 7.28 & 4.639 & 1.130 & 9.70 \\
8 & 3.966 & 1.012 & 8.17 & 4.199 & 1.150 & 7.44 & 3.895 & 1.449 & 6.27 & 4.640 & 1.366 & 8.32 \\
All & 3.949 & 1.223 & --- & 4.225 & 1.338 & --- & 3.758 & 1.436 & --- & 4.656 & 1.370 & --- \\
\hline
\end{tabular}

Table A3.6 Summary of Trust Manipulations

\begin{tabular}{|c|c|c|c|c|c|c|c|c|c|c|c|c|}
\hline \multirow[b]{2}{*}{$\begin{array}{l}\text { Treat } \\
\text {.\# }\end{array}$} & \multicolumn{4}{|c|}{ Benevolence } & \multicolumn{4}{|c|}{ Competence } & \multicolumn{4}{|c|}{ Integrity } \\
\hline & Mean & SD & $t$ & $p$ & Mean & SD & $t$ & $p$ & Mean & SD & $t$ & $p$ \\
\hline 1 & 2.325 & 0.068 & $\mathrm{n} / \mathrm{a}$ & $\mathrm{n} / \mathrm{a}$ & 2.726 & 0.070 & $\mathrm{n} / \mathrm{a}$ & $n / a$ & 2.576 & 0.072 & $\mathrm{n} / \mathrm{a}$ & $\mathrm{n} / \mathrm{a}$ \\
\hline 2 & 1.729 & 0.085 & 5.497 & 0.000 & 1.832 & 0.084 & 8.287 & 0.000 & 1.754 & 0.081 & 7.798 & 0.000 \\
\hline 3 & 1.719 & 0.075 & 6.005 & 0.000 & 1.751 & 0.085 & 8.962 & 0.000 & 1.731 & 0.085 & 7.775 & 0.000 \\
\hline 4 & 1.650 & 0.074 & 6.714 & 0.000 & 1.797 & 0.071 & 9.456 & 0.000 & 1.752 & 0.079 & 7.918 & 0.000 \\
\hline 5 & 1.729 & 0.084 & 5.504 & 0.000 & 1.812 & 0.094 & 7.897 & 0.000 & 1.740 & 0.089 & 7.459 & 0.000 \\
\hline 6 & 1.773 & 0.074 & 5.482 & 0.000 & 1.839 & 0.075 & 8.781 & 0.000 & 1.810 & 0.082 & 7.204 & 0.000 \\
\hline 7 & 1.949 & 0.083 & 3.503 & 0.001 & 2.129 & 0.085 & 5.473 & 0.000 & 1.964 & 0.077 & 5.982 & 0.000 \\
\hline 8 & 1.737 & 0.069 & 6.070 & 0.000 & 2.017 & 0.072 & 7.141 & 0.000 & 1.869 & 0.067 & 7.427 & 0.000 \\
\hline
\end{tabular}

1=control, 2=abnormal, 3=incompetence, 4=malevolence, $5=$ deceit, $6=$ ambiv. 1, 7=ambiv. 2, 8=ambiv. 3 
Table A3.7 Summary of Distrust Manipulations

\begin{tabular}{|c|c|c|c|c|c|c|c|c|c|c|c|c|}
\hline \multirow[b]{2}{*}{$\begin{array}{l}\text { Treat } \\
\#\end{array}$} & \multicolumn{4}{|c|}{ Malevolence } & \multicolumn{4}{|c|}{ Incompetence } & \multicolumn{4}{|c|}{ Deceit } \\
\hline & Mean & SD & $t$ & $p$ & Mean & SD & $t$ & $p$ & Mean & SD & $t$ & $p$ \\
\hline 1 & 874 & 078 & $\mathrm{n} / \mathrm{a}$ & $\mathrm{n} / \mathrm{a}$ & 522 & 08 & $\mathrm{n} / \mathrm{a}$ & $\mathrm{n} / \mathrm{a}$ & 672 & 0.0 & a & $\mathrm{n} / \mathrm{a}$ \\
\hline 2 & 664 & 113 & 5.746 & 0.000 & 2.717 & 0 & $7 . \varepsilon$ & 0.00 & 8 & 0.1 & 30 & .000 \\
\hline 3 & 2.727 & 0.089 & 7.221 & 0.000 & 2.937 & 0.089 & 11.753 & 0.000 & 2.856 & 0.090 & .486 & 0.000 \\
\hline 4 & 2.735 & 0.102 & 6.713 & 0.000 & 2.736 & 0.102 & 9.327 & 0.000 & 2.829 & 0.092 & 9.181 & 0.000 \\
\hline 5 & 2.823 & 0.119 & 6.685 & 0.000 & 2.719 & 0.123 & 8.125 & 0.000 & 2.865 & 0.132 & 7.589 & 0.000 \\
\hline 6 & 2.775 & 0.086 & 7.765 & 0.000 & 2.791 & 0.087 & 10.708 & 0.000 & 2.864 & 0.085 & 9.855 & 0.000 \\
\hline 7 & 2.466 & 0.087 & 5.070 & 0.000 & 2.416 & 0.095 & 7.160 & 0.000 & 2.446 & 0.093 & 6.114 & 0.000 \\
\hline 8 & 2.522 & 0.073 & 6.039 & 0.000 & 2.430 & 0.084 & 7.806 & 0.000 & 2.530 & 0.077 & 7.434 & 0.000 \\
\hline
\end{tabular}

1=control, 2=abnormal, 3=incompetence, 4=malevolence, $5=$ =deceit, $6=$ ambiv. 1, 7=ambiv. 2, 8=ambiv. 3

Table A3.8 Regression Results of Manipulations on Trust and Distrust Dimensions and Ambivalence

\begin{tabular}{lrrrrrrrrr}
\hline & \multicolumn{2}{c}{ Benevolence } & \multicolumn{4}{c}{ Malevolence } & \multicolumn{4}{c}{ Competence } \\
Manipulation & $\mathbf{C} \boldsymbol{\beta}$ & $\boldsymbol{t}$ & $\boldsymbol{p}$ & $\mathbf{C B}$ & $\boldsymbol{t}$ & $\boldsymbol{p}$ & $\mathbf{C \beta}$ & $\boldsymbol{t}$ & $\boldsymbol{p}$ \\
\hline Product-based & -0.078 & -2.19 & 0.029 & 0.161 & 3.73 & 0.000 & -0.176 & -4.70 & 0.000 \\
error & & & & & & & & & \\
Price & -0.097 & -2.79 & 0.006 & 0.152 & 3.61 & 0.000 & -0.136 & -3.71 & 0.000 \\
Pos. review & 0.233 & 4.32 & 0.000 & -0.237 & -3.65 & 0.000 & 0.278 & 4.93 & 0.000 \\
Neg. review & -0.329 & -6.62 & 0.000 & 0.411 & 6.87 & 0.000 & -0.393 & -7.56 & 0.000 \\
Info-based error & 0.066 & 1.86 & 0.063 & -0.050 & -1.17 & 0.244 & 0.105 & 2.82 & 0.005 \\
Constant & 1.859 & 14.67 & 0.000 & 2.392 & 15.63 & 0.000 & 2.146 & 16.16 & 0.000 \\
\hline & Incompetence & & & Integrity & & Deceit & \\
Manipulation & $\mathbf{C \beta}$ & $\boldsymbol{t}$ & $\boldsymbol{p}$ & $\mathbf{C \beta}$ & $\boldsymbol{t}$ & $\boldsymbol{p}$ & $\mathbf{C \beta}$ & $\boldsymbol{t}$ & $\boldsymbol{p}$ \\
\hline Product-based & 0.214 & 4.63 & 0.000 & -0.118 & -3.19 & 0.002 & 0.210 & 4.62 & 0.000 \\
error & & & & & & & & & \\
Price & 0.153 & 3.38 & 0.001 & -0.122 & -3.38 & 0.001 & 0.127 & 2.86 & 0.004 \\
Pos. review & -0.397 & -5.69 & 0.000 & 0.266 & 4.76 & 0.000 & -0.369 & -5.37 & 0.000 \\
Neg. review & 0.567 & 8.83 & 0.000 & -0.362 & -7.02 & 0.000 & 0.538 & 8.53 & 0.000 \\
Info-based error & -0.142 & -3.08 & 0.002 & 0.091 & 2.46 & 0.014 & -0.086 & -1.90 & 0.058 \\
Constant & 2.440 & 14.89 & 0.000 & 1.991 & 15.13 & 0.000 & 2.441 & 15.14 & 0.000 \\
\hline
\end{tabular}

\section{Manipulations}

The manipulations targeted process, information and website design abnormalities (i.e., mistakes). Each was manipulated as present - containing the listed errors, or absent- having no such errors. It was not the purpose of this study to explore what specific error causes what changes in a trust or distrust subdimension, but rather to ascertain that such a line of inquiry would be beneficial for future research. Based on previous literature (Everard \& Galletta, 2005; Ou \& Sia, 2010) and the results of our first pilot study, we identified the three general types of abnormalities that can be present on websites.

1. Process abnormality: an aspect of the typical buying process is disrupted.

- Present: The buying process involves providing additional information that is not usually collected (e.g., mother's maiden name, sexual orientation)

- Absent: Shopping cart with credit card payment option as typically offered through most sites

2. Information abnormality: information regarding the desired item/service is abnormal.

- Present: Extremely low or high price in comparison to listed other sellers, missing product description, highly negative review and rating score, product description and name do not match 
displayed picture, or no sales history for the given seller

- Absent: Comparable price to other listed sellers, commonly available description, expected customer reviews and ratings (average for sellers of this product)

3. WWebsite design abnormality: can include extremely poor website design, errors and/or broken links that are not specifically relevant to the product/service information.

- Present: Frequent and blatant misspellings, look-and-feel of webpage changes during the process

- Absent: Consistent appearance throughout the entire process

Distrust manipulations consists of three levels: malevolence, incompetence and deceit. These were manipulated by providing customer feedback on the feedback page of the experiment which specifically manipulated that dimension only.

\section{More Details on Experimental Description}

Participants were recruited from the two readily available subject pools at a large, public eastern US university. Initially, they were asked to complete a pre-experiment survey to gather stable personality characteristics (e.g., demographics, Internet experience and the dispositions to trust and distrust). Once participants completed the initial survey, they proceeded to an online survey containing the experimental manipulations, manipulation checks and post-manipulation survey.

Participants were told to imagine that they were buyers of a given product (i.e., battery pack) and that a given search provided the following scenario. They were asked to review the indicated screenshots and to respond to several questions concerning the attitudes and intentions that they would have if they had been making such a purchase. Each webpage was listed and described in the order that it appeared (screen shots of the webpages are given in Appendix 2).

First, participants viewed the main product page for the item that he or she was purchasing. This page contained an item picture, price, description and so on normally found on a product page. An initial view of the page was presented; then, additional zoomed-in portions of the page were presented to ensure that subjects became familiar with the information there (i.e., product description, price and seller information).

Second, customer reviews and ratings were displayed along with several comments from previous customers, such as those commonly found on Amazon.com. Like the product information page, portions of the customer ratings were zoomed in to increase the likelihood of subjects being familiar with those portions of that page. information.

Third, subjects were shown a buyer's information page, which requested personal and shipping

Fourth, subjects were shown a page where buyers would enter credit card and billing information. Finally, they were then shown a product confirmation page, which summarised the item, price, shipping and billing information.

To increase the likelihood of coexisting rival attitudes and potential ambivalence, several different yet important product attributes and dimensions were manipulated to be either normal or abnormal. Following research in ambivalence, several versions of the purchase process were utilised to focus on an overall attempted manipulation for normality, abnormality and ambivalence rather than focussing on specific manipulations of website factors. The abnormality manipulation groupings are summarised in Table A3.9.

Finally, subjects proceeded to the instruments to respond to questions about distrusting and trusting beliefs, intentions and ambivalence in regards to this situation if they imagined themselves being buyers in this situation. They were also asked to provide their intentions concerning the seller and the website. 
Table A3.9 Summary of Experimental Manipulations

\begin{tabular}{|c|c|c|c|c|c|c|c|c|}
\hline \multirow{2}{*}{$\begin{array}{l}\text { Treatment } \\
\text { condition }\end{array}$} & \multirow{2}{*}{ 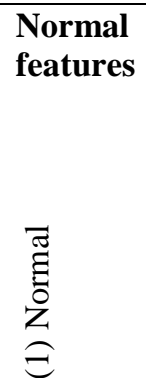 } & \multicolumn{4}{|l|}{ Abnormal features } & \multicolumn{3}{|c|}{ Ambivalent features } \\
\hline & & 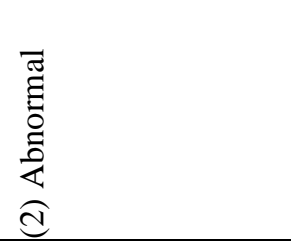 & 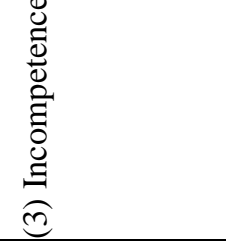 & 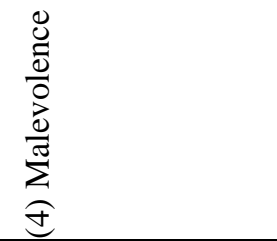 & 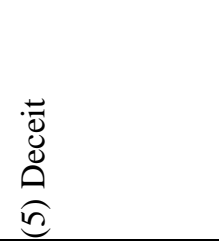 & 竞 & 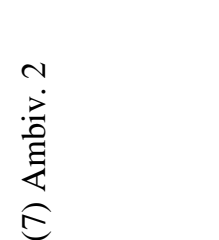 & 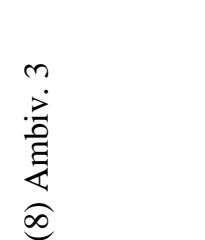 \\
\hline Process & Normal & $\begin{array}{l}\text { Change to Google } \\
\text { look and feel }\end{array}$ & $\begin{array}{l}\text { Sexual } \\
\text { orientation } \\
\text { Maiden name }\end{array}$ & $\begin{array}{l}\text { Sexual orientation } \\
\text { Maiden name }\end{array}$ & $\begin{array}{l}\text { Change to } \\
\text { Google look } \\
\text { and feel }\end{array}$ & Normal & $\begin{array}{l}\text { Sexual } \\
\text { orientation } \\
\text { Maiden name }\end{array}$ & $\begin{array}{l}\text { Sexual } \\
\text { orientation } \\
\text { Maiden name }\end{array}$ \\
\hline $\begin{array}{l}\text { Website } \\
\text { design }\end{array}$ & Normal & Wrong pic. & Misspellings & Misspellings & Wrong pic. & $\begin{array}{l}\text { Misspellings } \\
\text { Wrong pic. }\end{array}$ & Normal & Normal \\
\hline Informational & Normal & $\begin{array}{l}\text { Price high } \\
\text { Wrong prod. desc. } \\
\text { No ratings }\end{array}$ & $\begin{array}{l}\text { Low price } \\
\text { Missing prod. } \\
\text { desc. } \\
\text { Incomp. rating }\end{array}$ & $\begin{array}{l}\text { Low price } \\
\text { Missing prod. } \\
\text { desc. } \\
\text { Malev. rating }\end{array}$ & $\begin{array}{l}\text { Price high } \\
\text { Wrong prod. } \\
\text { desc. } \\
\text { Deceit ratings }\end{array}$ & $\begin{array}{l}\text { Normal price } \\
\text { Right prod. } \\
\text { desc. } \\
\text { Deceit rating }\end{array}$ & $\begin{array}{l}\text { High price } \\
\text { Right prod. } \\
\text { desc. } \\
\text { Incomp. } \\
\text { rating }\end{array}$ & $\begin{array}{l}\text { High price } \\
\text { Right prod. } \\
\text { desc. } \\
\text { Malev. rating }\end{array}$ \\
\hline
\end{tabular}




\section{ENDNOTES}

${ }^{\text {i }}$ Trusting beliefs is composed of three subconstructs, namely benevolence, competence and integrity (McKnight et al., 2002). Benevolence is exhibited by an organisation that cares about the individual and attempts to act in his/her best interests. Competence is exhibited by an organisation that has the capability to perform the desired behaviour. Finally, a firm with high integrity is honest in its interactions with the individual and will fulfil its promises to him/her.

ii This body of literature defines feelings as the emotional response and attachments which an individual ascribes to other individuals or objects (Kachadourian et al., 2005); beliefs are the logically held information regarding the characteristics of other individuals or objects (Kachadourian et al., 2005). Feelings thus involve affect, whereas beliefs involve cognition; thus, these concepts can also be referred to as affective beliefs and cognitive beliefs (Trafimow \& Sheeran, 1998). Finally, behaviours are actions that are performed by an individual (Kachadourian et al., 2005) that are intended to reflect the held feelings and beliefs of the individual.

${ }^{\text {iii }}$ For example, an online consumer can have trust in the TurboTax® website (the trustee) and believe that it has competent advice to assist consumers in the completion and filing of an accurate tax return. However, a consumer may simultaneously distrust advice from the website regarding money management software, largely because the company sells a product in that category. Thus, the proper response to whether an online consumer trusts the organisation should not be 'yes' or 'no' but 'to do what?' (Hardin, 1993). In complex relationships, which only magnify when introducing organisations as the object of trust, it is most important to refer to specifics to understand whether a consumer trusts an organisation via its website. For example, consumers are likely to trust that online orders to Apple's iTunes online store will be conducted without risking their future credit card transactions on other websites. However, they might also believe that their shopping history on the iTunes store might result in future target marketing. The various facets that make up a relationship allow trust and distrust to coexist, and thus support the bidimensional model of trust and distrust.

${ }^{\text {iv }}$ For example, if an online consumer believes that Amazon.com will ship a purchased item in a timely manner, the consumer cannot also believe the item will not be shipped in a timely manner. Information that is used to form the positive or negative expectations that will lead to trust or distrust cannot be inherently contradictory: Either the information will lead to a positive expectation that the trustee will perform some exact behaviour (e.g. ship an item), or it will lead to a negative expectation (e.g. not ship the item)

${ }^{v}$ For example, consumers of Delta Airlines will value information regarding Delta Airlines from the official website differently than information posted on websites such as DeltaReallySucks.com or other travel review websites.

${ }^{\text {vi }}$ For example, a consumer who uses YouSendIt.com for the transmission of files to various colleagues around the globe might believe that the organisation is able to receive and host these files. By using the service, the consumer accepts this belief and disregards the potential negative belief that the organisation is not able to receive and host the same files. Ultimately, the consumer either believes that the organisation is competent or incompetent in relation to this action. The various cues that are present on the website can be used to form both trust and distrust towards YouSendIt.com.

vii Ability is defined by the subdimensions competence and incompetence. Ability forms the assessment of the seller’s proficiency (or lack thereof) to complete a given task (i.e., competence and incompetence).

viii Orientation is defined by the subdimensions benevolence and malevolence. Orientation is the idea that the seller intends to do harm or good to the buyer.

ix Dependability is defined by the subdimensions integrity and deceit. Dependability is the notion that a buyer expects a seller to adhere to a set of guiding principles of being honest, or expects the seller to deceive him or her.

${ }^{\mathrm{x}}$ Of the subjects, $59 \%$ were male and $41 \%$ female. The average age was 28.1 years, with a standard deviation of 5.6 . The respondents reported an average of 7.1 completed collegiate semesters, with a standard deviation of 1.9. 
xi The use of such participants for this type of study follows the precedents set forth in past e-commerce research (Dinev \& Hart, 2006; Pavlou \& Fygenson, 2006; Lowry et al., 2008; Parboteeah et al., 2009; Lowry et al., 2012). Participants in this young but educated demographic had extensive experience with ecommerce, the Internet, and various computing technologies - particularly as users and consumers - which qualifies them as excellent targets for this study.

xii Because of the nature of formative measures, reliability checks cannot be reasonably made for formative measures (Diamantopoulos \& Winklhofer, 2001). To establish reliability, which refers to the degree to which a scale yields consistent and stable measures over time (Straub, 1989), PLS computes a composite reliability score as part of its integrated model analysis. This score is a more accurate measurement of reliability than Cronbach's $\alpha$ because it does not assume that loadings or error terms of the items to be equal (Chin et al., 2003). However, as a conservative check, Cronbach's $\alpha$ can also be used as a basis of comparison (Fornell \& Larcker, 1981; Nunnally \& Bernstein, 1994).

xiii The height of the dependent variable (z) is represented by the graphical display, and augmented with colour. Warmer colours (those near the red spectrum) represent higher scores for the dependent variable, while the cooler colours (those near the blue spectrum) represent lower scores. 